2014

\title{
Environmental Federalism: A Survey of the Empirical Literature
}

Daniel L. Millimet

Follow this and additional works at: https://scholarlycommons.law.case.edu/caselrev

Part of the Law Commons

\section{Recommended Citation}

Daniel L. Millimet, Environmental Federalism: A Survey of the Empirical Literature, 64 Case W. Rsrv. L. Rev. 1669 (2014)

Available at: https://scholarlycommons.law.case.edu/caselrev/vol64/iss4/9

This Symposium is brought to you for free and open access by the Student Journals at Case Western Reserve University School of Law Scholarly Commons. It has been accepted for inclusion in Case Western Reserve Law Review by an authorized administrator of Case Western Reserve University School of Law Scholarly Commons. 


\title{
EnVIRONMENTAL FEDERALISM: A Survey of THE EMPIRICAL LITERATURE
}

\author{
Daniel L. Millimet ${ }^{\dagger}$
}

\begin{abstract}
Generally, the debate over environmental federalism strongly focuses on anecdotal evidence and intuition. Empirical facts have not been the focus of arguments concerning the optimal allocation of environmental authority. For example, the Tiebout model, which highlights the positive side of decentralization as jurisdictions efficiently compete for mobile residents, relies on seven assumptions. Additionally, the group of models relying on the interjurisdictional competition framework, which have highlighted both the positive and negative outcomes of decentralized environmental authority, also rely on a number of assumptions. This Article assesses the empirical validity of many of these assumptions, concluding that the data may necessitate a rethinking of these assumptions.
\end{abstract}

\section{Contents}

INTRODUCTION 1670

I. Environmental Federalism in Theory ...................................... 1672

II. Environmental Federalism in Practice ...................................... 1677

A. Resource Mobility................................................................ 1677

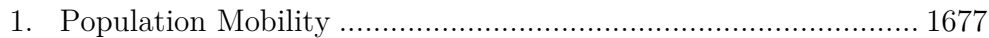

2. Capital Mobility ......................................................................... 1683

B. Preference Heterogeneity ....................................................... 1694

C. Interjursidictional Externalities.................................................. 1700

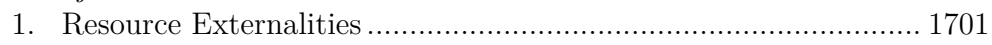

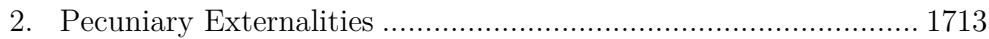

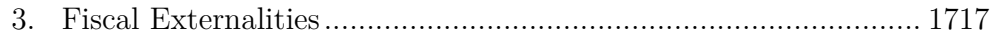

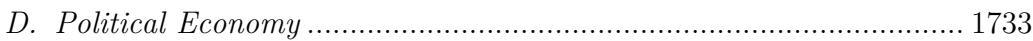

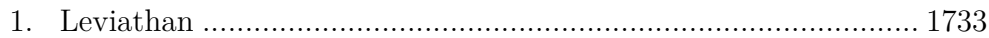

2. Lobbying and Corruption ..................................................... 1735

3. Political Participation ........................................................... 1745

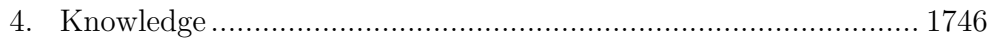

$\dagger$ Department of Economics, Southern Methodist University. Research Fellow, IZA. E-mail: millimet@smu.edu. Portions of this Article were prepared while the author was an Adjunct Professor, Department of Economics, Queensland University of Technology. The author would like to thank Per Fredriksson, Arik Levinson, and participants at the LEC-PERC Workshop on Environmental Federalism at the Case Western Reserve University School of Law. 


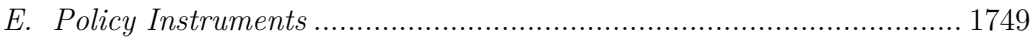

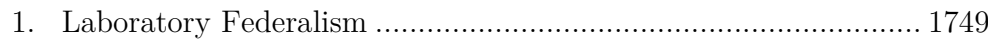

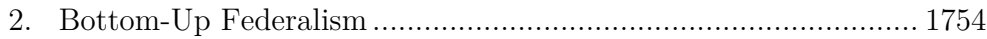

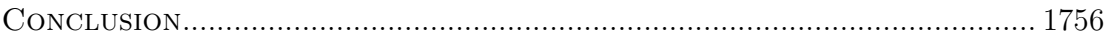

\section{INTRODUCTION}

Professor Bednar defines federalism as a "system of government characterized by semiautonomous states in a regime with a common central government" where "governmental authority is allocated between levels of government." 1 Professor Gordon notes that within a federal system "each unit of government decides independently how much of each type of public good to provide, and what types of taxes, and which tax rates, to use in funding the public goods." "While many countries contain a federal political system, the "optimal" allocation of authority across levels of government is the subject of constant research and debate. ${ }^{3}$ While much of this research and debate focuses on fiscal policy (taxation and expenditures), the allocation of authority over environmental decision making within a federal political system has also been discussed, deliberated, and agonized over for decades. ${ }^{4}$ The puzzle concerning the optimal allocation of environmental authority across levels of government is commonly referred to as environmental federalism.

Although the issue of environmental federalism receives widespread attention across the globe, there is no resolution in sight. ${ }^{5}$ Even some of the most prominent researchers in this area have a diverse set of beliefs. Professor Gordon concludes:

Competition among communities should lead to greater efficiency and innovation. However, this paper has shown the many ways in which decentralized decision-making can lead to inefficiencies, since a local government will ignore the effects of its decisions on the utility levels of nonresidents. . . In light of

1. Jenna Bednar, The Political Science of Federalism, 7 Ann. Rev. L. \& Soc. ScI. 269, 270 (2011).

2. Roger H. Gordon, An Optimal Taxation Approach to Fiscal Federalism, 98 Q.J. ECON. 567, 567 (1983).

3. See Bednar, supra note 1 , at 282 ("[C]oncern for the distribution of authority will remain focal to the federalism literature.").

4. See Wallace E. Oates, A Reconsideration of Environmental Federalism, in Recent Advances in Environmental Economics 1, 1-32 (John A. List \& Aart de Zeeuw eds., 2002).

5. See Bednar, supra note 1, at 282 ("[A]s federalism theory continues to develop, it may come back full circle to its original question: What is the optimal distribution of authority between federal and state governments?"). 
these costs arising from lack of coordination, it may be preferable to have the central government take responsibility for particular activities, in spite of the lost diversity. ${ }^{6}$

Professor Oates states: "My own sense is that where environmental quality is basically a local public good, the case for the setting of environmental standards at an appropriately decentralized level of government is quite compelling. At the same time, one can envision an essential informational and guidance role for the central authority."7 Professor Wilson concludes:

As such, competition among governments has both good and bad aspects, the importance of which vary across the attributes of the goods and services that the governments provide. This assessment suggests a role for intervention by a central authority, but both political considerations and information problems should be carefully addressed. ${ }^{8}$

Professor Adler states: "In sum, there is a strong case for a general presumption in favor of decentralization - a presumption that can be overcome in any specific policy context by demonstrating the need for federal intervention." Professor Levinson writes: "The conclusion must be that under most practical circumstances, local environmental authority will lead to inefficient regulations." 10

The diversity of views concerning the appropriate allocation of environmental authority also plays out in practice as different federations have "resolved" the issue differently. For example, the well-known Principle of Subsidiarity emanating from the Maastricht Treaty of 1992 constitutionalizes the delegation of environmental authority by dictating that centralized action is only allowed in situations where policy objectives cannot be sufficiently achieved through decentralized action. ${ }^{11}$ This is consistent with the so-called Decentralization Theorem put forth by Professor Oates:

6. Gordon, supra note 2, at 584-85.

7. Oates, supra note 4 , at 22-23.

8. John Douglas Wilson, Theories of Tax Competition, 52 NAT'L TAX J. 269, 298 (1999).

9. Jonathan H. Adler, Jursidictional Mismatch in Environmental Federalism, 14 N.Y.U. EnVTL. L.J. 130, 138 (2005).

10. Arik Levinson, Environmental Regulatory Competition: A Status Report and Some New Evidence, 56 NAT'L TAX J. 91, 103 (2003).

11. Richard L. Revesz, Federalism and Environmental Regulation: Lessons for the European Union and the International Community, $83 \mathrm{VA}$. L. REV. 1331, 1340-41 (1997). 
[I]n the absence of cost-savings from the centralized provision of a [local public] good and of interjurisdictional external effects, the level of welfare will always be at least as high (and typically higher) if Pareto-efficient levels of consumption of the good are provided in each jurisdiction than if any single, uniform level of consumption is maintained across all jurisdictions. ${ }^{12}$

In contrast, the delegation of authority is not constitutionalized in the United States except insofar as decentralized policymaking is not allowed to interfere with interstate commerce. ${ }^{13}$ As a result, environmental authority in the United States has oscillated between periods of relatively greater centralized and decentralized control. ${ }^{14}$

Given this backdrop, the objectives of this article are twofold. The first objective is to provide a very brief summary of the main theoretical models put forth in the literature. The reason for doing so is to illuminate the issues that play a fundamental role in conclusions regarding the optimal allocation of environmental authority. The second objective is to then provide a comprehensive survey of the relevant empirical literatures for the first time in the legal literature. By doing so, the goal is to limit the scope of the debate over environmental federalism moving forward, as well as make clear where the gaps in empirical knowledge exist.

\section{Environmental Federalism in Theory}

The two primary theoretical frameworks used to explore the effects of the decentralization of policy decisions such as taxes, expenditures, environmental standards, etc. derive from Professor Tiebout and the literature on interjurisdictional competition. ${ }^{15}$

The Tiebout model highlights the positive side of decentralization as jurisdictions compete for mobile residents in such a way that yields outcomes that are efficient. ${ }^{16}$ As laid out by Professor Revesz, the

12. Wallace E. Oates, Fiscal Federalism 54 (1972).

13. See Revesz, supra note 11, at 1340 ("In the United States, the choice between federal and state regulation (except when state regulation is coupled with trade restrictions) is, for the most part, a matter of policy.").

14. See E. Donald Elliott, Bruce A. Ackerman, \& John C. Millian, Toward a Theory of Statutory Evolution: The Federalization of Environmental Law, 1 J.L. ECON. \& ORG. 313 (1985); see also Levinson, supra note 10, at 96-97 (describing expenditures on environmental regulation and monitoring by states and the federal government from 1972 to 1994).

15. Charles M. Tiebout, A Pure Theory of Local Expenditures, 64 J. PoL. ECON. 416, 416 (1956).

16. See, e.g., Wallace E. Oates, An Essay on Fiscal Federalism, 37 J. ECON. Literature 1120, 1124 (1999) ("In this model, highly mobile households 'vote with their feet': they choose as a jurisdiction of 
model relies on "seven important assumptions."17 First, individuals are perfectly mobile across jurisdictions and have heterogeneous preferences over jurisdictional attributes. Second, individuals have perfect knowledge concerning the attributes of all jurisdictions, which include the "head tax" levied on residents and the level of public goods and services provided. Third, there exist a large number of jurisdictions. Fourth, employment does not affect individual residential choice as income is derived via dividends. Fifth, there are no interjurisdictional externalities. Sixth, every jurisdiction has a (known) optimal size where the average cost of services provided is minimized. Seventh, jurisdictions below their optimal size seek to attract new residents. ${ }^{18}$

Professor Brueckner provides a concise summary of the model:

Tiebout argued that, in attempting to attract residents, fiscally autonomous subnational governments will tailor public spending to suit individual preferences, leading consumers to sort across jurisdictions according to their demand for public goods. With each individual able to exactly fulfill his or her demand in some jurisdiction, the economy achieves a market-like outcome in the provision of public goods. ${ }^{19}$

Thus, under the assumptions of the model, this market-like outcome is efficient.

In contrast, the interjurisdictional competition framework nests both the positive and negative sides of decentralization as jurisdictions compete for mobile resources, typically taken as capital. Dating back at least to Oates's 1972 model, the framework has led to a variety of theoretical models. ${ }^{20}$ The 1988 model of Professors Oates and Schwab provides a useful starting point in the literature. ${ }^{21}$

residence that locality that provides the fiscal package best suited to their tastes. In the limiting case, the Tiebout solution does indeed generate a first-best outcome that mimics the outcome in a competitive market.").

17. Richard L. Revesz, Rehabilitating Interstate Competition: Rethinking the "Race-to-the-Bottom" Rationale for Federal Environmental Regulation, 67 N.Y.U. L. REV. 1210, 1236 (1992).

18. Id.

19. Jan K. Brueckner, Fiscal Decentralization with Distortionary Taxation: Tiebout vs. Tax Competition, 11 InT'L TAX \& PuB. Fin. 133, 133 (2004).

20. See generally OATES, supra note 12 .

21. Wallace E. Oates \& Robert M. Schwab, Economic Competition Among Jurisdictions: Efficiency Enhancing or Distortion Inducing?, 35 J. PUB. ECON. 333 (1988). 
Oates and Schwab find that it is possible for decentralized environmental authority to be efficient even with interjurisdictional competition for capital. ${ }^{22}$ However, this result requires numerous assumptions. ${ }^{23}$ First, individuals are homogeneous and immobile across jurisdictions. Second, capital is perfectly mobile across jurisdictions, seeking to maximize after-tax returns, and all production profits are earned locally. Third, capital has perfect knowledge concerning the attributes of all jurisdictions, which includes the tax rate on capital and level of public goods and services provided. Fourth, there exist a large number of jurisdictions that take the after-tax return on capital as given. Fifth, there are no interjurisdictional externalities. Sixth, governments maximize the (known) social welfare of their jurisdiction. Oates summarizes this model, stating that "the invisible hand works in much the same way as in the private sector to channel policy decisions in individual jurisdictions into an efficient outcome from a national perspective." ${ }^{24}$

In sum, the Tiebout and interjurisdictional competition frameworks provide a definitive answer to the environmental federalism debate under certain assumptions. Failure of these assumptions, however, may reverse this conclusion. For example, Oates stresses the limitations of his earlier work, stating: "The problem is that these models make some strong assumptions. ... [V]iolations of any of these conditions can lead to distorted outcomes." ${ }^{25}$ Indeed, many theoretical models have extended the Oates and Schwab model by relaxing various assumptions, finding that decentralized environmental policy making with interjurisdictional competition may lead to environmental standards that are inefficiently stringent or lax. ${ }^{26}$ Thus, the central takeaway message from this lengthy theoretical literature is eloquently provided by Oates:

The theoretical literature thus generates some diverse findings on this issue. There seem to be some basic efficiency-enhancing aspects of interjurisdictional competition, but there are clearly a

22. Bouwe R. Dijkstra \& Per G. Fredriksson, Regulatory Environmental Federalism, 2 Ann. Rev. Resource Econ. 319, 321 (2010) ("In this setup, it is not surprising that centralized environmental policy leads to the first-best outcome for the whole federation. ... Oates \& Schwab's (1988) finding that decentralized policy leads to the first-best outcome is perhaps more surprising.").

23. See Oates \& Schwab, supra note 21, at 335-38.

24. Oates, supra note 16, at 1135.

25. Id. at 1136 .

26. See Dijkstra \& Fredriksson, supra note 22, for an excellent survey of this literature. 
range of "imperfections" that can be the source of allocative distortions. The real issue here is the magnitude of these distortions. Are we dealing with minor deviations from efficient outcomes - or does such competition produce major welfare losses? The pure theory can't help us much in answering this question. ${ }^{27}$

The debate, then, over environmental federalism cannot be settled using theory alone. The range of possible theoretical outcomes can only be limited by an empirical understanding of the magnitudes of any violations of the various assumptions invoked in the Tiebout and interjursidictional competition frameworks. Surprisingly, a comprehensive review of what is known and unknown does not exist to the Author's knowledge. The result is that the debate over environmental federalism focuses too much on anecdotal evidence and intuition and not enough on empirical facts. The remainder of this Article seeks to remedy this by assessing our current knowledge of the imperfections alluded to above by Oates.

Prior to continuing, several comments are warranted. First, while violation of any of the assumptions noted above may cause decentralized environmental policy making to be inefficient, this does not imply that centralized policy making is efficient (or even less inefficient). Thus, interest lies in not just the validity of the prior assumptions, but also the contrast in social welfare under local versus central environmental authority because neither system is likely to yield the efficient outcome in practice. ${ }^{28}$ Such differences, to the extent possible, will be discussed in Part II.

27. Oates, supra note 16 , at 1136.

28. The alternative to decentralized policy making need not be complete centralization. A third option based on regional policy making may be possible. See generally Oates, supra note 4, at 17-19 ("A systematic study of such regional efforts that makes use of a sensible categorization into typologies of environmental interaction (for example, unilateral versus reciprocal pollution flows) and collective decision-making institutions might well reveal what sorts of structures and policy measures can work effectively for the regional management of environmental quality."); Terry Dinan \& Natalie Tawil, Solving Environmental Problems with Regional Decision-making: A Case Study of Ground-Level Ozone, 56 NAT'L TAx J. 123, 123 (2003) ("Regional decision making may offer solutions in cases where the problem is less than national in scope, but clearly extends beyond individual state boundaries."); Adler, supra note 9, at 141 ("Such interstate spillovers may constitute a regional problem, but this does not inherently justify national regulation. In such cases, regional solutions, such as the creation of regional entities or congressionally authorized interstate compacts, may be in order."). In the interests of limiting the scope of the discussion, the distinction between regional and central policy making is ignored. 
Second, neither environmental policy nor regulation are homogeneous concepts. There are important sources of heterogeneity across environmental issues (for example, air pollution, water pollution, hazardous waste disposal, and energy), across stages of environmental policy (for example, scientific research, standard setting, measurement, and enforcement), and across environmental instruments (for example, emissions taxes, cap-and-trade, subsidies, and command-and-control policies). In all likelihood there is no single answer to the question of optimal allocation of environmental authority across levels of government. Differences may arise across specific environmental issues or stages of the policy process. Moreover, certain policy instruments may not be available to all levels of governments. Such differences will also be emphasized when possible in the remainder of this Article.

Finally, the quest to understand the optimal level of government at which to assign environmental authority depends on, among other things, one's definition of optimal. Economists often equate optimality with efficiency, which requires the equating of marginal social costs and benefits in all locations. Others may wish to incorporate equity or political considerations into the notion of optimality. ${ }^{29}$ Still others may consider the optimal allocation of governmental authority as that which maximizes environmental quality. ${ }^{30}$ As evidenced by the theoretical discussion earlier in this Part, the structure of this Article is guided by the factors affecting the efficiency of policymaking in theoretical models. That said, the efficient outcome is generally unknown, making the "first-best policy.... typically impracticable." ${ }^{11}$ Thus, empirical evidence regarding the impact of local versus central control is often expressed in terms of the level or variance of environmental quality or the resulting nature of the political process. Professor Adler reminds us, however, to bear in mind that stricter regulation is not always efficient. ${ }^{32}$

29. See Robert P. Inman \& Daniel L. Rubinfeld, Rethinking Federalism, 11 J. ECOn. Persp., Fall 1997, at 43, 54 ("However one evaluates the economic efficiency performance of federal constitutions, it must be recognized that the federal institutions chosen will have important implications for political participation and the protection of individual rights and liberties, two other constitutional values central to past and current federalism debates.").

30. Jonathan H. Adler, When Is Two a Crowd? The Impact of Federal Action on State Environmental Regulation, 31 HaRv. Envtl. L. Rev. 67, 71 (2007) (" $\mathrm{I}] \mathrm{t}$ is common to suggest that more environmental regulation is better than less regulation ....").

31. H. Spencer Banzhaf \& B. Andrew Chupp, Fiscal Federalism and Interjurisdictional Externalities: New Results and an Application to US Air Pollution, 96 J. Pub. Econ. 449, 449 (2012).

32. See Adler, supra note 30, at 71 ("The optimal level of environmental regulation in a given context may be greater than current levels, but it 


\section{Environmental Federalism in Practice}

This Part discusses the empirical literature relating to several of the assumptions invoked in the Tiebout and interjursidictional competition frameworks. First, in Part II.A, the empirical literature on the mobility of capital and individuals is examined. Second, in Part II.B, preference heterogeneity is assessed. Third, in Part II.C, the importance of interjurisdictional externalities is evaluated. Fourth, in Part II.D, political economy issues are examined. Finally, in Part II.E, issues related to policy instruments are discussed.

\section{A. Resource Mobility}

The Tiebout framework has as its linchpin the perfect mobility of individuals. ${ }^{33}$ The interjurisdictional competition framework has its linchpin the perfect mobility of capital. ${ }^{34}$ Here, I review the empirical evidence on the mobility of these two resources, starting first with individual mobility.

\section{Population Mobility}

Efficiency in the Tiebout model is predicated upon the population to be perfectly mobile across jurisdictions in order for individuals to sort within communities that choose policies aligned with their preferences. Molloy, Smith, and Wozniak write: "The notion that one can pick up and move to a location that promises better opportunities has long been an important part of the American mystique." ${ }^{35}$ Clearly, however, individuals are not perfectly mobile. Revesz states that

may also be lower if the costs of a given level of regulation exceed the benefits.").

33. But see Oates, supra note 16, at 1124 ("In the limiting case, the Tiebout solution does indeed generate a first-best outcome that mimics the outcome in a competitive market. But the gains from decentralization, although typically enhanced by such mobility, are by no means wholly dependent upon them. In fact, if there were absolutely nothing mobilehouseholds, factors, or whatever-there would still exist, in general, gains from decentralization. The point here is simply that even in the absence of mobility, the efficient level of output of a 'local' public good, as determined by the Samuelson condition that the sum of the marginal rates of substitution equals marginal cost, will typically vary from one jurisdiction to another.").

34. See Brueckner, supra note 19, at 133-34 ("In contrast to the Tiebout tradition, the standard tax-competition model has immobile consumers and no demand heterogeneity. . . . [C]ompeting subnational governments pay for public goods with a tax on capital (i.e., business investment), which is mobile across jurisdictions but fixed in total supply.").

35. Raven Molloy, Christopher L. Smith \& Abigail Wozniak, Internal Migration in the United States, 25 J. Econ. PERsP., Summer 2011, at $173,173$. 
"much of the legal literature has dismissed as unrealistic the assumption of perfect mobility by individuals. There may, indeed, be substantial transaction costs in exiting one jurisdiction and moving to another, particularly in a world in which individuals have jobs and do not live solely on dividend income." 36 That said, how mobile are individuals? And, does mobility differ across socioeconomic groups?

Evidence on residential mobility in the United States and other countries in the 1970s and 1980s is presented by Long. ${ }^{37}$ Defining mobility as simply changing residential address, he finds that the United States has the second highest one-year residential mobility rate at $17.5 \%$ (behind New Zealand) and the third highest five-year residential mobility rate at $46.4 \%$ (behind Canada and Australia) in the early 1980s among the handful of countries analyzed. ${ }^{38}$ However, changing residences within a jurisdiction is not the type of mobility envisioned in the Tiebout model. Upon further examination, Long reports that roughly sixty percent of one-year and five-year residential mobility is due to moves within the same county; ${ }^{39}$ roughly eighty percent is due to moves within the same state. ${ }^{40}$ Thus, very little internal migration crosses jurisdictional boundaries that might entail significant changes in the provision of environmental quality.

Molloy, Smith, and Wozniak provide a more current, in-depth analysis of internal migration in the United States. The crux of their analysis points to an interesting puzzle: despite having one of the highest rates of internal migration in the world, internal migration in the United States has declined since roughly $1980 .{ }^{41}$ Specifically, five-

36. See Revesz, supra note 17 , at 1237.

37. Larry Long, Residential Mobility Differences Among Developed Countries, 14 Int'L Regional ScI. Rev. 133 (1991).

38. Id. at 136 tbl.1.

39. See $i d$. at 143 tbl.4 (indicating that, in $1980-81,10.4 \%$ of the population-or $60.4 \%$ of the moving population $(17.2 \%$ of the total population) - was attributed to moving within a county for the one-year residential mobility interval and $25.1 \%$ of the population-or $54.0 \%$ of the moving population ( $46.5 \%$ of the total population) - was attributed to moving within a county for the five-year residential mobility interval).

40. See id. (indicating that, in $1980-81,13.8 \%$ of the population-or $80.2 \%$ of the moving population $(17.2 \%$ of the total population)-was attributed to moving within a county for the one-year residential mobility interval and $34.9 \%$ of the population - or $75.1 \%$ of the moving population ( $46.5 \%$ of the total population) — was attributed to moving within a county for the five-year residential mobility interval).

41. See Molloy, Smith \& Wozniak, supra note 35, at 173-74 ("[I]nternal U.S. migration seems to have reached an inflection point around $1980 \ldots[\mathrm{T}]$ he share of the population that had migrated between states trended higher during much of the twentieth century, with the 
year, cross-state migration rates in the United States fell from $9.9 \%$ of the population in 1980 to $8.9 \%$ in $2000 .{ }^{42}$ Five-year, cross-county migration rates declined from $19.8 \%$ in 1980 to $18.6 \%$ in $2000 .{ }^{43}$ Molloy, Smith, and Wozniak state:

This decrease marks a noticeable departure from the longer-run trend, as migration shows a secular rise from 1900 to $1990 \ldots$. . Not only are migration rates lower in levels than at any point in the post-war period, they have also entered a period of continuous decline that is longer than any recorded in the twentieth century. ${ }^{44}$

Beyond simply documenting rates of internal migration, several studies have assessed the determinants of migration and destination choice. Among different socioeconomic groups, the largest differences in migration rates appear across education levels and homeownership status. For example, Molloy, Smith, and Wozniak estimate the annual interstate migration rate for individuals with at least a college degree to be $2.1 \%$ over the period from 2001 to 2010 in comparison to only $1.2 \%$ for high school graduates and $1.0 \%$ for high school dropouts. ${ }^{45}$ Similarly, the migration rate for renters is $3.5 \%$, but only $0.9 \%$ for homeowners. ${ }^{46}$ Surprisingly, there is little difference in migration rates by race or income status over this period. ${ }^{47}$

Several studies also investigate the role of economic factors on migration decisions. Professors Barro and Sala-I-Martin document a statistically significant, but small, effect of per capita income differentials on interstate migration. ${ }^{48}$ Davies, Greenwood, and Li use a different statistical technique and obtain larger effects. Specifically, the authors find that one standard deviation increase in the ratio of

exception of the Great Depression. However, migration rates have been falling in the past several decades ....").

42. Id. at 180 tbl.1.

43. Id.

44. Id. at $180-81$ (citation omitted).

45. Id. at 183 tbl.2.

46. Id.

47. See id. (finding a migration rate of $1.6 \%$ for individuals with an income status in the top fifty percent in comparison to $1.7 \%$ for individuals with an income status in the bottom fifty and finding a migration rate of $1.8 \%$ for white individuals in comparison to $1.7 \%$ for black individuals).

48. Robert J. Barro \& Xavier Sala-I-Martin, Convergence Across States and Regions, 1991 Brookings Papers Econ. ACtivity, no. 1, 1991, at 107, 132-33 ("Although the relation between the rate of in-migration and lagged per capita income is positive and highly significant (holding fixed our measure of amenities, population density, and some other variables), the magnitude of the relation is small."). 
the unemployment rate at a potential destination state to one's current state reduces the likelihood of migration to that destination by about nineteen percent. ${ }^{49}$ Similarly, one standard deviation increase in the ratio of per capita income at a potential destination state to one's current state increases the likelihood of migration to that destination by about sixteen percent. ${ }^{50}$ Finally, Professors Borjas, Bronars, and Trejo find that workers migrate to maximize their relative standard of living. In particular, high-skilled workers move to states where the return-to-skill rate is high (and, hence, income inequality is greater), while low-skilled workers move to states where the return-to-skill rate is low (and, hence, income inequality is lower) ${ }^{51}$

To the Author's knowledge, there is little empirical evidence on the role of environmental quality in explaining internal migration decisions. Barro and Sala-I-Martin explore interstate migration rates in the United States from 1900 to 1987. To proxy for environmental amenities, the authors include an independent variable measuring the average number of days requiring heating. This is admittedly an extremely crude proxy for environmental amenities. Nonetheless, the authors find it to be a meaningful determinant of net migration rates into particular states. ${ }^{52}$ Similarly, Professor Kahn explores the role of smog - measured as days per year exceeding the Clean Air Act's onehour standard for ozone on county-level population growth in California between 1980 and 1994. He finds that a county experiencing a ten-day decline in the number of "high ozone" days

49. See Paul S. Davies, Michael J. Greenwood \& Haizheng Li, A Conditional Logit Approach to U.S. State-to-State Migration, 41 J. REgionAL ScI. 337, 350 (2001) ("[A] one-standard deviation change in the destination-to-origin unemployment rate ratio reduces the probability of migration between 18 percent and 20 percent . . . .").

50. See id. ("[A] one-standard deviation change in the destination-to-origin per capita income ratio increases the probability of migration between 16 percent and 17 percent ....").

51. George J. Borjas, Stephen G. Bronars \& Stephen J. Trejo, Self-Selection and Internal Migration in the United States, 32 J. UrB. ECON. 159, 184 (1992) ("Individuals are more likely to migrate the greater is the mismatch between their skill endowments and the returns paid to skills in their native state. Moreover, the direction and skill composition of internal migration flows seem to be guided by comparative advantage. Skilled workers tend to move to states with greater wage dispersion than their native state, whereas unskilled workers are more likely to move to states with less dispersion.").

52. See Barro \& Sala-I-Martin, supra note 48, at 132 ("These results indicate that, all else being equal, people prefer warmer states."). 
over this time period registered a nearly $7.8 \%$ increase in population on average..$^{53}$

Professors Banzhaf and Walsh undertake a detailed analysis using more spatially disaggregate data than these prior studies. ${ }^{54}$ The authors use data from California over the period from 1990 to 2000. The authors divide urban areas of the state into mutually exclusive half-mile diameter circles. They then assess the relationship that changes in pollution have with changes in population and mean household income over this period..$^{55}$ Toxicity-weighted air emissions from the Toxic Release Inventory (TRI) are used as the measure of pollution. The results support the role of environmental amenities in household location decisions. Specifically, locations with the average level of emissions in 1990, as opposed to no emissions in 1990, experienced about a twelve percent reduction in the population growth rate between 1990 and $2000 .^{56}$ The average location experiencing an increase in emissions over the time period suffered a $6.9 \%$ reduction in the population growth rate. ${ }^{57}$ The average location experiencing a decline in emissions witnessed a $6.3 \%$ increase in the population growth rate..$^{58}$

Lastly, Professor Konisky, in tangentially related research, finds that better educated individuals are more likely to favor federal

53. Matthew E. Kahn, Smog Reduction's Impact on California County Growth, 40 J. Regional ScI. 565, 570 (2000) ("A county that experienced a 10-day reduction in high ozone days between 1980 and 1994 grew by 7.8 percent more than a county whose ozone level remained unchanged.").

54. H. Spencer Banzhaf \& Randall P. Walsh, Do People Vote with Their Feet? An Empirical Test of Tiebout's Mechanism, 98 Am. ECON. Rev. 843, 850 (2008) ("Census tracts may be too aggregate a unit . . . For these reasons, we take a different approach to neighborhood definitions. We define neighborhoods as a set of half-mile-diameter circles . . ..").

55. See $i d$. at 849 ("First, we identify a set of spatially delineated communities. Second, we construct demographic composition measures for each community for 1990 and 2000. Finally, for each community we construct measures of the toxicity-weighted level of exposure to air pollution in 1990 and 2000 based on data from the Toxics Release Inventory of the US Environmental Protection Agency (EPA).").

56. See $i d$. at 858 ("Focusing on the percentage change model, on average, baseline exposure to TRI emissions is associated with relative population declines that range from 10 to 16 percent, depending on the model.").

57. See $i d$. ("Likewise, the appearance of new toxic emissions in a previously untreated neighborhood is associated with population declines between 5 and 9 percent.").

58. See id. ("Finally, the model predicts consistent responses in the opposite direction for communities that lose exposure. On average, these communities are predicted to experience population gains of 5 to 7 percent."). 
control over most environmental issues, including local issues such as protecting community drinking water ${ }^{59}$ If the higher mobility rates of the better educated documented by Molloy, Smith, and Wozniak are related to environmental issues, one might expect the reverse to be true.

In sum, labor mobility is relatively high in the United States compared to many other developed countries, and there exists some evidence that location decisions are impacted by environmental amenities at a very spatially disaggregate level. But, mobility is on a "historically unprecedented" downward trajectory in the United States. ${ }^{60}$ Whether this low (and declining) mobility invalidates the Tiebout assumption, or simply reflects a population close to equilibrium where most individuals are currently residing in communities that maximize their utility is not clear. Moreover, whether the "threat" of migration exists and is sufficient to satisfy the assumptions of the Tiebout model is equally unclear. ${ }^{61}$

However, three facts work against the Tiebout model. First, migration patterns appear to be strongly related to employment, not the provision of public goods. Second, the survey evidence provided in Konisky indicates that more mobile segments of the population are more likely to favor federal authority over even local environmental issues. Finally, the fact that mobility rates are significantly lower for the less educated runs the risk that jurisdictions do not compete for residents of this type, but instead focus on the competition for more mobile, educated residents. If so, the Tiebout model would predict that the preferences of lower educated residents will be ignored. Provision of even purely local goods, such as drinking water, may not reflect the preferences of all residents. Bednar states: "If only a categorical portion of the population is immobile - the poor or ethnic minorities - then outcomes are even worse; governments compete for the wealthiest and are free to ignore these minority categories." ${ }^{2}$

59. David Konisky, Public Preferences for Environmental Policy Responsibility, 41 Publius: J. Federalism 76, 93 (2010) ("The parameter estimates on the education variable range from about 0.15 to 0.40 , which translates, on average, to a difference in the predicted probability of an individual without a high school degree choosing the federal government relative to someone with a post-graduate degree of about 0.17.").

60. Molloy, Smith \& Wozniak, supra note 35, at 194.

61. The threat of migration is analogous to the notion of contestable markets. In that case, a market with few firms may achieve the competitive equilibrium if the threat of entry exists due to: (1) a lack of entry and exit barriers; (2) no sunk costs; and (3) complete access to the same technology by both incumbents and new entrants. See, e.g., William J. Baumol, Contestable Markets: An Uprising in the Theory of Industry Structure, 72 Am. ECON. REV. 1, 3-4 (1982).

62. Bednar, supra note 1 , at 274. 


\section{Capital Mobility}

The empirical literature on capital mobility is much more extensive. Not only are there a number of studies assessing the impact of taxation on the location of industrial activity, but there are many studies focused solely on the impact of environmental regulation on the location of industrial activity. In the interest of relative brevity, this Article focuses solely on the latter and starts with the 1995 survey article by Jaffe, Peterson, Portney, and Stavins. ${ }^{63}$ The authors survey the literature at the time on the effects of the early period of environmental regulation in the United States (post-1970) on countrylevel competitiveness. ${ }^{64}$ To measure competitiveness, the authors focus on empirical studies examining trade patterns, both generally and specifically in pollution-intensive industries, domestic firm location decisions, and foreign direct investment (FDI). ${ }^{65}$ Jaffe, Peterson, Portney, and Stavins summarize the literature, concluding:

Overall, there is relatively little evidence to support the hypothesis that environmental regulations have had a large adverse effect on competitiveness, however that elusive term is defined... [S]tudies attempting to measure the effect of environmental regulation on net exports, overall trade flows, and plant-location decisions have produced estimates that are either small, statistically insignificant, or not robust to tests of model specification. ${ }^{66}$

Surveying the literature at roughly the same time, Levinson similarly notes that "the empirical literature suggests that... economic activity does not respond significantly to the different taxes and regulations in competing jurisdictions." ${ }^{\prime 67}$

However, there are a number of statistical problems that plague these early empirical studies. In their concluding remarks, Jaffe, Peterson, Portney, and Stavins discuss the issue of measuring

63. Adam B. Jaffe, Steven R. Peterson, Paul R. Portney \& Robert N. Stavins, Environmental Regulation and the Competitiveness of U.S. Manufacturing: What Does the Evidence Tell Us?, 33 J. ECON. Literature 132 (1995).

64. See Kirsten H. Engel, State Environmental Standard-Setting: Is There a "Race" and Is It "To the Bottom"?, 48 HASTINGS L.J. 271 (1997) (surveying the legal literature).

65. See Jaffee, Peterson, Portney \& Stavins, supra note 63, at 137.

66. Id. at $157-58$.

67. Arik Levinson, NIMBY Taxes Matter: The Case of State Hazardous Waste Disposal Taxes, 74 J. PuB. Econ. 31, 32 (1999). 
environmental stringency in practice. ${ }^{68}$ Environmental regulation is a complex concept which does not lend itself to precise measurement. Regulations differ across pollutants and depend not just on legislation (de jure regulation) but also enforcement (de facto regulation). Reliance on poor proxies for environmental regulation-referred to as measurement error in the econometric literature - might explain the lack of meaningful effects found in these early studies. A second problem with this early literature is that the results lacked a convincing causal interpretation. The authors note: "[T]he choice of a new plant location is obviously a complex one... Hence, isolating the effect of environmental regulations on the decision will inevitably be difficult." ${ }^{69}$ In particular, the choice of environmental stringency in a particular jurisdiction may be endogenous to the level (or expected level) of economic activity, or may be correlated with other locationspecific attributes that determine the location of economic activity but are unobserved by the researcher.

The empirical literature beginning in the late 1990s addresses these criticisms. As noted by Professors Jeppesen, List, and Folmer, this "second wave" of studies has consistently found meaningful, detrimental effects of environmental regulation on industrial activity. ${ }^{70}$ Professors Brunnermeier and Levinson conclude:

The early literature based on cross-sectional analyses typically tended to find that environmental regulations had an insignificant effect on firm location decisions. However, several recent studies that use panel data to control for unobserved heterogeneity, or instruments to control for endogeneity, do find statistically significant pollution haven effects of reasonable magnitude. Furthermore, it does not appear to matter whether these studies look across countries, industries, states, or counties, or whether they examine plant location, investment, or international trade patterns. ${ }^{71}$

68. See Jaffee, Peterson, Portney \& Stavins, supra note 63, at 158 ("[E]xisting data are severely limited in their ability to measure the relative stringency of environmental regulation .....").

69. Id. at 146 .

70. Tim Jeppesen, John A. List \& Henk Folmer, Environmental Regulations and New Plant Location Decisions: Evidence from a Meta-Analysis, 42 J. Regional SCI. 19, 23-24 (2002) ("Papers in the second research wave ...typically find much stronger evidence in favor of the hypothesis that environmental regulations affect the allocation of new firms.").

71. Smita B. Brunnermeier \& Arik Levinson, Examining the Evidence on Environmental Regulations and Industry Location, 13 J. ENV'T \& DEV. 6, 37-38 (2004). 
One branch of this second wave of studies uses the spatial and temporal variation in U.S. county-level environmental regulation induced by the Clean Air Act ${ }^{72}$ (CAA) to address the question of capital mobility. Specifically, beginning in 1972, every U.S. county is designated as either in attainment or out of attainment (nonattainment) of the federally designated standard for each of the criteria air pollutants established under the statute. ${ }^{73}$ Counties that are in nonattainment are subject to more stringent regulation. ${ }^{74}$ Thus, nonattainment status is synonymous with greater regulatory stringency.

Professor Henderson uses data on the ozone attainment status of urban counties over the period from 1977 to 1987, along with data on the number of establishments in each county during each year from the U.S. Census Bureau's County Business Patterns, to examine the effects of the more stringent regulations imposed in nonattainment counties. $^{75}$ He focuses on five pollution-intensive manufacturing industries: industrial organic chemicals, petroleum refining, miscellaneous plastics, plastic materials and synthetics, and blast furnace and primary steel. The results indicate that counties in attainment over the prior three years contain seven to ten percent more establishments than other counties. ${ }^{76}$

72. 42 U.S.C. $\S \S 7401-7642$ (2006).

73. 42 U.S.C. $\S 7407(\mathrm{c})-(\mathrm{d})$.

74. See, e.g., Michael Greenstone, The Impacts of Environmental Regulations on Industrial Activity: Evidence from the 1970 and 1977 Clean Air Act Amendments and the Census of Manufactures, 110 Journal POL. ECON. 1175, 1176-77 ("The Clean Air Act, originally passed in 1963 and amended in 1970, 1977, and 1990, is one of the most significant federal interventions into the market in the postwar period. Following the passage of the 1970 amendments, the Environmental Protection Agency (EPA) established separate national ambient air quality standards - a minimum level of air quality that all counties are required to meet - for four criteria pollutants: carbon monoxide $(\mathrm{CO})$, tropospheric ozone $\left(\mathrm{O}_{3}\right)$, sulfur dioxide $\left(\mathrm{SO}_{2}\right)$, and total suspended particulates (TSPs). As a part of this legislation, every U.S. county receives separate nonattainment or attainment designations for each of the four pollutants annually. The nonattainment designation is reserved for counties whose air contains concentrations of a pollutant that exceed the relevant federal standard. Emitters of the regulated pollutant in nonattainment counties are subject to stricter regulatory oversight than emitters in attainment counties. Nonpolluters are free from regulation in both categories of counties.").

75. See J. Vernon Henderson, Effects of Air Quality Regulation, 86 AM. ECON. REV. 789, 811 (1996).

76. See id. at 802 ("In summary, a county being in nonattainment for heavy volatile organic compound emitters discourages location there. A switch to a clean ozone record increases the number of plants in the county by about 8 percent."). 
In a subsequent study, Professor Henderson revisits the same data using a different statistical methodology and focusing on a binary indicator of the presence of at least one of the pollution-intensive establishments in a county during a given year. ${ }^{77} \mathrm{He}$ finds that the probability of a given industry being located in a county increases by at least fourteen percent in four of the five industries considered after a county switches from nonattainment to attainment. ${ }^{78}$

Becker and Henderson continue this line of inquiry, using plantlevel data over the period from 1963 to 1992 for the industrial organic chemicals, miscellaneous plastic products, metal cans and barrels, and the wood furniture sectors. ${ }^{79}$ The data used by Becker and Henderson came from the Longitudinal Research Database, administered by the Center for Economic Studies of the U.S. Census Bureau. The results are in line with the prior studies; nonattainment status reduces the expected number of new plant births by twenty-six to forty-five percent. ${ }^{80}$ However, the authors find that new plants locating in nonattainment counties are initially larger in size (relative to new plants locating in attainment areas). This size discrepancy disappears after roughly ten years. ${ }^{81}$

Greenstone builds on this research by examining approximately .75 million plant-level observations over the period from 1967 to 1987, obtained from the Census of Manufactures, to assess the separate impacts of carbon monoxide, ozone, sulfur dioxide, and total suspended particulate nonattainment status across all counties in the United States. ${ }^{82}$ With such rich data, the author is able to identify the

77. See Vernon Henderson, The Impact of Air Quality Regulation on Industrial Location, 45 AnNAls ECON. \& StAT. 123, 128-29 (1997) (addressing "the discrete choice problem of whether the county has the industry or not").

78. See id. at 132 ("Specifically, for each industry for the base, I take a county in non-attainment status and assign it a base probability of having the industry in year $t$ of 0.25 . I then calculate the positive effect of moving to attainment status.... The effects are very large. Probabilities rise from 0.25 to anywhere from 0.39 to 0.71 . This would suggest that attainment status is a key variable in firm location decisions." (citation omitted)).

79. Randy Becker \& Vernon Henderson, Effects of Air Quality Regulations on Polluting Industries, 108 J. PoL. ECON. 379, 386-88 (2000).

80. Id. at 397 ("Nonattainment status in the regulatory era reduces the expected number of births in a county by $26-45$ percent, depending on the industry, with the largest impact occurring for the industry with the largest plant sizes, industrial organic chemicals.").

81. See $i d$. at 411 ("New plants ... are significantly larger in nonattainment counties than in attainment counties, by 25-69 percent. That effect then diminishes with age, so that plants $10+$ years have a similar size in nonattainment counties.").

82. See Greenstone, supra note 74 , at $1183-84$. 
effect of nonattainment status on plants in sectors deemed to be high emitters of each of the four criteria pollutants using only the temporal variation within plants, controlling for industry-level and county-level unobserved attributes in an unrestricted way. The results indicate that over the period from 1972 to 1987, nonattainment counties (relative to in attainment counties) lost roughly 590,000 jobs, $\$ 37$ billion in capital stock, and $\$ 75$ billion in output. ${ }^{83}$

In a series of papers by Professor List and co-authors, the impacts of ozone nonattainment status on county-level industrial activity in New York State are examined over the period from 1980 to 1990. Annual data on new plant births by domestic and foreign firms, as well as plant relocations, are provided by the Industrial Migration File maintained by the New York State Department of Economic Development. ${ }^{84}$ List, McHone, and Millimet focus on plant relocations and find that being in nonattainment costs a county roughly 0.50 fewer relocating plants in pollution-intensive sectors per year relative to being in attainment. ${ }^{85}$ Given that the average county in the sample only receives about 0.2 relocating plants per year, this represents a sizeable decrease. List, Millimet, McHone, and Fredriksson analyze new plant births using similar statistical techniques. Here, the authors find even larger effects: nonattainment counties lose out on approximately one new pollution-intensive plant per year relative to counties in attainment. ${ }^{86}$ The average county in the sample obtains 0.4 new plant births per year. Finally, List, McHone, and Millimet revisit the data on new plant births, distinguishing between new plant births by foreign and domestic firms. The authors find that the prior deterrent effects of nonattainment status on new plant births is driven entirely by domestically owned plants; foreign-owned plants are unresponsive to spatial variation in environmental regulatory costs due to differences in ozone attainment status. ${ }^{87}$

83. See id. at 1178 .

84. John A. List, Daniel L. Millimet, Per G. Fredriksson \& W. Warren McHone, Effects of Environmental Regulations on Manufacturing Plant Births: Evidence from a Propensity Score Matching Estimator, 85 REV. Econ. \& Stat. 944, 945 (2003).

85. John A. List, W. Warren McHone \& Daniel L. Millimet, Effects of Air Quality Regulation on the Destination Choice of Relocating Plants, 55 OXford ECON. PAPERS 657, 674 (2003) ("[E]stimates suggest that approximately 0.50 fewer plants per year relocate in a county that is [out of attainment].").

86. See List, Millimet, Fredriksson \& McHone, supra note 84, at 948 ("[A]n estimated 'cost' of being out of attainment . . . is between 0.7 and 1.3 new plants per year.").

87. John A. List, W. Warren McHone \& Daniel L. Millimet, Effects of Environmental Regulation on Foreign and Domestic Plant Births: Is There a Home Field Advantage?, 56 J. URB. ECON. 303, 324 (2004) 
The other branch of this second wave of the empirical literature on the effects of environmental regulation on the location of industrial activity analyzes patterns of international trade and FDI (the socalled pollution haven hypothesis). The criticisms of the early literature are particularly worrisome when examining the effects of cross-country differences in environmental regulation. First, one needs a consistent measure of environmental regulation across multiple countries. Second, one needs extensive data on country (or industry) characteristics; otherwise any association between environmental stringency and the patterns of global trade or investment may simply reflect unobserved attributes of countries (or industries) correlated with both regulation and the location of industrial activity. The traditional econometric approach used to overcome measurement error in the proxy for environmental regulation and unobserved, countrylevel heterogeneity is the method of instrumental variables. While not all studies employing instrumental variables are necessarily sound (due to the use of weak or potentially invalid instruments), this Article focuses only on studies that employ this technique as the alternative - such as cross-sectional or fixed-effects estimationbecause this approach is not likely to produce causal estimates of the impacts of environmental regulation in this Article's author's view (due to the requirement that all independent variables in such models be strictly exogenous).

The first set of studies focus on patterns of FDI. Professors Xing and Kolstad assess the pattern on U.S. outbound FDI in six manufacturing sectors across twenty-two host countries using data from 1985 and $1990 .{ }^{88}$ As a proxy for environmental regulation, the authors utilize sulfur dioxide $\left(\mathrm{SO}_{2}\right)$ emissions. The authors find more lax regulation (as measured by higher $\mathrm{SO}_{2}$ emissions) leads to greater investment in the United States within two pollution-intensive industries: chemicals and primary metals. ${ }^{89}$ There is no meaningful effect for the other, less pollution-intensive, sectors considered.

Professors Fredriksson, List, and Millimet examine the impact of environmental stringency on U.S. inbound FDI across the forty-eight contiguous states for the period from 1977 to $1986 . .^{90}$ To measure

("[W]e find that domestic plants are responsive to environmental standards whereas foreign plants are not.").

88. See Yuquing Xing \& Charles D. Kolstad, Do Lax Environmental Regulations Attract Foreign Investment?, 21 ENvTL. \& RESOURCE ECON. 1, 11-12 (2002).

89. See $i d$. at 15 ("In general, lax environmental policy tends to attract more capital inflow from the US for pollution intensive industries.").

90. See Per G. Fredriksson, John A. List \& Daniel L. Millimet, Bureaucratic Corruption, Environmental Policy and Inbound US FDI: Theory and Evidence, 87 J. PuB. ECON. 1407, 1413-19 (2003). 
environmental regulation, the authors utilize an index based on the ratio of actual pollution abatement expenditures incurred by plants located in the state to the predicted level of expenditures based on the state's industrial composition. The results indicate a meaningful deleterious effect of stringency on inbound FDI. For example, the effect of one standard deviation in stringency in California in 1984 is predicted to lower employment in the foreign-owned chemical plants by six percent - or 2500 jobs. $^{91}$

Professors Cole and Elliott analyze the patterns of U.S. outbound FDI in Brazil and Mexico across thirty-one and thirty-six industries respectively from 1989-1994. ${ }^{92}$ The authors' goal is to disentangle the effects of environmental regulatory costs - measured by industry-level pollution abatement costs per unit of value added - on firm behavior from the effects of endowments of physical capital. Specifically, the authors contend that since many pollution-intensive sectors are also capital-intensive, the benefit to firms from more lax environmental standards in less developed countries may be offset by lower levels of physical capital in these same countries. ${ }^{93}$ Brazil and Mexico, the authors argue, are relatively well endowed with physical capital but have lax environmental standards, thus making it more likely that investment in these countries will be more sensitive to environmental costs. ${ }^{94}$ Indeed, the authors find evidence supporting the claim that sectors experiencing relatively high environmental regulatory costs in the United States do invest more in each country.

Cole and Fredriksson utilize data on inbound FDI to thirteen countries that are members of Organisation for Economic Cooperation and Development (OCED) and twenty less developed countries over the period from 1982 to $1992 .{ }^{95}$ The proxy variable for environmental regulation is the allowable lead content in gasoline. The results point to a sizeable, deleterious effect of environmental regulation on the amount of inbound FDI enjoyed by a country. For example, roughly one standard deviation increase in the authors' measure of regulation leads to approximately a 0.6 standard deviation reduction in a country's stock of FDI. ${ }^{96}$

91. See id. at 1424 .

92. See Matthew A. Cole \& Robert J.R. Elliott, FDI and the Capital Intensity of "Dirty" Sectors: A Missing Piece of the Pollution Haven Puzzle, 9 Rev. Dev. Econ. 530, 533-36 (2005).

93. See id. at 535 .

94. See $i d$. ("Brazil and Mexico are two developing countries with reasonably high capital-labor ratios, yet with reasonably low levels of environmental regulations.").

95. See Matthew A. Cole \& Per G. Fredriksson, Institutionalized Pollution Havens, 68 ECOLOGICAL ECON. 1239, 1245-46 (2009).

96. Id. at 1251 . 
Professor Kellenberg focuses on effects of country-level environmental stringency on the value added of majority-owned U.S. affiliates in fifty countries across nine industries over the period from 1999 to $2003 .{ }^{97}$ To measure environmental policy, Kellenberg uses data from the Global Competitiveness Report (GCR) on the stringency and enforcement of environmental regulations. The GCR creates separate indices related to stringency and enforcement based on survey responses elicited from executives..$^{98}$ The results point to a meaningful effect of environmental regulation on the location of production abroad by majority-owned U.S. affiliates. Specifically, for the top quintile of countries in terms of the increase in economic activity by majority-owned U.S. affiliates over the sample period, $8.6 \%$ of this increase is attributable to more lax environmental policies in these countries. ${ }^{99}$

Finally, Professors Millimet and Roy analyze the pattern of inbound FDI across the forty-eight contiguous U.S. states from 1977 to 1986 and 1988 to 1994 using recently developed econometric techniques designed for situations where valid instrumental variables are difficult to envision. ${ }^{100}$ The measure of state-level environmental regulation is identical to that used by Fredriksson, List, and Millimet. ${ }^{101}$ The authors find an adverse impact of environmental regulation on the amount of FDI locating in a state for the pollutionintensive chemical sector, but no effect on the level of FDI for manufacturing as a whole. ${ }^{102}$

The second set of studies focus on patterns of international trade. Cole and Elliot examine the impact of environmental regulation on the net exports of sixty countries in four pollution-intensive sectors in 1995. ${ }^{103}$ The sectors studied include iron and steel, chemicals, pulp

97. See Derek K. Kellenberg, An Empirical Investigation of the Pollution Haven Effect with Strategic Environment and Trade Policy, 78 J. OF INT'L ECON. 242, 244-46 (2009).

98. Id.

99. See id. at 250 ("Put differently, approximately $8.6 \%$ of U.S. affiliate value added growth by the top 20th percentile countries can be attributed to falling environmental policy.").

100. See Daniel L. Millimet \& Jayjit Roy, Three New Empirical Tests of the Pollution Haven Hypothesis When Environmental Regulation Is Endogenous 7-9 (Institut zur Zukunft der Arbeit (IZA), Discussion Paper Series No. 5911, 2011).

101. See Fredriksson, List \& Millimet, supra note 90, at 1414.

102. See Millimet \& Roy, supra note 100, at 22 ("[W]e consistently find ... a negative and economically significant impact of own environmental stringency on inbound FDI in the chemical sector.").

103. Matthew A. Cole \& Robert J.R. Elliott, Do Environmental Regulations Influence Trade Patterns? Testing Old and New Trade Theories, 26 WORLD ECON. 1163, 1166-67 (2003). 
and paper, and non-ferrous metals. Two measures of environmental stringency are employed. The first is an index based on country reports concerning environmental policies and enforcement compiled under United Nations Conference on Environment and Development guidelines. The second is a proxy variable computed using information on the energy intensity of production. The authors find no effects of environmental stringency on net exports, but they do find effects on the composition of trade: stricter regulation leads to a greater fraction of trade that is inter-industry. ${ }^{104}$

Several studies utilize U.S. industry-level measures of environmental costs based on pollution abatement expenditures to assess the impact of regulation on industry-level measures of U.S. imports or exports. Professors Ederington and Minier analyze data on the net imports of 374 U.S. industries over the period of 1978, 1980 to 1986, and 1988 to $1992 .{ }^{105}$ The authors find extremely large effects of environmental costs on net imports. Specifically, they find that a one percent increase in pollution abatement costs results in a thirty percent increase in net imports scaled by the total value of U.S. shipments in the industry. ${ }^{106}$ Similarly, Cole, Elliott, and Shimamoto analyze the effect of environmental costs on U.S. net exports across ninety-six industries over the same time period. ${ }^{107}$ The authors also control for the human and physical capital intensity of sectors, finding a detrimental effect of environmental costs on net exports. However, the magnitude of the effect is much smaller than that attributable to human or physical capital considerations. ${ }^{108}$

104. See id. at 1179 ("[W]e found no evidence to suggest that either of our two measures of environmental regulations were statistically significant determinants of 'dirty' net exports. ... Our results suggest that the shares of trade that are intra- and inter-industry are indeed influenced by environmental regulation differentials between two countries.").

105. Josh Ederington \& Jenny Minier, Is Environmental Policy a Secondary Trade Barrier? An Empirical Analysis, 36 Can. J. Econ. 137, 142-43, 150 app.A (2003).

106. See id. at 146 ("[W]e estimate that an industry with pollution abatement costs 1 percentage point higher than otherwise identical industries will have a net import ratio over 30 percentage points higher ....").

107. Matthew A. Cole, Robert J.R. Elliott \& Kenichi Shimamoto, Why the Grass Is Not Always Greener: The Competing Effects of Environmental Regulations and Factor Intensities on US Specialization, 54 ECOLOGICAL ECON. 95 (2005).

108. See id. at 107 ("We illustrate in a variety of ways that pollution intensive industries are typically more intensive in the use of physical and human capital than cleaner industries. These factor intensities appear to be important determinants of US specialization patterns, suggesting that factor intensities and environmental regulations have a competing influence on revealed comparative advantage."). 
Finally, Professors Levinson and Taylor examine U.S. net imports from Mexico and Canada across 132 industries over the period from 1977 to 1986. ${ }^{109}$ The authors also find a large, adverse effect of environmental costs on domestic production. For example, net imports from Canada increased by $\$ 601$ million for the average industry in the sample over this period; $\$ 79$ million of this increase is attributable to the rise in pollution abatement costs. ${ }^{110}$ Among the twenty industries in the U.S. that experienced the largest rise in pollution abatement costs, the numbers are $\$ 595$ million and $\$ 453$ million, respectively. ${ }^{111}$

The final two studies utilize data across several countries. Professors Jug and Mirza analyze the import patterns of twelve countries in the EU15 and export patterns of nineteen countries from the EU15, central Europe, and eastern Europe across nine industries over the period from 1996 to $1999 .{ }^{112}$ Environmental regulation is measured using data from the Eurostat Environmental Expenditures and Environmental Taxes database on total current expenditures related to environmental protection activities for all manufacturing. The results indicate a meaningful, negative effect of environmental stringency on domestic production, with results of greater magnitude for eastern Europe. ${ }^{113}$

Professors Mulatu, Gerlagh, Rigby, and Wossink utilize data on sixteen industries across thirteen countries to assess the role of environmental regulation on the share of production in each industry that occurs in each country. The objective is to determine whether countries with relatively less stringent regulation are responsible for a greater share of production in pollution-intensive sectors over the period from 1990 to 1994. The country-level measure of regulation is given by the Environmental Sustainability Index (collected in 2001) developed by the World Economic forum, Yale Center for Environmental Law, and Center for International Earth Science Information Network at Columbia University. As with the prior

109. Arik Levinson \& M. Scott Taylor, Unmasking the Pollution Haven Effect, 49 InT'L ECON. REv. 223, 237-40 (2008).

110. See id. at 246, 252 (calculating the net import increase from the average increase in trade volume as compared to the abatement costs).

111. See id. at 252 .

112. Jerneja Jug \& Daniel Mirza, Environmental Regulations in Gravity Equations: Evidence from Europe, 28 WORLD ECON. 1591, 1600-03 (2005).

113. See id. at 1612 ("[E]nvironmental stringency matters more for Eastern European exporters, since EU importers might be more sensitive to developing countries' average lower product quality and lack of varieties provided."). 
studies, the findings point to significantly greater domestic production in pollution-intensive industries in countries with lax regulation. ${ }^{114}$

In sum, second generation studies - utilizing better data to identify the causal effect of environmental policy - have consistently documented a meaningful effect of environmental stringency on the location of economic activity. That said, these findings must be interpreted carefully. First, environmental costs are a small fraction of the total production costs for most industrial sectors. ${ }^{115}$ Thus, the effects documented in the literature typically apply to only the most pollution-intensive industries. For the vast majority of industries, environmental costs are a small fraction of overall costs and location decisions are dominated by other factors. For example, Henderson and Millimet allow for heterogeneous effects of more stringent environmental policy on the amount of foreign investment and find the effects to be negative for some locations and positive for others. ${ }^{116}$ Consistent with this finding, Henderson and Millimet had previously found no overall effect of environmental stringency on the Gross State Product of U.S. states. ${ }^{117}$

Second, the effects estimated by econometric models are ceteris paribus effects. In other words, they indicate the impact of more stringent environment regulation with "other things being equal" or with the assumption that all other variables are being held constant. ${ }^{118}$ In practice, other important determinants of the location of economic activity are not held fixed such as a location's endowment of physical and human capital. This fact is highlighted in several analyses. Studies by Ederington, Levinson, and Minier and Levinson show that the rate of increase in total U.S. imports has risen faster over the past few decades than the rate of imports of pollution-

114. See $i d$. at 475 ("[I]ncreased environmental regulatory laxity does not result in an increased share of the 'average' industry. However, when the most polluting, rather than the average, industry is considered, increased environmental regulatory laxity does result in a higher proportion of this dirty industry locating there.").

115. See Jaffee, Peterson, Portney \& Stavins, supra note 63, at 158 ("[F]or all but the most heavily regulated industries, the cost of complying with federal environmental regulation is a relatively small fraction of total cost of production.").

116. Daniel J. Henderson \& Daniel L. Millimet, Pollution Abatement Costs and Foreign Direct Investment Inflows to U.S. States: A Nonparametric Reassessment, 89 Rev. Econ. \& Stat. 178, 179 (2007).

117. Daniel J. Henderson \& Daniel L. Millimet, Environmental Regulation and US State-Level Production, 87 ECON. LetTers 47, 52 (2005) ("[T]he lack of an observed association between the stringency of environmental regulation and state-level output is robust.").

118. Black's LaW Dictionary 260 (9th ed. 2009) (defining "ceteris paribus"). 
intensive goods. ${ }^{119}$ As such, the pollution content of U.S. imports has fallen over a period where U.S. regulatory stringency has increased markedly. ${ }^{120}$ Professors Grether, Mathys, and de Melo analyze the pollution content of imports across forty-eight countries and find that environmental standards play a small role in the overall pattern of trade. ${ }^{121}$ In this vein, Cole and Elliott conclude: "We do not suggest that pollution havens are widespread." 122

Finally, while the studies reviewed in this Part make use of instrumental-variables or fixed-effects strategies in an attempt to isolate the causal effect of environmental regulation, not all identification strategies are convincing. ${ }^{123}$ Accordingly, readers should be cognizant that simply because researchers employ panel-data-fixedeffects or instrumental-variables methods does not mean that such strategies produce credible inferences.

\section{B. Preference Heterogeneity}

The Tiebout framework relies on heterogeneous individuals sorting themselves across communities offering different combinations of taxes and public goods. In equilibrium, the policies of each community will reflect the preferences of its homogeneous residents. The literature on environmental federalism, and fiscal federalism more generally, has long touted the ability of communities to synchronize policy choices with individual preferences as the primary advantage of decentralized policy making. Gordon states: "One of the key advantages of decentralization is the resulting diversity of policies." ${ }^{24}$

119. See, e.g., Josh Ederington, Arik Levinson \& Jenny Minier, Trade Liberalization and Pollution Havens, 4 Advances Econ. Analysis \& POL'Y 1, 6 fig.1B (2004) (demonstrating an increase in U.S. imports overall as compared to the import of pollution-intensive products).

120. Arik Levinson, Offshoring Pollution: Is the United States Increasingly Importing Polluting Goods?, 4 Rev. Envtl. ECON. \& POL'y 63, 79 (2010) ("Today the United States imports proportionally more clean goods and proportionally fewer polluting goods than was the case 30 years ago. Perhaps even more surprisingly, the green shift in imports is even larger than the green shift in domestic production. In other words, the analysis here finds that the United States has not been offshoring pollution.").

121. Jean-Marie Grether, Nicole Andréa Mathys \& Jaime de Melo, Unravelling the Worldwide Pollution Haven Effect, 21 J. INT'L TradE \& ECON. DEV. 131, 131 (2012) ("[E]conometric estimates suggest a significant pollution haven effect.... On a global scale, because the bulk of trade is intra-regional with a high North-North share, these effects are small relative to the 'deep' determinants of worldwide PCI [pollution content of imports].").

122. Cole \& Elliott, supra note 92, at 541.

123. E.g., Millimet \& Roy, supra note 100, at 4-6.

124. See Gordon, supra note 2, at 582 . 
Oates writes: "The hope is that state and local governments, being closer to the people, will be more responsive to the particular preferences of their constituencies ...."125 Adler asserts that "localized control of environmental policy will produce environmental measures that are more likely to reflect the preferences and needs of those who will be most affected by them." ${ }^{126}$

In practice, the advantages to decentralized policy making depend on three factors: (1) the extent of preference heterogeneity in the population; (2) the degree to which individuals act on such preferences to sort themselves into homogeneous communities; and (3) the ability of local governments to better respond to community preferences than the central government. I discuss the empirical evidence on each in turn.

For the purposes of evaluating the benefits of decentralization, empirical evidence on the extent of heterogeneous preferences over environmental issues is scant. Several papers utilize survey or voting data to examine associations between socioeconomic characteristics and preferences. Elliott, Seldon, and Regens use data from the General Social Survey, which is administered by the U.S. National Opinion Research Center, to analyze public attitudes toward environmental spending over the periods from 1974 to 1978, 1980, and 1982 to $1991 .{ }^{127}$ The authors find that liberalism, lower age, being female, being nonwhite, urban status, education, and income are positively associated with preferences for environmental spending. ${ }^{128}$ However, one is not able to discern how much overall variation in preferences exists, nor how much of this variation is explained by these attributes.

Additional analyses have been undertaken using individual-level, cross-country data. Professors Israel and Levinson utilize data spanning thirty-three countries from the World Values Survey during the mid-1990s. ${ }^{129}$ Consistent with the prior study, the authors find that lower age, being female, education, and income are positively associated with willingness to pay for environmental improvements. ${ }^{130}$ However, the vast majority of the variation in willingness to pay

125. See Oates, supra note 16 , at 1120.

126. See Adler, supra note 9, at 138.

127. Euel Elliott, Barry J. Seldon \& James L. Regens, Political and Economic Determinants of Individuals' Support for Environmental Spending, 51 J. Envtl. Mgmt. 15, 17-19 (1997).

128. See id. at 20-25.

129. Debra Israel \& Arik Levinson, Willingness to Pay for Environmental Quality: Testable Empirical Implications of the Growth and Environment Literature, 3 Contributions to ECON. AnAlysis \& POL'Y no. 1, 2004, at 1, 9-15.

130. See id. at 12 . 
(seventy-two percent) is explained by the country one resides in, not by the socioeconomic attributes included in the analysis. ${ }^{131}$ As such, over two-thirds of the international variation in willingness to pay occurs across countries, with the rest representing within-country variation. ${ }^{132}$

Lorenzoni and Pidgeon discuss data collected by the European Opinion Research Group in 2002 across EU15 member states on individual concerns regarding climate change. ${ }^{133}$ The authors report the percentage of survey respondents in each country reporting that they are "very worried" about climate change. The percentages varied from about twenty-one percent in The Netherlands to about sixtythree percent in Greece. ${ }^{134}$ When asked about concern over future trends in climate change, the percentage responding "very much" or "quite a lot" varied from roughly forty-nine percent in the Netherlands to roughly eighty-five percent in Greece and Italy. ${ }^{135}$ Thus, there is variation in concern over climate change both within and across countries.

Professors Kahn and Matsusaka examine county-level voting on sixteen environmental ballot initiatives in California spanning 1970 to 1994. ${ }^{136}$ The authors report the county with the lowest and highest fraction of votes in favor of each ballot initiative. ${ }^{137}$ For example, Proposition 1986-65 that sought to restrict the release of chemicals into drinking water sources received $32.7 \%$ votes in favor in the least favorable county and $78.3 \%$ votes in favor in the most favorable county. ${ }^{138}$ Other ballot measures yielded greater variation. Votes in favor of Proposition 1990-130 that sought to ban clear-cutting of forests and authorize a $\$ 742$ million bond issue to buy forest land ranged from $15.3 \%$ in the least favorable county to $70.7 \%$ in the most

131. See id. at $12,21$.

132. See $i d$. at 15 ("[E]ven though we have included ample demographic characteristics of respondents, the country fixed effects explain a large fraction of the variation in the responses.").

133. Irene Lorenzoni \& Nick F. Pidgeon, Public Views on Climate Change: European and USA Perspectives, 77 Climatic Change 73, 76 (2006).

134. See id. at 76 ("Some of the most worried were southern European states such as Greece (63\%) and Italy (49\%), whilst among the least worried were northern European nations such as The Netherlands (21\% of very worried respondents), Ireland (25\%) and the UK (26\%) ....").

135. Id. at 77 .

136. Matthew E. Kahn \& John G. Matsusaka, Demand for Environmental Goods: Evidence from Voting Patterns on California Initiatives, 40 J.L. \& ECON. 137, 142-45, 149-51 (1997).

137. See id. at $144-45$.

138. Id. at 144 . 
favorable county. ${ }^{139}$ This is indicative of significant variation in preferences across counties. Kahn and Matsusaka further find that much of this cross-county variation is explained by differences in per capita income, urban status, education, and per capita income derived from specific industries (construction, farming, forestry, and manufacturing). ${ }^{140}$

Rather than relying on survey response data, several studies utilize information on home values and environmental amenities (or disamenities) to assess the demand for environmental quality. Professors Zabel and Kiel combine data from the American Housing Survey, the U.S. Census Bureau, and the EPA across four cities (Chicago, Denver, Philadelphia, and Washington, D.C.) from 1974 to 1991 to estimate household-level marginal willingness to pay for air quality by relating local air quality to home values. ${ }^{141}$ The authors then examine the association between household characteristics and this value. In contrast to the results above, Zabel and Kiel find lower marginal willingness to pay for nonwhites and no meaningful association with gender. ${ }^{142}$

Professors Brasington and Hite utilize data on home sales across six metropolitan areas in Ohio (Akron, Cincinnati, Cleveland, Columbus, Dayton, and Toledo) in 1991 to first estimate the implicit price of distance from the nearest environmental hazard and then examine the effect of price, income, and other attributes on the demand. ${ }^{143}$ The authors find a small, negative price elasticity of demand for distance from the nearest environmental hazard and a positive income elasticity of demand for distance from the nearest environmental hazard. ${ }^{144}$ Carruthers and Clark follow the strategy

139. Id. at 145 .

140. See $i d$. at 167 ("[A] small set of standard economic variables can account for the majority of the variance in county voting patterns.").

141. Jeffrey E. Zabel \& Katherine A. Kiel, Estimating the Demand for Air Quality in Four U.S. Cities, 76 LAND ECON. 174, 180-82 (2000).

142. See id. at 189 ("The MWTP [marginal willingness to pay] for all four air quality measures is significantly lower for black and Hispanic households. Whether the household head is married or male does not appear to have a consistently significant effect on MTWP [sic] for the four air quality measures.").

143. David M. Brasington \& Diane Hite, Demand for Environmental Quality: A Spatial Hedonic Analysis, 35 Regional Sci. \& Urb. Econ. 57, 59$72(2005)$.

144. Id. at 77 ("Among the demand shift variables, higher income is statistically significantly related to higher demand for environmental quality. The non-spatial models achieved the same result, but suggested a stronger effect than the spatial model. The estimated income elasticity of demand for the spatial model is 0.044 . The result suggests that people do not purchase much more environmental quality when their incomes rise."); see also id. at 78 ("The implicit price of environmental quality is 
utilized by Brasington and Hite and examine data on home sales in King County, Washington in 2004. ${ }^{145}$ The authors obtain similar results in terms of the price and income elasticity of demand for distance from the nearest environmental hazard. ${ }^{146}$

The second factor affecting the advantages to decentralization relates to the degree to which individuals act on variation in environmental preferences to sort themselves into homogeneous communities. The preceding studies on preferences over environmental quality provide little evidence in this regard. With the exception of Kahn and Matsusaka, the studies discussed using survey responses or voting behavior are geographically aggregated. Thus, while preferences vary across individuals, there is no information concerning the level of variation in the total population versus the level of variation in a single community. Kahn and Matsusaka, however, do provide evidence of significant variation in voting behaviors across California counties driven by differences in income and industrial composition.

Studies utilizing housing prices to infer something about the willingness to pay for environmental amenities or how the prices of environmental amenities affect its demand also fail to provide insights into the amount of overall variation in preferences or whether preferences are more homogeneous at the city level than at the state or country level. Lastly, the empirical evidence on population mobility discussed in Part II.A.1 indicates that residential location choices, at least in the United States, are driven primarily by employment prospects.

The final factor impacting the advantages to decentralized policy making pertains to the ability of local governments to better respond to community preferences than the central government. If preferences concerning the environment do vary across individuals and individuals do sort into homogeneous communities, both of which are far from certain, are local policy makers better able to align environmental policies with these preferences? While this is typically asserted, as evidenced by some of the quotes above, there is no evidence to support this contention. Wilson states:

negatively related to quantity demanded; the price elasticity of demand of -0.12 suggests a relatively inelastic demand curve.").

145. John I. Carruthers \& David E. Clark, Valuing Environmental Quality: A Space-Based Strategy, 50 J. Regional ScI. 801, 807-12 (2010).

146. Id. at 828 ("These results are remarkably consistent with work done by Brasington and Hite (2005), who also found an inelastic price elasticity of demand ....."); see also id. at 829 ("That said, as expected, all of the elasticities that come out of this calculation are positive, meaning that distance from environmental hazards is a normal good so, other things being equal, households spend more on it as their incomes rise."). 
[W]e do not have a good understanding of how information asymmetries occur between different levels of government, and what exact form these asymmetries take. Rather, we have vague ideas, such as the understanding that local officials know more because they are "closer to the people." ... [I]t seems difficult to justify why the central authority cannot easily obtain the information that is assumed absent. ${ }^{147}$

In sum, the empirical evidence regarding preference heterogeneity and its implications on environmental federalism is limited and incomplete. While it seems likely that preferences do vary, perhaps much of this variation is across countries. The main drivers of withincountry variation are income, education, and industry. Because these attributes are easily observed, Wilson's point about central governments being as capable as localities of understanding local preferences appears valid. That said, it is not clear that communities are particularly homogeneous with respect to these attributes. For example, in terms of income, the level of income inequality in 1999 across all households in the United States was 0.463 as measured by the Gini coefficient, a common measure of inequality. ${ }^{148}$ The Gini coefficient ranges from zero to one, where zero indicates perfect equality (all households have identical incomes) and one indicates perfect inequality (one household possesses all income). The corresponding state-level Gini coefficients ranged from 0.402 (Alaska) to 0.499 (New York). ${ }^{149}$ County-level Gini coefficients are available pooling data from 2006 to 2010. Between counties, the Gini coefficients vary from 0.207 (Loving, TX) to 0.645 (East Carroll Parish, Louisiana), while the Gini coefficient for the United States as a whole was 0.467 over this time period. ${ }^{150}$ Among the twenty-five most populous counties in the United States, the Gini coefficients range from 0.417 (Suffolk County, New York) to 0.601 (New York County, New York). ${ }^{151}$

This suggests that there is not much sorting at the state or county level according to income, which is a strong predictor of environmental preferences. In any event, much more research is needed on the extent of preference heterogeneity and, more

147. See Wilson, supra note 8 , at 277 .

148. U.S. Census Bureau, Income: Table S4. Gini Ratios by State (2010), available at http://www.census.gov/hhes/www/income/data/his torical/state/state4.html.

149. Id.

150. U.S. Census Bureau, Household Income Inequality Within U.S. Counties: 2006-2010, at 1, 4 (2012), available at http://www.census. gov/prod/2012pubs/acsbr10-18.pdf.

151. Id. at 4 . 
importantly, whether individuals sort themselves such that localities within a country are less heterogeneous than the country as a whole.

\section{Interjursidictional Externalities}

Efficiency of decentralized policy making in both the Tiebout and interjurisdictional competition frameworks requires local governments to internalize all externalities. ${ }^{152}$ A lengthy empirical literature has emerged assessing the practical relevance of spillovers across jurisdictions. This is crucial because the failure of local governments to internalize all externalities is often cited as the main argument against decentralized policy making. For example, Engel writes:

The interstate spillover rationale is the classic economic efficiency argument that federal intervention is necessary to prevent the environmental, social, and economic losses that accrue when air and water pollution originating in one state are carried by natural forces into other states. States from which the pollution originates have little incentive to curb interstate pollution because they benefit from having the harmful effects of pollution externalized while they enjoy the economic benefits of the polluting activity. ${ }^{153}$

Professor Sigman notes that the size of "spillovers across jurisdictions . . . is a central question in the literature on the problem of assigning functions to different levels of government." 154 Adler states: "The strongest case for federal involvement comes in the context of interstate spillovers." "155 Hall writes: "One of the foundational justifications for the federalization of environmental law is the problem of interstate environmental harms." 156 Dijkstra and Fredriksson state: "Transboundary pollution is a standard and wellknown reason for preferring centralized environmental policy

152. See Levinson, supra note 10, at 93 ("Without these simplifying and externality internalizing assumptions, the efficiency result evaporates."); see also Revesz, supra note 17, at 1212 ("Most importantly, the other prominent market-failure argument for federal environmental regulation is that, in the absence of such regulation, interstate externalities will lead states to underregulate because some of the benefits will accrue to other states.").

153. See Engel, supra note 64, at 285.

154. Hilary Sigman, Letting States Do the Dirty Work: State Responsibility for Federal Environmental Regulation, 56 NAT'L TAX J. 107, 117 (2003).

155. Adler, supra note 9 , at 140.

156. Noah D. Hall, Political Externalities, Federalism, and a Proposal for an Interstate Environmental Impact Assessment Policy, 32 HARV. EnVtL.

L. REV. 49, 50 (2008). 
making . ..."157 Professor Esty notes: "While a few environmental harms (some waste problems, for example) are geographically localized, many forms of pollution (surface water contamination and most air pollutants, for example) spread across the land. Because state boundaries often do not fully encompass airsheds and watersheds, interjurisdictional externalities arise." 158

The empirical literature can be categorized by the type of externality considered. This Article will refer to the first category as resource externalities. This is the case where the actions of one jurisdiction affect the resource quantity or quality available to other jurisdictions. ${ }^{159}$ These situations are discussed in Part II.C.1. The second category is referred to as "pecuniary externalit[ies]" by Wilson. ${ }^{160}$ This refers to situations where the actions of one jurisdiction affect prices in other jurisdictions. These situations are discussed in Part II.C.2. A final category of externalities is denoted by Wilson as "fiscal externalit[ies]." "Th1 This is the case where the policy choices of one jurisdiction have effects on the policy choices of other jurisdictions through strategic policy making. ${ }^{162}$ This will be discussed in Part II.C.3.

\section{Resource Externalities}

The empirical literature on resource externalities focuses on whether jurisdictions fail to consider the effects of their actions on the quality or quantity of a resource available in other jurisdictions. Transboundary pollution is the canonical example. With transboundary pollution, one jurisdiction fails to consider the full environmental consequences of its actions as some of the coststypically in terms of greater air or water pollution - fall outside one's jurisdiction. Another type of spillover may occur when resources are shared across multiple jurisdictions. Common examples of such shared

157. See Dijkstra \& Fredriksson, supra note 22, at 320.

158. Daniel C. Esty, Revitalizing Environmental Federalism, 95 Мich. L. REV. 570, 625 (1996).

159. Often resource externalities are referred to simply as spillovers. See, e.g., Jan K. Brueckner, Strategic Interaction Among Governments: An Overview of Empirical Studies, 26 Int'L Regional SCI. Rev. 175, 176 (2003).

160. See Wilson, supra note 8 , at 272 .

161. Id.

162. The policy choices in one location may impact prices in neighboring locations as well. Thus, pecuniary and fiscal externalities do overlap. However, the Author invokes the distinction that pecuniary externalities occur even absent a behavioral response from neighboring governments, whereas fiscal externalities explicitly require a policy response by neighboring jurisdictions. 
resources are watersheds, fisheries in the ocean, and endangered species that are present in multiple jurisdictions.

Professors Murdoch, Sandler, and Sargent examined emissions of sulphur and nitrogen oxides in twenty-five European countries during the 1980s and early 1990s. ${ }^{163}$ The authors explore the reductions in these types of emissions achieved after the formulation of the 1979 Convention on Long-Range Transboundary Air Pollution (LRTAP). In particular, the authors are motivated by the fact that mandated reductions for sulfur were more likely to be met than for nitrogen oxides $\left(\mathrm{NO}_{\mathrm{x}}\right)$. In an attempt to understand this, the authors investigate the importance of transboundary spillovers in explaining cross-country variation in emissions reductions achieved under LRTAP. Specifically, the authors estimate separate econometric models for the two types of emissions and incorporate two measures of spillovers as independent variables in the model. The first measure captures the fraction of a country's emissions that stay within its own borders. The second measure captures the amount of emissions originating outside of one's own jurisdiction that ends up in one's jurisdiction. ${ }^{164}$

Since sulfur emissions are less likely to spill across jurisdictional boundaries, if these variables are meaningful (in a statistical and economic sense) determinants of emissions, then externalities not only play an important role in determining emissions, but also help explain the disparate trends in sulfur and nitrogen oxide emissions in Europe over this time period. The results point to a very meaningful effect of the second measure of spillovers: as the amount of emissions entering one's jurisdiction from other countries declines, a country's own emissions rise. The authors interpret this finding as indicative of free riding behavior by countries. ${ }^{165}$ However, the first measure is found to have at best a weak statistical relationship with emissions. ${ }^{166}$

Kahn examines the importance of transboundary pollution using data at the county-level from the United States. ${ }^{167}$ Specifically, he assesses the impact of manufacturing activity in one's own county, as

163. James C. Murdoch, Todd Sandler \& Keith Sargent, A Tale of Two Collectives: Sulphur Versus Nitrogen Oxides Emission Reduction in Europe, 64 ECONOMICA 281, 287-92 (1997).

164. Id. at 290-91 (describing the first measure as "OWNSUL" and the second measure as "SPILL").

165. Id. at 294 ("The negative and significant estimate on the SPILL term is entirely consistent with strategic (within-region) free-riding associated with the Nash assumption ....").

166. See $i d$. at 295 (finding the OWNSUL parameter estimates significant only in one specific model).

167. Matthew E. Kahn, The Silver Lining of Rust Belt Manufacturing Decline, 46 J. URB. ECON. 360, 363-65 (1999). 
well as adjacent counties, on ambient concentrations of total suspended particulates (TSP). The data are from 1977, 1982, and 1987, thus spanning a period during which manufacturing activity experienced large declines. However, the spatial and temporal variation in this decline allows Kahn to assess its impact on own and neighboring county air quality.

Kahn's results suggest that manufacturing activity in adjacent counties has meaningful effects on a county's own ambient concentrations. ${ }^{168}$ For example, a full standard deviation increase in a county's own activity in the primary metal industry raises ambient concentrations of TSP by 3.5\%. A standard deviation increase in activity in the primary metals industry in a county's adjacent neighbors raises a county's own ambient concentrations of TSP by $1.1 \%$. A standard deviation increase in activity in the stone, clay, and glass industry in a county's adjacent neighbors raises a county's own ambient concentrations of TSP by $4.1 \%{ }^{169}$ For the other industries Kahn considers, the discrepancy between the effects of a county's own activity and that of its neighbors is smaller.

A series of studies by Sigman investigates pollution in rivers in order to assess the empirical relevance of transboundary spillovers. In the first study, Sigman uses international data on water quality obtained from monitoring stations on rivers administered by the United Nations' Global Environmental Monitoring System Water Quality Monitoring Project (GEMS/Water). ${ }^{170}$ The data span 291 river monitoring stations across forty-nine countries over the period from 1979 to 1996. Sigman measures water quality using biochemical oxygen demand (BOD). The results are consistent with free riding behavior by countries. ${ }^{171}$ Pollution is meaningfully higher at upstream locations (locations before a river flows into another country), as well as in rivers that form the political border between two countries. Interestingly, these effects apply predominantly to non-European Union (EU) countries. ${ }^{172}$ Thus, institutional arrangements within the EU are hypothesized to limit the extent of free riding in terms of river pollution.

168. See id. at 369 .

169. Id.

170. Hilary Sigman, International Spillovers and Water Quality in Rivers: Do Countries Free Ride?, 92 Am. Econ. REv. 1152, 1152-56 (2002).

171. Id. at 1158 ("My empirical analysis provides evidence that international spillovers significantly impair water quality in rivers. . . This evidence of free-riding suggests that cooperation has not evolved between countries sharing rivers.").

172. See $i d$. ("The EU appears to have successfully ameliorated free-riding: one cannot reject that stations upstream of internal EU borders have typical pollution levels."). 
In her next study, Sigman undertakes a similar analysis with U.S. data obtained from the National Stream Quality Accounting Network, administered by the U.S. Geologic Survey. ${ }^{173}$ The data come from 501 monitoring stations and span the period from 1973 to 1995. Sigman uses changes in the "authorization" or "primacy" status of neighboring states under the Clean Water Act ${ }^{174}$ to assess the extent of upstream states to free ride on their downstream neighbors. ${ }^{175}$ Since the statistical procedure only utilizes temporal variation within states arising from changes in authorization status, the results are more likely to capture the causal effect of decentralized control. ${ }^{176}$ Measuring water pollution using the EPA's water quality index based on five major pollutants (dissolved oxygen, fecal coliform, total suspended solids, phosphorous, and nitrogen), the results indicate a four percent reduction in water quality at sites downstream from an authorized state. ${ }^{177}$ In addition, rivers forming the border between states suffer a six percent reduction in water quality if at least one state is authorized. ${ }^{178}$

In a more recent study, Sigman continues to examine pollution levels in rivers at the international level using data from GEMS/Water spanning forty-seven countries over the period from 1979 to $1999 .{ }^{179}$ Two measures of pollution are examined: BOD and fecal coliform. Compared to BOD, fecal coliform is considered to be more of a local pollutant. ${ }^{180}$ In contrast to his earlier studies, here Sigman assesses the impact of decentralization, defined at the country-level, on subnational variation in pollution. ${ }^{181}$ Decentralization is either measured using a binary indicator for a federalist system, or as a continuous measure of the ratio of

173. Hilary Sigman, Transboundary Spillovers and Decentralization of Environmental Policies, 50 J. Envtl. Econ. \& MGmt. 82, 85-91 (2005).

174. 33 U.S.C. $\S \S 1251-1387$ (2012).

175. Id. at $89-90$.

176. See id. at 96 ("By focusing on changes in policy regimes in upstream states, the estimated equations address unobserved geographic heterogeneity that might otherwise make it difficult to isolate such effects.").

177. Id. at 92 ("The coefficient on being downstream from an authorized state is negative and statistically significant, which is consistent with free riding.").

178. Id. at 92-93.

179. Hilary Sigman, Decentralization and Environmental Quality: An International Analysis of Water Pollution Levels and Variation, 90 LAND ECON. 114, 115-16 (2014).

180. Id. at 116 .

181. Id. at 114-15. 
subnational government expenditures to total government expenditures (net of any intergovernmental transfers). ${ }^{182}$ The most convincing results that utilize only temporal variation in the continuous measure of decentralization suggest a harmful effect of decentralization on BOD but not fecal coliform. ${ }^{183}$ Moreover, decentralization is also found to increase the subnational variation in both BOD and fecal coliform, consistent with a tailoring of decentralized policies to local preferences. ${ }^{184}$

Other papers pursue a similar strategy to Sigman and assess the impact of proximity to political boundaries on pollution. Professors Helland and Whitford use reported emissions by U.S. establishments from the Toxic Release Inventory (TRI) spanning between 1987 and 1996 to determine if emissions are higher from establishments located in counties that border neighboring states (either any border or only along the eastern edge). ${ }^{185}$ The results point to significantly higher air and water emissions in establishments located on any border, and effects even larger among establishments located on eastern borders. ${ }^{186}$ Interestingly, the results point to greater spillovers when the authors allow for the possibility that establishments located in border counties may systematically differ in unobserved dimensions from other establishments. ${ }^{187}$

Professors Gray and Shadbegian utilize data on 409 U.S. pulp and paper mills, from thirty-eight states, over the period from 1985 to 1997. ${ }^{188}$ The authors examine plant-level air emissions of particulates (PM10) and sulfur dioxide $\left(\mathrm{SO}_{2}\right)$ and water emissions of $\mathrm{BOD}$ and total suspended solids. The importance of spillovers is measured by

182. Id. at 118 .

183. See $i d$. at 123-24 ("For BOD, the coefficient is statistically significant and positive, with an elasticity of BOD levels to expenditure decentralization of 0.188 . A somewhat higher point estimate emerges when the decentralization measure excludes national defense spending .... In the fecal coliform equations, the coefficients are not statistically significant for either measure of decentralization.").

184. Id. at 126 ("A positive effect of federalism on interjurisdictional variation is consistent with the traditional view of decentralization: when localities have more power, they choose environmental quality levels to correspond to local tastes and costs, resulting in greater heterogeneity than under central authority.").

185. Eric Helland \& Andrew B. Whitford, Pollution Incidence and Political Jurisdiction: Evidence from the TRI, 46 J. EnvTL. ECON. \& MGMT. 403, 407-11 (2003).

186. See id. at $413-22$.

187. Id. at $411-22$.

188. Wayne B. Gray \& Ronald J. Shadbegian, "Optimal" Pollution Abatement-Whose Benefits Matter, and How Much?, 47 J. EnVTL. ECON. \& MGMT. 510, 516-21 (2004). 
assessing the sensitivity of a plant's emissions to the distance to the nearest state or Canadian border, as well as by the marginal benefits to reductions in air and water emissions enjoyed by neighboring jurisdictions. ${ }^{189}$ For plants located within fifty miles of the Canadian border, only BOD emissions are higher than other plants further from the Canadian border; $\mathrm{SO}_{2}$ emissions are lower (attributable to the focus on acid rain near the U.S.-Canadian border). ${ }^{190}$ The results also suggest that plants reduce their emissions by less when the marginal benefits from such reductions are enjoyed by neighboring jurisdictions. For example, the authors find that out-of-state benefits to a reduction in $\mathrm{SO}_{2}$ emissions have only one-third the impact of in-state benefits. ${ }^{191}$

Professors Lipscomb and Mobarak assess pollution in rivers at upstream and downstream locations in Brazil. ${ }^{192}$ The authors analyze quarterly data on BOD levels from several hundred monitoring stations during the timeframe from 1990 to 2007. The importance of spillovers on pollution levels are investigated by measuring the distance of each station from its nearest upstream and downstream border. While generally such distances may be endogenous, Brazil frequently redraws its jurisdictional boundaries allowing the authors to exploit only the temporal variation in the distance of a given station to its nearest borders. ${ }^{193}$ Lipscomb and Mobarak find meaningful evidence that spillovers matter. As the distance to the nearest downstream border falls from ten to nine kilometers, say, pollution increases by $1.3 \%$; pollution rises by $1.9 \%$ as distance falls from one kilometer to zero (zero represents the point at the actual border). ${ }^{194}$ Thus, BOD levels rise at an increasing rate as the river approaches its downstream border. In further analysis, the authors examine pairs of station monitors and find that BOD levels at the

189. Id. at $516-21$.

190. Id. at 528 ("The results for plants near the Canadian border suggest different impacts for different pollutants. On the water pollution side we observe more BOD pollution and fewer inspections. On the air pollution side we observe less $\mathrm{SO}_{2}$ pollution and more enforcement actions. This focus on $\mathrm{SO}_{2}$ emissions is consistent with the substantial political attention paid to acid rain caused by $\mathrm{SO}_{2}$ emissions from US plants in the AQA treaty.").

191. Id. at 530 .

192. Molly Lipscomb \& Ahmed Mushfiq Mobarak, Decentralization and Pollution Spillovers: Evidence from the Re-drawing of County Borders in Brazil (Feb. 20, 2013) (unpublished manuscript), available at http://faculty.som.yale.edu/mushfiqmobarak/papers/decentralization. pdf.

193. Id. at $18-20$.

194. Id. at 22 ("Ten kilometers from the border, pollution increases at a rate of $1.3 \%$ per kilometer, whereas 1 kilometer from the border it increases at a rate of $1.9 \% . ")$. 
downstream monitor, relative to BOD levels at the upstream monitor, are $3.1 \%$ higher per jurisdictional boundary that the river crosses between the two stations. ${ }^{195}$

In more recent work, Hatfield and Kosec exploit the variation in the number of counties spanned by U.S. metropolitan areas to determine if areas divided across more counties experience greater pollution. ${ }^{196}$ Because division into multiple jurisdictions may not be random, the authors exploit jurisdictional boundaries caused by the presence of streams in order to isolate the causal effect of the number of jurisdictions on pollution. ${ }^{197}$ Pollution is measured using the average of the EPA's Air Quality Index over the years between 1999 and 2002, as well as the ambient concentrations of several individual pollutants. ${ }^{198}$ Finally, the authors also examine the effect of increasing the number of jurisdictions within a metropolitan area on drinking water quality using data from the EPA's Safe Drinking Water Information System database. Since drinking water is a local good, the authors did not expect to find any effect of jurisdictional boundaries on this outcome. ${ }^{199}$ The results indicate a sizeable effect of increasing the number of counties within an area on air pollution. ${ }^{200}$ For example, changing a metropolitan area from being entirely contained in one county to split among two counties worsened air quality by half a standard deviation and added an additional thirteen days per year where the air is considered unhealthy. ${ }^{201}$ Moreover, Hatfield and Kosec find that a similar increase from one to two counties within a metropolitan area increases the concentrations of carcinogenic pollutants by anywhere from nineteen percent to $250 \%$, depending on the pollutant. ${ }^{202}$ However, the authors found no effect on drinking water quality, consistent with their results being driven by interjurisdictional externalities. ${ }^{203}$

195. Id. at 25 ("For each additional border crossed, pollution increases by $3.1 \% . ")$

196. John William Hatfield \& Katrina Kosec, Local Environmental Quality and Inter-Jurisdictional Spillovers 2, 10-16 (Apr. 17, 2013) (unpublished manuscript), available at http://works.bepress.com/katrina_kosec/19/.

197. Id. at $8-10$.

198. Id. at 11 .

199. See $i d$. at 3 ("As a placebo analysis, we examine the effects of having more jurisdictions on public drinking water quality. This is a local, environmental, publicly-provided good without significant spillovers.").

200. Id. at 20 .

201. $I d$. at 18 .

202. Id. at 20 .

203. Id. at 22 . 
Professors Kahn, Li, and Zhao assess river pollution in China, taking advantage of a unique natural experiment. ${ }^{204}$ Using data from 2004 to 2010, the authors assess relative pollution levels at internal versus border locations. ${ }^{205}$ Beginning in 2005, the central government began monitoring local compliance with environmental targets related to the chemical oxygen demand (COD) of rivers. Compliance became a criterion upon which the political promotion of local officials is based. Prior to 2005, local officials had little incentive to reduce river pollution near jurisdictional boundaries. After 2005, this is no longer the case for officials seeking promotion. ${ }^{206}$ However, other pollutants besides COD are not a part of the promotion criteria. Using pollution data from 499 river monitoring stations located in China's seven major rivers, the authors find that the 2005 change reduced COD levels. Moreover, the decline was greater at border locations, consistent with significant transboundary pollution prior to $2005 .{ }^{207}$ Finally, the authors find no impact of the promotion criteria on other measures of pollution. ${ }^{208}$

Other studies pursue very different strategies for assessing the importance of interjurisdictional externalities. Banzhaf and Chupp present a detailed simulation model of the U.S. electricity sector, incorporating $\mathrm{NO}_{\mathrm{x}}$ and $\mathrm{SO}_{2}$ emissions. ${ }^{209}$ They then compare the level of welfare achieved under a first-best policy where each state fully internalizes all transboundary pollution damages, a second-best uniform policy across all states, and the decentralized case where each states acts only in its best interest. The results indicate that social welfare is only $0.2 \%$ lower under the second-best uniform policy

204. Matthew E. Kahn, Pei Li \& Daxuan Zhao, Pollution Control Effort at China's River Borders: When Does Free Riding Cease? (Nat'l Bureau of Econ. Research, Working Paper No. 19620, 2013), available at http://www.nber.org/papers/w19620.

205. Id. at $11-14$.

206. See id. at 3 ("In 2005, the central government changed the rules of the game and provided local officials with strong incentives to reduce specific indicators of water pollution along rivers that flow within. For local officials, who sought to be promoted within the Chinese political promotion system, compliance with these new environmental targets motivated them to cease free riding at boundaries.").

207. Id.

208. See $i d$. at 19 ("We find evidence consistent with the hypothesis that local governors have responded to the new promotion rules by taking more effort to reduce water pollution at political boundaries. Our study also points out a fault of the current system. Local governors focus on the environmental measures set by central government rather than a broader set of water criteria that might be more relevant for public health ...." (citation omitted)).

209. Banzhaf \& Chupp, supra note 31 , at $454-57$. 
compared to the first-best policy. ${ }^{210}$ However, the decentralized case with self-interested states results in a $31.5 \%$ reduction in social welfare. ${ }^{211}$ This discrepancy does not arise due to a lack of preference heterogeneity across states. Rather, the welfare cost of ignoring such heterogeneity under the second-best uniform policy is swamped by the welfare cost of failing to internalize the pollution externalities. ${ }^{212}$ Evidence of the magnitude of the externality is further provided by Chupp in separate work. He illustrates for two states, Arizona and North Carolina, that the in-state marginal benefit per ton of $\mathrm{SO}_{2}$ reduction is only about one-fourth the marginal benefit to the nation as a whole. ${ }^{213}$ Banzhaf and Chupp conclude that "inter-jurisdictional spillovers appear to be a bigger problem in this application than heterogeneous benefits." ${ }^{214}$

Lastly, Perino and Talavera assess the determinants of state sulfur emissions rate standards prior to the Acid Rain Program in 1995. ${ }^{215}$ In particular, the authors are interested in the relative importance of the internal costs and benefits of reduced emissions versus the external benefits on the state emissions standard. The state sulfur standard is measured by pounds of $\mathrm{SO}_{2}$ per million British thermal units (MMBtu). The marginal cost of a more stringent standard is proxied by the transportation costs incurred to import low-sulfur coal from Wyoming. Finally, internal and external benefits to emissions reductions are measured by the state's own acidity of rainwater and the average acidity of rainwater in northeastern states (for states located in the Midwest). The results indicate that marginal abatement costs and internal and external benefits matter in a statistical sense. However, the effect of a state's own acidity is more

210. Id. at 458 ("More surprising is that the second-best uniform policy achieves benefits of $\$ 59.6$ billion, a loss of only $0.2 \%$ of the first-best benefits!").

211. See id. ("More to the point, the states on their own are estimated to achieve national net benefits of $\$ 40.9$ billion, simply acting out of their own self-interest. This is a loss of $31.5 \%$ of the total potential benefits, which is substantial ....").

212. See id. at 462 .

213. B. Andrew Chupp, Environmental Constituent Interest, Green Electricity Policies, and Legislative Voting, 62 J. EnvtL. Econ. \& MGmT. 254, 256 (2011).

214. Banzhaf \& Chupp, supra note 31 , at 450.

215. Grischa Perino \& Olena Talavera, The Benefits of Spatially Differentiated Regulation: The Response to Acid Rain by U.S. States Prior to the Acid Rain Program, 96 Am. J. Agric. Econ. 108, 110-16 (2014). 
than twenty times larger than the effect of the acidity of rainwater in the northeast. ${ }^{216}$

Rather than focusing on pollution, several empirical studies test for the presence of spillover effects on enforcement of environmental regulations. Gray and Shadbegian, in the study of 409 paper and pulp establishments in the United States discussed earlier in this Part, ${ }^{217}$ also examine determinants of the number of air and water pollution inspections and enforcement actions. ${ }^{218}$ The results are generally weaker than their reported results pertaining to emissions. ${ }^{219}$ Nonetheless, the authors find some evidence that air pollution enforcement actions are higher against establishments near the Canadian border (consistent with the lower $\mathrm{SO}_{2}$ emissions found in the analysis), but fewer water pollution inspections take place against such plants. ${ }^{220}$

In a subsequent study, Gray and Shadbegian use emissions data from 1997 on 521 U.S. manufacturing plants located within fifty miles of the center of three cities located near state borders (St. Louis, Cincinnati, and Charlotte). ${ }^{221}$ The primary purpose of the study is to examine the effect of prior environmental enforcement - against either oneself (so-called specific deterrence) or against other plants within ten miles (so-called general deterrence) - on subsequent plant-level emissions. However, a very interesting finding emerges: inspections of other plants within ten miles reduce a plant's own emissions of air toxics (obtained from the TRI) as long as those other plants are located within the same state. Inspections of other nearby plants, which are located in another jurisdiction, fail to produce any general deterrent effect.222 In this case, the lack of a spillover across

216. See id. at 117 ("The severity of the acid rain problem in the Northeast affected regulation in the Midwest, which is in line with the main interstate externality for acid rain in the United States. The positive sign of the coefficient confirms that states at least partially internalized this externality (i.e., lower $\mathrm{pH}$ level in the Northeast tightened emission standards in the Midwest). However, the effect is by more than an order of magnitude weaker than the effect of a state's own exposure to acid rain.").

217. See supra notes 188-191 and accompanying text.

218. See Gray \& Shadbegian, supra note 188, at 518.

219. See $i d$. at 532 ("The results for the regulatory activity equations are generally less consistent with our hypotheses than those for the emissions equations.").

220. See id. at $525-28$.

221. Wayne B. Gray \& Ronald J. Shadbegian, The Environmental Performance of Polluting Plants: A Spatial Analysis, 47 J. Regional SCI. 63, 69-71 (2007).

222. See $i d$. at 80 ("Turning to the importance of jurisdictional boundaries for regulatory analyses, the negative sign on INSPNBOUT shows that 
jurisdictional boundaries reduces welfare. If enforcement were instead the responsibility of a higher level of government, each inspection would result in a greater reduction in emissions through general deterrence.

More recently, Professors Konisky and Woods assessed the impact of proximity to jurisdictional borders on plant-level enforcement actions. ${ }^{223}$ Data on state-led enforcement actions - inspections, total punitive actions, and formal punitive actions - under the CAA between 1990 and 2000 are aggregated to the county-level and used to determine if counties on state or international borders are subject to less enforcement. The results indicate approximate twenty-five percent and fifty percent reductions in the count of inspections in counties bordering Canada and Mexico, respectively, but no meaningful effect in counties bordering other states. ${ }^{24}$

In a follow-up study, Konisky and Woods utilize data from the EPA's Integrated Database for Enforcement Analysis to assess the determinants of enforcement actions - compliance monitoring and punitive actions - against roughly 6400 facilities regulated under the Clean Water Act from 1995 to 2005. ${ }^{225}$ The importance of spillovers is assessed by examining whether a facility that discharges its effluent into an interstate river or a multi-state watershed is the subject of less enforcement action. The authors also assess, among other things, the impact of distance to the nearest downstream state from the point where a facility's effluent likely enters a river. Konisky and Woods fail to find any evidence consistent with fewer enforcement actions being taken against firms more likely to be responsible for transboundary

inspections on plants in neighboring states are not as effective at improving compliance. In fact, the negative coefficient on INSPNBOUT is larger in magnitude than the positive one on INSPNB, so increased inspections at plants in neighboring states would be predicted to reduce a plant's compliance, although this effect is not statistically significant.").

223. David M. Konisky \& Neal D. Woods, Exporting Air Pollution? Regulatory Enforcement and Environmental Free Riding in the United States, 63 PoL. RES. Q. 771, 774-76 (2010).

224. See id. at 779 ("[T]his represents about 25 percent and 50 percent fewer inspections for counties bordering Canada and Mexico, respectively."); see also id. at 778 ("[W]e do not find evidence that states attempt to export their pollution across interstate borders or to oceans or the Great Lakes through lax regulatory enforcement of facilities in border counties.").

225. David M. Konisky \& Neal D. Woods, Environmental Free Riding in State Water Pollution Enforcement, 12 St. PoL. \& PoL'y Q. 227, 23339 (2012). 
pollution. ${ }^{226}$ Thus, the empirical studies to date assessing the spatial and temporal variation in enforcement behavior indicate less free riding than those assessing pollution directly. Understanding the source(s) of this difference is necessary.

The final set of papers examining the empirical relevance of resource externalities assess the impact of decentralized decision making on the exploitation of shared resources. Professor McWhinnie analyzes data on the global exploitation status of various fish stock according to the Food and Agriculture Organization (FAO) in 1994 and 2002. ${ }^{227}$ Specifically, the FAO designates each fish stock in fifteen regions as underexploited, moderately exploited, fully exploited, overexploited, depleted, or recovering. The author then examines whether the number of countries that report catching a given fish in a given region and year help predict the exploitation status of the fish stock. McWhinnie finds that exploitation is increasing in the number of countries accessing the fish stock. ${ }^{228}$ For example, if the fish stock is shared by two countries rather than one, "it is $9 \%$ more likely to be overfished and 19\% more likely to be depleted." 229 If the fish stock is shared by five countries rather than one, "it is $36 \%$ more likely to be overfished and $82 \%$ more likely to be depleted." 230

The analysis by Burgess, Hansen, Olken, Potapov, and Sieber is similar to that by Hatfield and Kosec in that it explores the impact of dividing a given geographic area into a larger number of jurisdictions on the environment. ${ }^{231}$ However, Burgess, Hansen, Olken, Potapov, and Sieber examine the impact of the number of administrative jurisdictions in a given Indonesian province on the rate of deforestation between 2001 and 2008. ${ }^{232}$ The results indicate nearly a four percent increase in the annual rate of deforestation if an

226. See id. at 240 ("Looking across the models for inspections and punitive actions, the absence of any statistically discernable border effects is striking.").

227. Stephanie F. McWhinnie, The Tragedy of the Commons in International Fisheries: An Empirical Examination, 57 J. Envtl. Econ. \& MGMT. 321, 323-26 (2009).

228. See id. at 327 ("The number of countries is statistically significant at the $5 \%$ level and works in the anticipated direction; the more countries a fish stock is shared between, the more likely it is to be overexploited or depleted.").

229. Id.

230. Id. at $327-28$.

231. Robin Burgess, Matthew Hansen, Benjamin A. Olken, Peter Potapov \& Stefanie Sieber, The Political Economy of Deforestation in the Tropics, 127 Q.J. ECON. 1707, 1714-30 (2012).

232. Id. at 1715 . 
additional district is formed within a province. ${ }^{233}$ The authors conclude that their analysis provides a "counterexample to those who argue that decentralization of control over natural resources in weakly governed tropical environments should enhance their conservation." ${ }^{234}$

\section{Pecuniary Externalities}

The second category of externalities includes pecuniary externalities. This refers to situations where jurisdictions ignore the ramifications of their actions on prices in other areas. However, empirical evidence regarding pecuniary externalities is rare. One source of pecuniary externalities, in theory, is referred to as tax exporting and dates back at least to Gordon. ${ }^{235}$ This refers to localities levying excessive taxes in situations where at least a portion of the tax bill is paid by nonresidents (for example, hospitality taxes). In the context of environmental regulation, environment importing (as opposed to tax exporting) can arise in either of two ways. First, a jurisdiction may enact excessive regulation if producers of polluting goods are located in other jurisdictions as long as the costs cannot be passed fully onto consumers located in the jurisdiction. Second, a jurisdiction where the pollution-generating production of goods occurs may enact excessive regulation if producers are able to pass at least a portion of the regulatory costs onto consumers in other jurisdictions.

Anecdotal evidence of the first type of behavior is found in a paper by Elliott, Ackerman, and Millian. The authors provide a historical account of the development of the Motor Vehicle Air Pollution Control Act of $1965 .{ }^{236}$ This was the first statute to provide the federal government with regulatory power over air pollution. The

233. See $i d$. at 1734 (reporting that "the annual rate of deforestation increases by $3.85 \%$ if an additional district is formed within a province").

234. Id. at 1751 .

235. See Gordon, supra note 2, at 580 (noting that decentralization can lead to inefficient outcomes due to externalities, one of which is the imposition of taxes on nonresidents). Another type of pecuniary externality is what Hall refers to as psychological externalities. This is the case where resources within one jurisdiction are valued by residents of another jurisdiction. Unique natural elements, such as Old Faithful, are primary examples. Destruction of such resources by the jurisdiction in which the resource is located can be thought of as imposing a pecuniary externality on residents of other jurisdictions as the price of utilizing (or visiting) the resource becomes infinite. See Hall, supra note 156, at 57; see also Esty, supra note 158, at 594-97 (discussing the psychological externalities that people outside of the "regulating jurisdiction" may suffer and deeming it a "choice of public" issue).

236. Pub. L. No. 89-272, § 202(a), 79 Stat. 992 (codified as amended in 42 U.S.C. $\S 7401$ (2012)). For the authors' historical account of this Act, see Elliott, Ackerman \& Millian, supra note 14, at 330-31. 
legislation was supported by the automobile industry, not because it favored reducing pollution, but rather because several states had adopted or were in the process of adopting stringent regulations regarding automobile emissions. ${ }^{237}$ Since the production of automobiles is geographically concentrated in a few areas, the costs of these regulations were born predominantly by nonresidents. ${ }^{238}$ Thus, prior to the passage of the federal statute, states were importing a cleaner environment at the expense of nonresidents.

This history is repeating itself as states are once again pursuing regulations on automobile emissions for the purposes of achieving greenhouse gas (GHG) reductions. Professor Rabe writes:

Still another state economic development incentive may relate to policy opportunities that, in effect, will shift most of the compliance costs to other jurisdictions. California's alliance with other states pursuing vehicle emissions reductions can be considered through this lens, as none of these jurisdictions host large vehicle manufacturing sectors that might be jeopardized through aggressive transition toward lower-emission vehicles. ... In turn, some of the proponent states were actively developing next-generation vehicle technology within their boundaries that might receive a boost through a regulatory burden imposed on conventional vehicles generally manufactured elsewhere. ${ }^{239}$

Professors McAusland and Millimet provide indirect evidence of environmental importing by subnational jurisdictions. ${ }^{240}$ The authors use data on trade among U.S. states, among Canadian provinces, and between U.S. states and Canadian provinces from 1997 and 2002 to explore the effect of intranational and international trade on emissions reported in the TRI for the United States and the Canadian National Pollutant Release Inventory (NPRI) ${ }^{241}$ McAusland and Millimet show theoretically that environmental regulation should become more

237. See Elliott, Ackerman, \& Millian, supra note 14, at 330 (providing that California had adopted new regulations, and that Pennsylvania and New York were considering doing so).

238. See id. ("The automobile industry is in a very different strategic position, however, because it is geographically concentrated and its product, not its factories, is the main source of its pollution.").

239. Barry Rabe, Contested Federalism and American Climate Policy, 41 Publius: J. Federalism 494, 502 (2011).

240. Carol McAusland \& Daniel L. Millimet, Do National Borders Matter? Intranational Trade, International Trade, and the Environment, $65 \mathrm{~J}$. Envtl. Econ. \& Mgmt. 411 (2013).

241. Id. at 423-26. 
stringent as trade increases because the resulting higher prices on locally produced goods are passed on to consumers in other jurisdictions. ${ }^{242}$ Moreover, because environmental regulation in the United States and Canada is a mix of centralized and decentralized control, the effect on regulatory stringency should be stronger when higher prices are passed onto foreign consumers. ${ }^{243}$ Thus, the theoretical model predicts that international trade should result in greater reductions in emissions than intranational trade. The authors' findings are consistent with the idea of environment importing. ${ }^{244}$

Professors Chakravorty, Nauges, and Thomas provide additional evidence of price spillovers due to decentralized environmental policy making. ${ }^{245}$ The authors examine the effect of clean fuel programs permitted under the CAA. Under the Act, states are permitted to implement their own clean fuel program for gasoline in an effort to reduce air pollution. The result is a proliferation of clean fuel blends; at least fifteen different fuel specifications are in use, which-when combined with three different octane levels - yield more than fortyfive unique blends. ${ }^{246}$ The authors examine the temporal and spatial variation in wholesale gasoline prices across states between 1995 and 2002 due to the required usage of so-called "boutique fuels." 247

242. See id. at 412 ("In regions that import actively, the majority of goods in a household's consumption basket is produced abroad. Since the price of these imported goods depends on foreign supply conditions, overall consumption will be relatively unaffected by changes in local environmental regulation. Moreover, in actively exporting regions, much of consumers' share of the regulatory burden falls largely on foreigners. In effect, trade partly decouples consumer welfare from the costs of local regulation, leading to stricter environmental regulation in states that trade intensely.").

243. See id. ("[T]he extent to which trade decouples consumption from regulation is substantially weaker for intranational trade, suggesting that the ceteris paribus effect of intranational trade on the environment will be smaller than of international trade.")

244. Id. at 434 ("Our results indicate that international trade generates statistically, and economically, significant benefits for the environment. On the other hand, intranational trade has a statistically and economically significant, adverse effect on the environment.").

245. Ujjayant Chakravorty, Céline Nauges \& Alban Thomas, Clean Air Regulation and Heterogeneity in US Gasoline Prices, 55 J. EnVTL. Econ. \& MGMt. 106 (2008).

246. Id. at 106-07 ("At least 15 different types of fuel specifications are currently in use. Combined with the three octane grades of gasoline available at pumps - regular, mid-grade and premium - over 45 different blends are used nationwide. A new ozone rule proposed by the EPA is expected to add another 24 new blends into the mix in the near future. These fuels are often called 'boutique fuels."').

247. See id. at 119-20. 
Specifically, the authors estimate not only the direct effect on prices due to requirement of a cleaner gasoline blend, but also the indirect effect of market segmentation. ${ }^{248}$ In other words, as the type of fuel required in one state becomes more distinct from the type of fuel required in neighboring states, prices should rise due to greater demands placed on refineries. ${ }^{249}$ The results confirm not only that the market segmentation effect is important, but that it is nearly as important as the direct cost effect. ${ }^{250}$ If a state changes from no gasoline regulation to requiring clean fuel (of the type considered in the analysis) for the entire state, wholesale gasoline prices are expected to rise by sixteen percent. ${ }^{251}$ On the other hand, if a state transitions from requiring the same fuel as its neighbors to a completely unique blend not used by any of its neighbors, wholesale gasoline prices are expected to rise by at least fourteen percent. ${ }^{252}$ To the extent that states do not take into account the higher prices occurring elsewhere when a state decides to require a unique fuel blend and thus increases its "regulatory distance" from its neighbors, decentralization in this case will lead to excessive heterogeneity in fuel blends. ${ }^{253}$

248. Id. at 113 .

249. This is related to the general argument concerning uniform product standards as a rationale for centralization. See, e.g., Silvana Dalmazzone, Decentralization and the Environment, in HANDBOOK OF Fiscal Federalism 459, 466 (Ehtisham Ahmad \& Giorgio Brosio eds., 2006) ("[L]ocally differentiated environmental regulations in some cases may translate themselves in differences in product standards and in a consequent fragmentation of the market ...."); Oates, supra note 4, at 21 ("A second role for central government can arise in cases where standardization in pollution-control activities across jurisdictions involves large cost savings. The most obvious case here involves the determination of emissions standards for motor vehicles. It would obviously be very costly for auto manufacturers to have to produce 50 different variants of cars to satisfy the particular emissions standards of each state."); Adler, supra note 9, at 148 ("[C]onsumers may benefit from national product standards, insofar as lower compliance costs result in lower consumer prices."); Esty, supra note 158, at 618 ("In some circumstances uniform standards may be welfare enhancing. When environmental regulations are focused on products (as opposed to production processes), harmonization across jurisdictions can create important economies of scale for the businesses selling these products and for the states administering environmental controls." (citation omitted)).

250. See Chakravorty, Nauges \& Thomas, supra note 245, at 117 ("This segmentation effect is found to be highly significant for both the RFG and OXY markets.").

251. Id.

252. $I d$.

253. Id. at 118 . 
In sum, the empirical evidence suggests that localities ignore interjurisdictional externalities related to transboundary pollution and resource exploitation and these externalities entail significant welfare loss. The evidence is less convincing when enforcement of environmental regulations is examined. However, the inability of the general deterrent effect of local enforcement to cross political boundaries is noteworthy. Finally, some evidence exists suggesting that localities ignore the impact of their policies on the prices paid and the profits earned by nonresidents. More empirical evidence on the prevalence of tax exporting (or environment importing) is needed.

\section{Fiscal Externalities}

The final category of externalities is referred to as fiscal externalities - a holdover from the fiscal federalism literature. However, Wilson defines fiscal externalities more broadly as instances where the policy choices of one jurisdiction have effects on the policy choices of other jurisdictions through strategic policy making. ${ }^{254}$ Thus, the presence of such externalities violates the assumptions required for decentralized policy making to be efficient just as in the case of resource or pecuniary externalities. Konisky writes: "The economic efficiency results emerge from local regulators making decisions solely based on intrajurisdictional, not interjurisdictional, factors." ${ }^{255}$

Brueckner provides an excellent introduction to the notion of strategic interactions between governments. ${ }^{256}$ Such interactions may arise for three reasons. First, jurisdictions are, or are perceived to be, in competition for mobile resources. Second, policies in one jurisdiction lead to spillovers (for example, transboundary pollution) that alter the payoffs to different policies in other jurisdictions. Third, voters may judge the performance of policy makers through interjurisdictional comparisons, thereby creating a situation referred to as yardstick competition. ${ }^{257}$

Before discussing the existing empirical evidence on strategic interaction, three comments are warranted. First, all three sources of strategic interaction are empirically equivalent in that each predicts that the policy choices of one jurisdiction depend on the choices of other jurisdictions. ${ }^{258}$ Thus, without more information, differentiating among the underlying causes is not possible.

254. See Wilson, supra note 8 , at 272 .

255. David M. Konisky, Assessing U.S. State Susceptibility to Environmental Regulatory Competition, 9 ST. PoL. \& POL'Y Q. 404, 406 (2009).

256. See Brueckner, supra note 159.

257. See id. at $176-81$.

258. See $i d$. at 182 ("[B]oth the spillover and resource-flow models of strategic interaction generate reaction functions, which relate each 
Second, whether strategic interactions occur depends upon policy maker perceptions. ${ }^{259}$ For example, if resources - people or capitalare immobile, but policy makers mistakenly believe that resources are mobile, then strategic interactions may occur. However, if resources are mobile but policy makers naively assume they are not, then strategic interactions may be absent. Thus, the question of whether governments act strategically is fundamentally distinct from the question of resource mobility (and, similarly, the presence of actual spillovers or yardstick competition). ${ }^{260}$

Third, strategic interaction is not synonymous with a race-to-thebottom. In theory, strategic interaction may lead to decentralized policies that are inefficiently lax or inefficiently stringent (referred to as a race-to-the-top). ${ }^{261}$ That said, one of the most common justifications given for centralization of environmental policy making is fear over a race-to-the-bottom. Engel states: "Of the numerous theoretical rationales used to justify federal environmental regulation, perhaps the most broadly compelling is the argument that without such regulation, states would engage in a welfare-reducing 'race-tothe-bottom' in environmental standard-setting." ${ }^{262}$ Professors List and Gerking argue that "in a second-best world in which initial distortions are present, locally determined environmental regulations are likely to be suboptimal when jurisdictions compete with each other to attract

jurisdiction's chosen [decision variable] to its own characteristics and to the choices of other jurisdictions.").

259. Daniel L. Millimet \& Vasudha Rangaprasad, Strategic Competition Amongst Public Schools, 37 Regional Sci. \& Urb. ECon. 199, 204 (2007) ("[W]hat is relevant is the perception among the administrative units ....").

260. See Esty, supra note 158, at 573 ("While economists downplay fears of a race to the bottom, politicians cannot escape the image, in Ross Perot's memorable words, of a 'giant sucking sound' as U.S. factories and jobs go down the drain to jurisdictions with more lax environmental standards and lower compliance costs." (quoting Ross PEROT, SAVE Your Job, Save Our Country 41 (1993))); see also Oates, supra note 4, at 16 ("In fact, irrespective of the actual facts on the location decisions in polluting industries, whether or not officials use environmental regulations for competitive purposes depends largely on perceptions. If policymakers think that these regulations matter, then they may well craft environmental legislation in the light of their objectives for economic development. Perceptions matter here.").

261. See Brueckner, supra note 159, at 177 ("Theory is silent regarding the sign of the reaction function's slope."); Engel, supra note 64, at 346 (referring to the implication of strategic interaction as simply a "race to inefficiency" and highlighting the irrelevance of whether the race is actually to the top or the bottom if one simply cares about efficiency).

262. Engel, supra note 64, at 274. 
capital." ${ }^{263}$ Konisky states: "A principal objection to decentralization of environmental regulatory authority to subnational governments in federal systems is the concern that it will result in a 'race to the bottom."'264

The empirical literature on strategic interaction can be parsed into two strands. The first examines the impact of decentralization on pollution levels directly, using temporal variation in the level of centralization. The second directly estimates so-called spatial reaction functions to determine if policy choices in one jurisdiction are affected by the choices of other jurisdiction. A subset of this group pushes the analysis further in an attempt to determine if strategic interaction, to the extent it exists, is consistent with a race to the bottom or a race to the top.

Within the first strand, several empirical papers have used President Ronald Reagan's swift devolution of many aspects of environmental policy - referred to as new federalism - as a natural experiment from which to form indirect inferences concerning the race-to-the-bottom hypothesis. ${ }^{265}$ List and Gerking utilize state-level data on pollution abatement expenditures by manufacturing industries obtained from the Annual Survey of Manufactures over the period from 1973 to 1990, as well as state-level emissions data on $\mathrm{SO}_{2}$ and $\mathrm{NO}_{\mathrm{x}}$ from the EPA over the period from 1929 to $1994 . .^{266}$ The objective is to determine if there were shifts in the levels of these variables in the mid-1980s after controlling for other potential determinants of abatement and emissions. In terms of abatement expenditures, the authors find mixed evidence as expenditures were found to increase in some sectors and decrease in others. ${ }^{267}$ There is no evidence that emissions worsened after the early 1980s and some evidence that $\mathrm{SO}_{2}$ emissions declined. ${ }^{268}$

263. John A. List \& Shelby Gerking, Regulatory Federalism and Environmental Protection in the United States, 40 J. Regional ScI. 453, 453 (2000).

264. David M. Konisky, Regulatory Competition and Environmental Enforcement: Is There a Race to the Bottom?, 51 Am. J. Pol. ScI. 853,853 (2007).

265. See, e.g., Daniel L. Millimet, Assessing the Empirical Impact of Environmental Federalism, 43 J. ReGional SCI. 711, 714-16 (2003) (providing a detailed description of the changes implemented under President Reagan).

266. See List \& Gerking, supra note 263, at 456-59.

267. See id. at 462-63 (indicating that abatement tended to increase for the chemical and allieds and food and kindred product sectors).

268. See id. at 467 ("Results for sulfur dioxides indicate that emissions net of real per capita income growth tended to decline after 1982."). 
Two follow-up studies utilize the same data as by List and Gerking but apply alternative econometric techniques. In a different study, Millimet and List compare the entire distribution of emissions and abatement expenditures across states before and after President Reagan's new federalism policies. ${ }^{269}$ This allows the authors to investigate the possibility of finer changes in these variables that may have been overlooked in List and Gerking. Millimet and List find stronger evidence of a reduction in emissions and increase in abatement efforts in the 1980s. ${ }^{270}$ In another study, Millimet allows for the determinants of emissions and abatement to have differential effects over time and then tests for any residual effect of President Reagan's new federalism policies. ${ }^{271} \mathrm{He}$ finds little meaningful association between the decentralization of the 1980s and emissions, but does find a positive association with abatement expenditures. ${ }^{272}$

Fomby and Lin perform a similar analysis. ${ }^{273}$ The authors use time series data on aggregate emissions of $\mathrm{SO}_{2}, \mathrm{NO}_{\mathrm{x}}$, and volatile organic compounds (VOCs) in the United States from 1940 to 1998 to test for a structural break where the possible date of any break is unknown. ${ }^{274}$ The results point to structural breaks for all three pollutants (where the breaks represent the start of downward trends). However, the breaks occur in the late 1960s or 1970s, corresponding to the beginning of the environmental movement in the United States. ${ }^{275}$ There is no meaningful evidence of further breaks during the Reagan era. ${ }^{276}$

269. Daniel L. Millimet \& John A. List, A Natural Experiment on the "Race to the Bottom" Hypothesis: Testing for Stochastic Dominance in Temporal Pollution Trends, 65 Oxford Bull. Econ. \& Stat. 395, 398-403 (2003).

270. See id. at 418 ("Our findings strongly reject the notion that a race to the bottom materialized for these three indicators when Reagan greatly expanded the discretionary power of states in the determination of environmental policy in the US during the 1980s.").

271. See Millimet, supra note 265, at 716-19.

272. See $i d$. at 731 ("The results are striking, suggesting that environmental decentralization did instigate a race to the top in pollution control expenditures by the mid-1980s when the financial position of states improved. Nitrogen oxide and sulfur dioxide emissions results are less conclusive, but suggest that environmental decentralization may have halted the deterioration of air quality that began in the 1970s.").

273. Thomas B. Fomby \& Limin Lin, A Change Point Analysis of the Impact of "Environmental Federalism" on Aggregate Air Quality in the United States: 1940-98, 44 ECON. INQUiRY 109, 113-14 (2006).

274. Id. at $112-14$.

275. See $i d$. at 118 ("Although it is impossible to attribute the occurrence of the change points of these series to any one federal legislative act, one might surmise, given the proximity of the change points, that the Air Quality Act of 1967, the Clean Air Act of 1970, and the 1977 
Related to Fomby and Lin is the analysis by Professors Bulte, List, and Strazicich. ${ }^{277}$ Here, the authors examine a related, but distinct, question. In particular, the authors are interested in whether emissions levels are converging across states over time and whether such convergence accelerated after the 1970s. Thus, the authors are not concerned with the Reagan era per se, but rather the general era of relative federal involvement in environmental policy making beginning in 1970. Data on $\mathrm{SO}_{2}$ and $\mathrm{NO}_{\mathrm{x}}$ from the EPA between 1929 and 1999 are examined. ${ }^{278}$ The results indicate that emissions were converging across some states prior to 1970 and across many more states after $1970 .{ }^{279}$ While it is not obvious if this analysis offers much guidance regarding the realization of a race to the bottom, the results are consistent with federal involvement since 1970s leading to more homogeneity across states.

Two final studies address related questions. Potoski assesses whether U.S. states have chosen to adopt air quality standards in excess of that required by the federal government. ${ }^{280}$ Data came from the State Air Pollution Control Survey conducted in 1998. ${ }^{281}$ Thirtyeight states responded to the survey. Eleven of the thirty-eight states indicated that the state standards exceed the EPA's ambient air quality standards for at least one of the six criteria pollutant. ${ }^{282}$ Eight states reported adopting new source performance standards that are more stringent than required by the EPA. ${ }^{283}$ Potoski interprets this as

amendments to the Clean Air Act played important roles in changing the trends of the $\mathrm{SO}_{2}$ and VOC series from positive to negative and at least arresting the positive trend of the NOx series.").

276. See id. ("With respect to the effect of Reagan's environmental federalism on the trends in the $\mathrm{NO}_{\mathrm{x}}, \mathrm{SO}_{2}$, or VOC series, in none of them did there occur any additional change points after the initial change point occurred.").

277. Erwin Bulte, John A. List \& Mark C. Strazicich, Regulatory Federalism and the Distribution of Air Pollutant Emissions, 47 J. Regional SCI. 155 (2007).

278. See id. at $155-57$.

279. See id. at 157 .

280. See Matthew Potoski, Clean Air Federalism: Do States Race to the Bottom?, 61 Pub. Admin. Rev. 335 (2001).

281. See id. at 335 .

282. Id. at 337 (" $[\mathrm{F}]$ ive states (13 percent) reported that their standard for one of the NAAQS pollutants exceeds the USEPA's minimum criteria, and six states (16 percent) reported standards exceeding NAAQS criteria for two or more pollutants. Thus, nearly one-third (29 percent) of the responding states have one or more ambient air standards that exceed USEPA requirements.").

283. Id. 
"no evidence of a race to the bottom." ${ }^{284}$ Oates is less optimistic, writing that "with a couple of minor exceptions ... environmental authorities have not adopted standards for these pollutants that are more stringent than the federal standards." ${ }^{285}$ That said, Oates does not interpret this as evidence of a race to the bottom; he explains this by the "extraordinarily stringent" federal standards. ${ }^{286}$

Chang, Sigman, and Traub examine state applications for "authorization" or "primacy" status ${ }^{287}$ under both the Resource Conservation and Recovery Act ${ }^{288}$ (RCRA) and the Clean Water Act (CWA). As of 2002, forty-five states have authorization under the CWA and forty-eight states have authorization under the RCRA. ${ }^{289}$ The authors explore the determinants of how quickly states were authorized in the two cases. The results indicate that states with more "green" preferences - measured by the average League of Conservation Voters environmental scores for a state's federal congressmen - authorize significantly sooner. ${ }^{290}$ The authors infer that "states seek authorization in order to adopt stricter rather than weaker environmental policies than the federal government." ${ }^{291}$

The preceding studies do not suggest a race to the bottom. However, they do not shed any light on whether decentralization leads to an efficient outcome or to a race to the top. Levinson states: "The important question is more subtle than whether emissions go up or down. It is whether interjurisdictional competition and the Reagan decentralization caused regulations to be laxer than if they had been set by a welfare maximizing central planner." ${ }^{292}$ Thus, the second strand of the literature tests for evidence of strategic policy making by jurisdictions. Brueckner provides an excellent, general overview of the theoretical and empirical literature concerned with strategic interactions between governments. ${ }^{293}$ Not only does he provide an introduction to the spatial econometric techniques employed to test

284. Id. at 339 .

285. Oates, supra note 4, at 13.

286. Id.

287. Howard F. Chang, Hilary Sigman \& Leah G. Traub, Endogenous Decentralization in Federal Environmental Policies, 37 InT'L REV. L. \& ECON. 39 (2014).

288. Pub. L. No. 94-580, 90 Stat. 2795 (1976) (codified at 42 U.S.C. $§ 6901$ (2012)).

289. Chang, Sigman \& Traub, supra at note 287, at 41.

290. Id. at 49 .

291. Id.

292. Levinson, supra note 10 , at 97.

293. See Brueckner, supra note 159. 
for strategic behavior, but he also discusses studies examining other policy areas such as welfare benefits and taxation. ${ }^{294}$ Thus, this Article focuses exclusively on papers looking at environmental issues.

Murdoch, Rahmatian, and Thayer use data on public recreation expenditures per acre of recreation land across eighty-five communities in the Los Angeles metropolitan area in 1987.295 The authors are motivated by the question of whether communities free ride by reducing their own expenditures when neighboring communities' expenditures increase. Instead, they find the opposite; community expenditures increase by roughly $\$ 1000$ if neighboring expenditures increase by $\$ 2700 .{ }^{296}$ This is consistent with a model of yardstick competition or competition for mobile households.

Brueckner tests for strategic interaction using an index of growth controls across 173 California cities in 1988. ${ }^{297}$ The index reflects the number of measures adopted that are designed to constrain population or construction growth. Brueckner finds meaningful evidence of positive strategic interaction; more stringent growth controls in a city lead to more stringent controls in neighboring jurisdictions. ${ }^{298}$

Fredriksson and Millimet test for strategic interaction across the forty-eight contiguous states using two measures of environmental regulation over the period from 1977 to 1986 and 1988 to $1994 .{ }^{299}$ First - as in Fredriksson, List, and Millimet - the authors use an index based on the ratio of actual pollution abatement expenditures incurred by plants located in the state to the predicted level of expenditures based on the state's industrial composition. ${ }^{300}$ Second,

294. Id. Subsequent research tests for the presence of strategic interactions in U.S. educational policy making as well. See, e.g., Millimet \& Rangaprasad, supra note 259; Daniel L. Millimet \& Trevor Collier, Efficiency in Public Schools: Does Competition Matter?, 145 J. ECONOMETRICS 134 (2008).

295. James C. Murdoch, Morteza Rahmatian \& Mark A. Thayer, A Spatially Autoregressive Median Voter Model of Recreation Expenditures, 21 Pub. Fin. Q. 334, 341-43 (1993).

296. See id. at 347.

297. Jan K. Brueckner, Testing for Strategic Interaction Among Local Governments: The Case of Growth Controls, 44 J. URB. ECON. 438, 448-50 (1998).

298. See $i d$. at 458 ("This finding provides evidence of spatial interaction in the choice of growth controls. The positive coefficients indicate that... cities' reaction functions are upward sloping, so that the decision variables are strategic complements.").

299. Per G. Fredriksson \& Daniel L. Millimet, Strategic Interaction and the Determination of Environmental Policy Across U.S. States, 51 J. URB. ECON. 101 (2002).

300. See id. at 109-11; Fredriksson, List \& Millimet, supra note 90, at 1414. 
they utilize state-level abatement expenditures scaled by state manufacturing output. The results indicate strong, positive effects of neighboring environmental stringency on a state's own environmental stringency ${ }^{301}$ Furthermore, Fredriksson and Millimet explore whether the results are consistent with a race to the bottom or a race to the top by allowing for asymmetric responses to neighboring policies. Specifically, they allow for the possibility that states may respond differently to changes in neighboring states depending on whether one is currently more or less stringent than one's neighbors. The results are consistent with a race to the top as states are responsive only to changes in neighboring policy if one is initially less stringent than one's neighbors. ${ }^{302}$

Several analyses have extended this work of Fredriksson and Millimet in different directions. In a follow-up study, the same authors test for a particular pattern of strategic interaction, referred to as the "California effect." "303 Specifically, the authors test for the presence of abnormally large spillovers from California's environmental policy choices to other states. The results do not indicate a special role of California in the degree of cross-state strategic interaction. ${ }^{304}$ Fredriksson, List, and Millimet extend the previous models to allow for cross-policy strategic interactions. ${ }^{305}$ In other words, in contrast to earlier models of strategic interaction, the authors do not estimate a model that restricts the response of one jurisdiction to policy changes in another jurisdiction to be limited to the same policy (for example, a state need not respond to changes in environmental regulation in neighboring states by only adjusting its environmental regulation). Specifically, the authors estimate a model that allows for the possibility that environmental, tax, and

301. Fredriksson \& Millimet, supra note 299, at 114 ("[T] he elasticity of own state environmental stringency with respect to current neighboring environmental abatement costs is positive and significant to at least the $10 \%$ level of significance ....").

302. Id. at 117 ("The fact that increases in relative abatement costs have larger effects on the own state if neighbors initially have relatively stricter environmental standards implies that states are 'pulled' to stricter levels by improvements in relatively clean states (where marginal abatement costs may be the greatest).").

303. Per G. Fredriksson \& Daniel L. Millimet, Is There a "California Effect" in US Environmental Policymaking?, 32 Regional Sci. \& URB. ECON. 737 (2002).

304. Id. at 740 ("[W]hile states are generally engaged in strategic environmental policymaking, we find at best a minor overall environmental leadership role for California.").

305. Per G. Fredriksson, John A. List \& Daniel L. Millimet, Chasing the Smokestack: Strategic Policymaking with Multiple Instruments, 34 Regional Sci. \& URB. Econ. 387 (2004). 
expenditure policies are jointly determined and thus any policy may respond to changes in neighboring states. Environmental regulation is measured as in the prior studies. Tax policy is measured using data on tax effort obtained from the Advisory Commission on Intergovernmental Relations. And expenditures are measured using data on total general expenditures obtained from the Compendium of State Government Finances. The results provide strong evidence of not only cross-state strategic interactions within policy arenas, but also across arenas. ${ }^{306}$ This is consistent with the empirical fact that states utilize a package of incentives in an attempt to attract capital.

Levinson extends this work in an interesting direction. First, he combines the spatial models of strategic interaction with the natural experiment concerning President Reagan's decentralization to see if cross-state strategic interaction accelerated during the Reagan era. ${ }^{307}$ He finds little meaningful evidence that the extent of strategic policy making changed after 1981; states act strategically in both periods. ${ }^{308}$ Second, Levinson tests for the presence of strategic interaction in the setting of hazardous waste disposal tax rates across states over the period from 1989 to $1995 .{ }^{309}$ He finds strong evidence of strategic interaction beginning in 1992, after the Supreme Court ruled that states are not able to levy different rates depending on whether the waste originated instate or out-of-state. ${ }^{310}$

Several studies test for cross-state strategic interaction using measures of environmental enforcement. Woods examines state enforcement of environmental regulation in the surface-mining industry. ${ }^{311}$ Enforcement is measured using the number of violations

306. See id. at 408 ("Our findings are consistent with the notion that reaction functions between policies have a nonzero slope. For example, we find that states respond to increased governmental expenditure levels of neighbors by lowering their own pollution standards.").

307. See Levinson, supra note 10, at 98-100.

308. See id. at 100 ("After 1981, the coefficient on neighboring states' regulations seems to decrease, suggesting that reaction functions got a tiny bit less steep, though the coefficient estimate on the interaction term is not statistically significant.").

309. Id. at $100-02$.

310. See $i d$. at 102 ("The reaction functions look somewhat different, however, when we compare them before and after the 1992 Supreme Court decision prohibiting discriminatory taxation. One way to view this is that before 1992 there was no particular reason to raise one's own disposal tax in response to a neighbor. Instead, states could simply raise the tax they charge other states for disposal, while leaving disposal taxes low for waste generated locally.").

311. See Neal D. Woods, Interstate Competition and Environmental Regulation: A Test of the Race-to-the-Bottom Thesis, 87 Soc. SCI. Q. 174 (2006). 
and cessation orders issued by a state in a year scaled by the number of mines in the state. The data for the twenty-three states that had primary enforcement authority for this industry are obtained from the Office of Surface Mining Annual Report for the period between 1987 and 1999. ${ }^{312}$ The results, first and foremost, indicate the presence of strategic interaction; state enforcement depends on how one's own past enforcement levels compare to one's neighbors. ${ }^{313}$ However, the results are counter to Fredriksson and Millimet in that states are found to only respond to their neighbors if the neighbors are relatively lax in terms of enforcement. ${ }^{314}$

A series of studies by Konisky use state-level data on inspections and punitive actions taken under the CAA, CWA, and RCRA from 1985 to $2000 .^{315}$ The data are obtained from the EPA's Integrated Database for Enforcement Analysis. In the first study, Konisky affirms the primary result from prior studies; a ten percent increase in neighboring enforcement activity leads to a five to fifteen percent increase in a state's own enforcement activity. ${ }^{316}$ In the second study, Konisky extends the analysis by allowing for asymmetric responses depending on whether or not a state is considered economically susceptible. However, he finds that states are equally likely to engage in strategic policy making regardless of their current level of economic vulnerability. ${ }^{317}$

Professors Davies and Naughton utilize a similar econometric framework but assess country-level decisions to ratify any of 110 multilateral environmental agreements (MEAs) containing explicit environmental targets or requirements. ${ }^{318}$ The data contain 139

312. Id. at $180-83$.

313. Id. at 185 ("[S]tate enforcement stringency declines significantly in states in which the enforcement stringency exceeded their competitor's average during the previous year.").

314. See id. at 184 ("[S]tates do not respond to the regulatory behavior of competitor states when their average stringency is greater than the state's own.").

315. See Konisky, supra note 264; Konisky, supra note 255.

316. Konisky, supra note 264, at 853-54 ("I find elasticities in the range of about .5 to 1.5 , which suggests that states respond to a $10 \%$ increase (decrease) in their competitor states' enforcement efforts with a $5 \%$ to $15 \%$ increase (decrease) in their own enforcement efforts.").

317. See Konisky, supra note 255, at 416 ("[I]n none of the models is it the case that states more susceptible to interstate economic competition are more likely to respond to the regulatory enforcement behavior of competitor states.").

318. Ronald B. Davies \& Helen T. Naughton, Cooperation in Environmental Policy: A Spatial Approach, InT'L Tax \& Pub. Fin., Apr. 27, 2013, available at http://link.springer.com/article/10.1007\%2Fs10797-0139280-1\#. 
countries spanning the period from 1980 to 1999. The results provide meaningful evidence of strategic interaction in environmental policy making at the country level; a ten percent increase in the number of treaties participated in by one's neighbors raises one's own participation by about $1.5 \%{ }^{319}$ Furthermore, the analysis reveals that this strategic interaction is driven by countries - OECD and nonOECD alike - reacting to ratifications by other OECD countries. ${ }^{320}$ This result is consistent with the asymmetric results in the initial Fredriksson and Millimet study in that OECD countries are likely to be more environmentally stringent on average.

Two final studies on strategic interaction in environmental policy making merit attention. Engel and Konisky explore the possibility of strategic policy making not by estimating a spatial econometric model, but rather by directly surveying state environmental managers in the United States. ${ }^{321}$ Engel surveyed eighty state environmental regulators in 1996. Engel summarizes the findings: "[T]he possibility that industry might relocate or site a new plant elsewhere is something of a concern to the environmental regulators in many states, and affects environmental policy making in some manner in most states." ${ }^{22}$ However, the survey responses do not yield much guidance as to whether such strategic behavior is more in line with a race to the bottom or race to the top. ${ }^{323}$

Konisky surveyed senior managers in state environmental agencies in 2005. The survey was mailed to 1459 officials; the response rate was roughly thirty-four percent. In contrast to Engel, the sample size is larger and contains career managers rather than political appointees. ${ }^{324}$ Several findings are noteworthy. First, only about ten percent of the respondents indicated that they were "not sure" how enforcement in their state ranked relative to other states. ${ }^{325}$ Second, more than sixty percent responded that other states' actions influenced their own state's actions; over ten percent indicated it has a significant effect. ${ }^{326}$ Third, while more than seventy percent of the

319. See id. at 21 ("[W]e find positive and significant coefficients of approximately $0.15 . ")$.

320. Id. at 25 ("[T] reaty participation by OECD countries impacts that of both OECD and non-OECD countries.").

321. See Engel, supra note 64, at 337-47; David M. Konisky, Regulator Attitudes and the Environmental Race to the Bottom Argument, $18 \mathrm{~J}$. Pub. Admin. Res. \& Theory 321, 325-26 (2007).

322. Engel, supra note 64 , at 340-41.

323. See id. at 345 .

324. Konisky, supra note 321 , at 326 .

325. Id. at 328 tbl.1.

326. Id. at 329 . 
respondents indicated their belief that environmental regulations are a "fairly important" or "very important" factor in firm location decisions, this ranked lower than their perceived importance of transportation, labor costs and quality, proximity to customers or markets, taxes, and proximity to natural resources or raw materials. ${ }^{327}$ That said, almost sixty percent responded that concerns over the impact on industry played a "fairly important" or "very important" role in the discouragement or opposition to adoption of a more stringent environmental standard. ${ }^{328}$ More than twenty-five percent said that concern over the impact on industry played a "fairly important" or "very important" role in the decision to allow or advocate allowing greater emissions or discharges. ${ }^{329}$

In sum, the evidence concerning the presence of strategic policy making in the environmental arena is much stronger than the evidence concerning the influence of environmental policy making on firm location or industry competitiveness. One possible explanation for this apparent contradiction is that politicians are not economically rational. Engel discusses the possibility that "state regulators are simply not aware of the evidence demonstrating the unimportance of environmental standards to firm location." ${ }^{330}$ However, she goes on to argue that it is more plausible that "environmental regulators . . . are responding to different incentives" as they are "subject to politically rational, but not always economically rational, political pressures to accommodate industry with the use of less stringent environmental standards." ${ }^{331}$ Consistent with the notion that politicians are responding to political incentives, evidence indicates that states favor uniform environmental standards. Engel writes:

[S]tates strive to mimic the standards of other states - activity that is at least consistent with the hypothesis that states act strategically when establishing environmental standards. On average, environmental regulators agreed "strongly" with the proposition that their state's standards be of about the same stringency as the standards of neighboring states. ${ }^{332}$

Thus, yardstick competition may be a more likely explanation for strategic behavior than "economically irrational" resource competition. Regardless of the source, the empirical evidence of

327. Id. at 331 .

328. Id. at 334 .

329. Id. at 333 tbl.4.

330. Engel, supra note 64 , at 352 .

331. Id. at 353 .

332. Id. at 344 (citation omitted). 
strategic interaction in environmental policy making at the city, state, and national level is convincing.

There is an additional issue regarding strategic policy making that merits discussion. The preceding studies test for horizontal strategic interaction in an environmental context. Here, horizontal refers to the fact that the governments being examined are at the same level. Vertical interactions, on the other hand, may arise due to fiscal externalities spanning different levels of government when each possesses some regulatory power over the same base. ${ }^{333}$ While apparently unexplored in the environmental context, this issue is a potentially salient one moving forward given increasing reliance on a system of cooperative federalism in the United States and elsewhere. For example, Esty discusses arrangements whereby the U.S. federal government sets minimum standards and allows states the possibility of exceeding these standards if desired. ${ }^{334}$ Professor Williams states: "In recent years [cases in which state governments chose to override federal environmental regulation with tighter regulations of their own] have become more common, even for pollutants that have substantial spillovers across states . . ." ${ }^{335}$ In other situations, it may be that the federal government sets standards related to some environmental issues (for example, federal ambient air quality standards for criteria pollutants), but states settle other environmental issues (for example, hazardous waste disposal taxes). ${ }^{336}$ Thus, federal and state governments can be seen as both taxing the same industrial base. Professors Goulder and Stavins write: "The coexistence of state and

333. Specifically, externalities arise because each level of government fails to account for the fact that its taxes reduce the size of the tax base available to other levels. See Wilson, supra note 8, at 289-91.

334. See Esty, supra note 158, at 620-21 ("Centralized environmental regulation, moreover, need not mandate fixed uniform standards. One important alternative is minimum standards that provide a limited common goal, ensuring that all parties meet a basic level of environmental protection. For some jurisdictions, baseline standards may be the most appropriate endpoint for their environmental programs given their level of economic development and other specific circumstances. In other jurisdictions, more stringent standards will be appropriate given higher levels of available resources and greater public demand for environmental protection. Under a system of minimum standards, governments remain free to adopt a higher level of environmental protection.").

335. Roberton C. Williams III, Growing State-Federal Conflicts in Environmental Policy: The Role of Market-Based Regulation, 96 J. Pub. ECON. 1092, 1092 (2012).

336. Cf. James Alm \& H. Spencer Banzhaf, Designing Economic Instruments for the Environment in a Decentralized Fiscal System, 26 J. Econ. SuRv. 177, 182 (2012) ("[M]ultiple instruments are often used for a single pollution problem in a single country."). 
federal policies raises questions about their interactions. Problems arise when state and federal policies overlap." ${ }^{337}$

There seems to be no formal empirical evidence regarding the nature of any strategic interactions between subnational and national governments in the context of environmental policy. ${ }^{338}$ Thus, if there is indeed a push for something akin to the cooperative federalism described in Esty, ${ }^{339}$ this is an area in desperate need for both theoretical and empirical research. However, as a starting point, there are several studies looking at vertical policy interactions in tax setting.

A series of studies examine the case of gasoline and cigarette taxation in the United States. Professors Besley and Rosen utilize data from 1975 to $1989 .{ }^{340}$ The results indicate that states increase their gasoline and cigarette taxes by about three to four cents per each ten cent increase in the corresponding federal tax rate. ${ }^{341}$ Professors Devereux, Lockwood, and Redoano analyze data over the period from 1977 to $1997 .{ }^{342}$ They obtain weaker results for cigarette taxes, but continue to find a positive effect of federal gasoline tax rates on state tax rates. ${ }^{343}$ However, Professors Fredriksson and Mamun revisit the issue of cigarette taxation using data from 1975 to $2001 .^{344}$ The authors find a meaningful effect. When focusing on data

337. Lawrence H. Goulder \& Robert N. Stavins, Challenges from StateFederal Interactions in US Climate Change Policy, 101 Am. Econ. REV. 253, 257 (2011).

338. But see Chang, Sigman \& Taub, supra note 287 (assessing federal delegation of environmental authority to states under the CWA and RCRA); W. Bowman Cutter \& J.R. DeShazo, The Environmental Consequences of Decentralizing the Decision to Decentralize, $53 \mathrm{~J}$. Envtl. ECON. \& MGMt. 32 (2007) (examining the implementation of authorization under the RCRA in California in the early 1990s and determining that once cities received authorization to regulate enforcement efforts increased but that it is unlikely that authorization of other cities would result in the same increase).

339. See Esty, supra note 158, at 620-21.

340. See Timothy J. Besley \& Harvey S. Rosen, Vertical Externalities in Tax Setting: Evidence from Gasoline and Cigarettes, 70 J. PuB. Econ. (1998).

341. See id. at 392 .

342. See M.P. Devereux, B. Lockwood \& M. Redoano, Horizontal and Vertical Indirect Tax Competition: Theory and Some Evidence from the USA, 91 J. Pub. ECON. 451 (2007).

343. See id. at 475 ("For gasoline . . . the federal tax plays a significant role, indicating the presence of some vertical competition.").

344. See Per G. Fredriksson \& Khawaja A. Mamun, Vertical Externalities in Cigarette Taxation: Do Tax Revenues Go Up in Smoke?, 64 J. URB. ECON. 35, 37-40 (2008). 
from 1982 to 2001, the results indicate that states reduce their taxes by up to five cents per each ten cent increase in the federal tax rate. ${ }^{345}$ The authors attribute this difference to the additional years of data from the Reagan era of new federalism, as well as the addition of various independent variables to control for political economy issues.

Professor Goodspeed uses data across thirteen OECD countries from 1975 to 1984 to test if local income tax rates are affected by national income tax rates. ${ }^{346}$ Local tax rates are measured by total local personal income tax revenue scaled by gross national product (GNP). National tax rates are measured by total federal and state income tax revenue scaled by GNP. Thus, states are lumped together with the central government. He obtains a negative effect of national tax rates on local tax rates; the estimates imply an elasticity of about $-0.5 .^{347}$

Professors Esteller-Moré and Solé-Ollé assessed the impact of federal tax rates on state personal income and general sales taxes. ${ }^{348}$ The data covered the forty-one states with an income tax between 1987 and 1996. Tax rates were measured as state or federal income tax revenue scaled by personal income. State tax rates were also measured by the sum of state income and general sales tax scaled by personal income. The results are consistent with the Besey and Rosen study. Specifically, a ten percent increase in the federal tax rate leads to about a one percent increase in state income tax rates and a two percent increase in state income plus general sales tax rates. ${ }^{349}$

A final set of analyses is based on Canadian, Swedish, and Swiss data. Professors Hayashi and Boadway focused on business taxation in Canada and define the provincial business tax rate as corporate income tax revenues scaled by corporate profits earned in the

345. See id. at 47 ("Our empirical results for the 1982/83-2001 time period suggest the presence of a negative vertical externality between different levels of government in the US. In particular, our evidence suggests that an increase in the federal cigarette tax may reduce the average state cigarette tax rate by 15 to 48 cents."); $i d$. at $42-43$ ("Model VIII suggests that states reduce their real cigarette tax rates by 48 cents per real dollar increase in the federal tax rate.").

346. See Timothy J. Goodspeed, Tax Structure in a Federation, 75 J. PuB. ECON. 493 (2000).

347. See $i d$. at 500 ("The point estimate for the most complete specification . . . corresponds to an elasticity of about -0.5.").

348. See Álex Esteller-Moré \& Albert Solé-Ollé, Vertical Income Tax Externalities and Fiscal Interdependence: Evidence from the US, 31 Regional ScI. \& URb. Econ. 247 (2001).

349. See id. at 262 ("[T]here is a significant positive interdependence between federal and state tax rates. A $1 \%$ point change in the federal tax burden supposes an average variation in the income state tax rate around $0.10 \%$ and of $0.22 \%$ in the combined state income plus sales tax rate."). 
province. ${ }^{350}$ The federal rate is obtained similarly using federal corporate income tax revenues. The data covered the period from 1963 to 1996. Contrary to the prior study on the United States, the results indicate that provinces respond to higher federal tax rates by substantially reducing their own rates. ${ }^{351}$ Professors Andersson, Aronsson, and Wikström study local (municipality) and regional (county) personal income tax rates in Sweden from 1981 to 1990. ${ }^{352}$ Again, the results indicate that local tax rates are reduced in response to higher regional tax rates. ${ }^{353}$ Brülhart and Jametti examined local (municipality) and regional (canton) tax rates in Switzerland in select years spanning in the period from 1985 to $2001 .^{354}$ Here, the results indicated higher local tax rates in response to an increase in regional tax rates. ${ }^{355}$

Thus, the empirical evidence appears to confirm the existence of vertical tax externalities in federations. However, whether strategic policy making leads to inefficiently high or low taxation is unclear and may vary across locations and the type of tax considered. Theoretically, the effects of vertical tax competition on efficiency have been shown to depend crucially on the order of moves and the political objectives of the different levels of government, which is the subject of Part II.D. Wilson concludes: "Clearly, the best case for efficiency will occur when the federal government is benevolent and is able to move first, so that it can influence the behavior of the state governments." ${ }^{356}$ However, significant research is needed that incorporates the peculiarities of cooperative federalism with regards to

350. See Masayoshi Hayashi \& Robin Boadway, An Empirical Analysis of Intergovernmental Tax Interaction: The Case of Business Income Taxes in Canada, 34 Can. J. Econ. 481 (2001).

351. See $i d$. at 501-02 ("[V]ertical responses of provincial taxes to the federal tax are negative ....").

352. See Linda Andersson, Thomas Aronsson \& Magnus Wikström, Testing for Vertical Fiscal Externalities, 11 InT'L TAX \& Pub. Fin. 243, 250$52(2004)$.

353. See $i d$. at 256 ("[T]here is a negative relationship between the tax rates chosen by the two levels of government.").

354. See Marius Brülhart \& Mario Jametti, Vertical Versus Horizontal Tax Externalities: An Empirical Test, 90 J. PuB. ECON. 2027, 2042-45 (2006)

355. See id. at 2051 ("This suggests that the strategic complementarity of municipal and cantonal tax rates is two-directional: municipalities on average react to higher cantonal tax rates by raising their own tax rate, and cantonal governments react to higher municipal tax rates by raising the cantonal tax rate.").

356. Wilson, supra note 8, at 290. 
environmental regulation into existing theoretical and empirical models of vertical interactions.

\section{Political Economy}

Both the Tiebout and interjurisdictional competition frameworks make strong assumptions concerning the behavior of governments. The Tiebout model assumes that communities adjust policies optimally to attract (or repel) residents. ${ }^{357}$ The interjurisdictional competition model assumes that governments maximize a known social welfare function. ${ }^{358}$ In practice, there are several reasons why decentralized policy makers may not behave in this fashion. First, as posited in so-called Leviathan models of government behavior, policy makers may seek to maximize the size of the local tax base rather than social welfare. Second, lobbying behavior or explicit corruption may induce policy makers to deviate from socially optimal policies. Third, individuals may abstain from participation in the political process. Fourth, policy makers may aim to maximize social welfare but make mistakes. Mistakes may arise either due to imperfect scientific knowledge or the so-called winner's curse. A final reason, in the context of the Tiebout model, for local governments possibly deviating from the assumed behavior pertains to differential mobility rates across population segments discussed in Part II.A. Thus, this Part does not revisit that issue in its discussion.

Before discussing the empirical literatures with regard to these issues, it is important to reiterate that what is relevant for the debate over environmental federalism is not simply whether local policy makers stray from socially optimal decisions, but rather how any such deviations compare to political economy distortions at the federal level.

\section{Leviathan}

Leviathan models suppose that governments seek to maximize tax revenues rather than social welfare. ${ }^{359}$ As such, tax rates (or, in this case, any revenue-generating environmental instrument) are set inefficiently high. Wilson notes that capital mobility limits the ability of policy makers to behave in this manner; capital can move to avoid

357. See, e.g., Revesz, supra note 17 , at 1236 ("[C]ommunities below the optimal size seek to attract new residents in order to lower the average cost of providing services.").

358. See Oates, supra note 16, at 1136 ("[P]ublic officials seek in their decisions to maximize the welfare of their constituencies ....").

359. See Wallace E. Oates, Searching for Leviathan: A Reply and Some Further Reflections, 79 Am. Econ. Rev. 578, 578 (1989); Wilson, supra note 8 , at 296 . 
excessively high taxes. ${ }^{360}$ Because capital may be less mobile across countries than within countries, the federal government may be more capable of acting like a Leviathan. Thus, decentralization is predicted to result in lower tax rates as rates move towards the efficient level. However, Wilson goes on to state that if decentralized policy makers behave strategically, as discussed in Part II.C.3, then capital mobility may lead to a race to the bottom in which decentralized tax rates are inefficiently low and less than what would be set by the federal government. ${ }^{361}$ As a result, Leviathan and race to the bottom models both predict that decentralized tax rates will be lower than those set by the central government. ${ }^{362}$ In the former case, this reduction entails a movement toward the socially optimal level, while the latter results in a movement away from social optimality.

This theoretical result implies that obtaining empirical evidence supporting or refuting the Leviathan model is difficult. One can certainly assess the empirical associations between the relative power of the top tier of government (referred to as "centralism"), the extent of competition among lower tiers of government (referred to as "fragmentation"), and policy outcomes. ${ }^{363}$ However, whether the results support or refute the Leviathan model is unknown without knowledge of the efficient tax rate. ${ }^{364}$ Evidence of smaller public sectors in decentralized economies is consistent with, but not proof of, the Leviathan model.

Aside from the difficulties arising from the inability to observe the efficient level of taxation, the empirical literature must also confront data issues surrounding the proper measurement of decentralization, as well as the possible endogeneity of decentralization. In light of the

360. See Wilson, supra note 8 , at 298 ("[C]apital mobility... is likely to play a similar efficiency-enhancing role. In this case, government officials will engage in expenditure competition by increasing those public inputs that enhance the productivity of capital.").

361. See $i d$. ("[I]t is also possible that this competition for capital might inefficiently distort the pattern of public expenditures away from expenditures on public goods or inputs that do not enhance capital productivity ....").

362. See $i d$. at 296 ("It is difficult to ascertain empirically whether the welfare-improving or welfare-worsening view of tax competition is more accurate, since both views seem to predict that an increase in the number of competing governments should reduce the total size of government.")

363. See, e.g., Jeffrey S. Zax, Is There a Leviathan in Your Neighborhood?, 79 Am. ECON. Rev. 560 (1989) (measuring the effects of the "two distinct dimensions" of decentralization: centralism and fragmentation).

364. See id. at 566 ("The effects of increased centralism are consistent with the monopoly predictions of Leviathan models.... Whether a local government sector configured in this way would be 'optimal' remains, of course, an open question."). 
numerous difficulties testing the Leviathan model empirically, this Article does not provide a detailed survey of the existing literature. However, Oates provides an early survey. ${ }^{365}$ And Professors Crowley and Sobel offer a recent addition to the literature and provide a more current literature review. ${ }^{366}$ The authors state that the "previous literature has examined local, state, and international data and has found mixed results." ${ }^{667}$ Thus, whether the Leviathan model can be empirically supported, particularly in the context of environmental issues, is an open question.

\section{Lobbying and Corruption}

Aside from government preferences as to tax revenues, policies may also deviate from socially optimal levels due to lobbying influence or corruption. Esty concludes that there exists no evidence on the relative size of special interest distortions at the local versus federal levels. ${ }^{368}$ Revesz counters the notion that environmental interest groups are stronger at the federal level and hypothesizes that the reverse may be true because of the typical grass-roots nature of environmental groups. ${ }^{369}$ Professors Fredriksson and Gaston posit a theoretical model where capital has no incentive to lobby at the local level if it is mobile; it can simply relocate if policies are not to its liking. ${ }^{370}$ Thus, environmental lobbying is offset by capital mobility, not industry lobbying, at the local level. However, with centralized policy making, both environmental and industry groups have an

365. See Oates, supra note 359.

366. See George R. Crowley \& Russell S. Sobel, Does Fiscal Decentralization Constrain Leviathan? New Evidence from Local Property Tax Competition, 149 Pub. Choice 5 (2011).

367. Id. at 6 .

368. See Esty, supra note 158, at 649-50 ("[E]nvironmental decisionmaking is particularly susceptible to special interest distortion. Rent-seeking behavior undoubtedly affects national as well as state environmental policymaking, but there is no evidence that public decisionmaking is systematically more distorted at the federal than at state and local levels. Indeed, given general popular indifference to many state and local environmental decisions, as well as greater media attention to federallevel activities, one might suggest precisely the opposite." (citations omitted)).

369. See Richard L. Revesz, Federalism and Environmental Regulation: A Public Choice Analysis, 115 Harv. L. Rev. 553, 568-71 (2001).

370. See Per G. Fredriksson \& Noel Gaston, Environmental Governance in Federal Systems: The Effects of Capital Competition and Lobby Groups, 38 ECON. INQUiRY 501, 508 (2000) ("[C]apital owners are unlikely to engage in costly lobbying activities if they can move ...."). 
incentive to lobby (if capital is not perfectly mobile across national borders). ${ }^{371}$

In terms of corruption, theoretical arguments are also ambiguous. For example, Professor Weingast argues that decentralization limits corruption through interjurisdictional competition. ${ }^{372}$ However, Professors Shleifer and Vishny hypothesize that access to the same bribe base (as opposed to tax base) may result in greater levels of corruption. ${ }^{373}$ Notably, Shleifer and Vishny's argument does not make the case for greater corruption at the federal or local level, but rather it indicates that the system of simultaneous policy making itself results in greater corruption.

The empirical evidence on lobbying and corruption is equally as mixed in the findings as the theoretical arguments. To begin the review of the empirical evidence, one strand of the literature addresses this issue indirectly by examining specific policy examples to ascertain whether the outcome was influenced by political motives. Two such studies examine particular instances of EPA behavior; thus, the findings shed some light on political influences within federal environmental decision making.

In the first of these studies, Professor Hird examines EPA outlays under Superfund. ${ }^{374}$ Under the program, abandoned hazardous waste sites are evaluated and given a Hazard Ranking System (HRS) score. If the HRS score exceeds a certain threshold, the site is added to the National Priorities List (NPL). Hird obtains data on 799 sites on the NPL as of December 31, 1988, from the Superfund data collection system (CERCLIS). He examines determinants of the number of NPL

371. See id. ("[T]he immobility which leaves capital exposed to stricter regulation of its production may be offset by a 'lobbying effect' that creates increased political pressure for more lenient regulation.").

372. See Barry R. Weingast, The Economic Role of Political Institutions: Market-Preserving Federalism and Economic Development, 11 J.L. ECON. \& ORG. 1, 6 (1995) ("Federalism thus greatly diminishes the level and pervasiveness of economic rent-seeking and the formation of distributional coalitions. Competition among the lower units limits the success from rent-seeking."); see also Andrei Shleifer \& Robert W. Vishny, Corruption, 108 Q.J. ECON. 599, 610 (1993) ("[C]ompetition between bureaucrats in the provision of government goods . . . will drive bribes down to zero.").

373. See Schleifer \& Vishny, supra note 372, at 615 ("[T]he weakness of central government, which allows various governmental agencies and bureaucracies to impose independent bribes on private agents seeking complementary permits from these agencies. When the entry of these agencies into regulation is free, they will drive the cumulative bribe burden on private agents to infinity.").

374. See John A. Hird, Superfund Expenditures and Cleanup Priorities: Distributive Politics or the Public Interest?, 9 J. POL'Y ANALYsis \& MGMT. 455 (1990). 
sites per state, the length of time spanned between when a site was initially proposed and when its status became final, total expenditures on a site as of 1988, and planned future expenditures by the EPA on a site. ${ }^{375}$ The empirical model assesses whether political variables related to the committee assignments of a state's U.S. senators and representatives influence these allocation outcomes after controlling for other attributes of a site such as its HRS score. The results indicate that having senators or representatives from a state on key Senate and House subcommittees may influence the total number of sites on the NPL in a given state and how quickly a site progresses to final status. ${ }^{376}$ However, these political variables have no meaningful influence on the level of current or future expenditures at a given site. ${ }^{377}$

The second of these studies is by Cropper, Evans, Berardi, DuclaSoares, and Portney, who analyze EPA decisions concerning cancercausing pesticides between 1975 and 1989. ${ }^{378}$ Under the Federal Insecticide, Fungicide, and Rodenticide Act (FIFRA), the EPA was required to reregister the 600 active ingredients appearing in various pesticides. If the ingredient was found to pose a significant risk to humans or animals, the EPA was to conduct a special review to weigh the benefits and costs of the reregistration of the ingredient. ${ }^{379}$ Over the time period studied, a special review was completed for thirtyseven ingredients. Of these, nineteen involved ingredients used to treat food crops and found to cause cancer in laboratory animals. For each of these ingredients, the EPA made separate decisions for each type of crop to which it is applied. In total, 245 ingredient-crop combinations were decided upon by special review; ninety-six were banned. ${ }^{380}$ Controlling for cancer risk as well as economic importance, the authors assess whether public comments submitted to the EPA during the review process by environmental groups, industry groups, and academics affected the outcome. The results do indicate that the cancellation decisions were affected by the existence of public comments by each of the three groups; comments by environmental groups raised the probability of cancellation, while the existence of comments by industry groups and academics lowered the cancellation

375. Id. at $469-71$.

376. See id. at $477-78$.

377. See $i d$. at 477 .

378. See Maureen L. Cropper, William N. Evans, Stephen J. Berardi, Maria M. Ducla-Soares \& Paul R. Portney, The Determinants of Pesticide Regulation: A Statistical Analysis of EPA Decision Making, 100 J. PoL. ECON. 175 (1992).

379. Id. at 178-79.

380. Id. at 179, 180 tbl.1. 
probability. ${ }^{381}$ While the magnitude of the effect of environmental groups was larger than the corresponding effect of industry groups, the combined effect of industry groups and academics was greater. ${ }^{382}$

A similar strand of studies has undertaken analyses at the state level. Professors Hays, Esler, and Hays examine cross-state variation in the Green Policy Index, which is a function of the existence of fifty different environment-related policies and the extent of commitment to seventeen environmental programs common to all states. ${ }^{383}$ The index is computed based on data from 1987 to 1991. Among the various determinants of the index considered, the authors include a measure of environmental pressure - state membership in environmental groups as a fraction of the population - and industry pressure - fraction of state employment in the manufacturing sector. Surprisingly, the results indicate a positive association between both environmental and industry pressure and the index. ${ }^{384}$ The latter could represent a failure of the statistical analysis to identify the causal effect of industry pressure on environmental policy.

Professor Helland uses data from the EPA's Performance Compliance Database to assess inspections, violations, and effluent discharge at 232 pulp and paper mills across thirty states under the CWA from 1989 to $1993 .^{385}$ Enforcement of the CWA is either the responsibility of regional offices of the federal EPA or the responsibility of the states; seventy percent of the sample is under state control. ${ }^{386}$ With the set of potential determinants of inspections, violations, and effluent discharges, the authors include local environmental pressure (measured by the share of the state population belonging to the Sierra Club) and economic pressure (measured by the size of the plant and the local unemployment rate).

381. See $i d$. at 194 ("[I]intervention in the regulatory process-by both business and environmental groups - affects the likelihood of pesticide use restrictions.").

382. Id. at 194-95 ("All other things being equal, interventions by environmental groups have about twice the impact on the likelihood of cancellation as those by growers (although the combined effect of growers and academic commenters, who weigh in against cancellations, outweighs that of environmentalists).").

383. See Scott P. Hays, Michael Esler, \& Carol E. Hays, Environmental Commitment among the States: Integrating Alternative Approaches to State Environmental Policy, 26 Publius: J. Federalism 41 (1996).

384. See $i d$. at 53 ("[E]nvironmental commitment is a function of pressure for greater commitment from both environmental groups and manufacturing interests ....").

385. See Eric Helland, Environmental Protection in the Federalist System: The Political Economy of NPDES Inspections, 36 ECON. INQUIRY 305 (1998).

386. Id. at 312 tbl.II. 
The results indicate state responsibility for enforcement is associated with a lower probability of inspection and higher effluent discharge. ${ }^{387}$ Greater environmental pressure is associated with a higher probability of a plant being inspected, lower probability of a plant being in violation, and lower effluent discharge. ${ }^{388}$ Plant size, particularly in areas of high unemployment, is associated with a lower probability of a plant being inspected and a higher probability of a plant being in violation. ${ }^{389}$

Joskow and Schmalensee investigate the role of politics in the $\mathrm{SO}_{2}$ tradable allowances program created by Congress in $1990^{390}$ to combat acid rain. ${ }^{391}$ Specifically, the authors investigate whether political variables help explain the allocation of allowances across electric utilities. The outcome examined is the difference between the actual allowances allocated to a given utility and the expected allocation derived under different objective allocation rules. Political variables considered include measures of the political clout of the state in which the utility belongs (for example, whether it is considered a swing state, whether it has a competitive Senate or gubernatorial election, and its number of electoral votes) and the committee assignments of its U.S. senators and representatives. ${ }^{392}$ The authors find some evidence that states with greater political clout fared better in terms of allocations. ${ }^{393}$ That said, Joskow and Schmalensee conclude: "If anything, the resulting allocation of Phase II allowances appears more to be a majoritarian equilibrium than one heavily weighted toward a narrowly defined set of economic or geographical interests. It is not strongly consistent with the predictions of standard models of interest group politics or of congressional control." ${ }^{1394}$

387. Id. at 315 tbl.III.

388. See id. at 311-12.

389. See $i d$. at 313 (noting that "as the unemployment rate rises, larger employers are inspected less frequently," but these circumstances "increase[] the probability of a violation").

390. Pub. L. No. 101-549, 104 Stat. 2584 (1990) (codified at 42 U.S.C. § 7651) (amending the Clean Air Act).

391. See Paul L. Joskow \& Richard Schmalensee, The Political Economy of Market-Based Environmental Policy: The U.S. Acid Rain Program, 41 J.L. \& ECON. 37 (1998).

392. Id. at 74 .

393. See id. at 79 ("[T] here is strong evidence that states with political 'clout'-because they were large states that were swing states in the 1988 presidential election, or because they were large states that happened to have competitive gubernatorial campaigns in 1990, or because they had representatives in the House Energy and Commerce leadership - tended to do well in Phase II, and weak evidence that they also did well in Phase I, all else equal.").

394. Id. at 81 . 
Another strand of the literature explicitly investigates the link between (fiscal) decentralization and corruption. As is the case in the empirical literature testing the Leviathan model, studies in this area must confront data issues surrounding the proper measurement of decentralization, the potential endogeneity of decentralization, as well as the proper measurement of corruption.

Several studies use cross-country data and measure federalism using a discrete measure of federal structure. Professor Treisman analyzes country-level data on perceived corruption obtained from Transparency International (TI) from 1996 to 1998.395 The index is based on a combination of surveys of businesses, local populations, economic risk analysts, and country experts. Federalism is measured using a simply binary indicator. The number of countries covered varies by year, ranging from fifty-two in 1997 to eighty-five in $1998{ }^{396}$ The results indicate that federal structures have a meaningful, positive association with corruption holding constant the level of economic development and democratic history of a country. ${ }^{397}$

Professors Gerring and Thacker investigate corruption across 125 countries using a measure developed elsewhere that combines several sources of data from the late 1990s. ${ }^{398}$ Federalism is measured on a three-point scale (non-federal, semi-federal, and federal). The results are in line with those found by Treisman, indicating a positive association between federalism and corruption. ${ }^{399}$ Interpreting the findings as causal, the results suggest that moving from a federal to a unitary system would decrease corruption. For example, Nigeria would fall from the seventh most corrupt country to number forty-six and the United States from the 108th most corrupt country to number $119 .^{400}$ The authors conclude:

[N]ational bureaucracies are large and interdepartmental transfers tend to be frequent. It is more difficult to maintain clientelistic networks under such circumstances. ... Following Madison, largeness of size and heterogeneity of constituency

395. See Daniel Treisman, The Causes of Corruption: A Cross-National Study, 76 J. Pub. Econ. 399, 407-14 (2000).

396. See id. at 410 .

397. See id. at 430 ("[A] state that was federal tended to rank from about half a point to more than one point higher on the corruption scale than a similar state that was unitary.").

398. See John Gerring \& Strom C. Thacker, Political Institutions and Corruption: The Role of Unitarism and Parliamentarism, 34 BRITISH J. POL. SCI. 295 (2004).

399. See $i d$. at 310 ("[T]he findings are strong: unitarism and parliamentarism mitigate political corruption.").

400. Id. at 326 . 
may be seen as conducive to more transparency, more publicity and more anti-corruption efforts generally, at least in so far as these may stem from the dynamics of political competition. ${ }^{401}$

Bohara, Mitchell, and Mittendorff analyze corruption across roughly ninety countries using the World Bank Institute Governance Research Indicator to measure corruption in 1996, 1998, and 2000. ${ }^{402}$ Federalism is measured using a simply binary indicator. Contrary to the results of Gerring and Thacker, this analysis found no statistically meaningful association between federalism and corruption. ${ }^{403}$

Other studies in the literature utilize continuous measures of decentralization to reflect the degree to which countries are decentralized in practice. Fisman and Gatti analyze corruption across fifty-nine countries. ${ }^{404}$ Corruption is measured using an index provided by the International Country Risk Guide. Decentralization is measured as the subnational share of total government spending obtained from the International Monetary Fund. The data are averaged over the years available from the period between 1980 and $1995 .^{405}$ In contrast to the study by Treisman, the authors find a meaningful, negative association between fiscal decentralization and corruption. ${ }^{406}$

Professor Gulsun Arikan uses corruption data from TI for about forty countries in 1998 along with several measures of fiscal decenteralization: per capita number of local jurisdictions, per capita number of local and intermediate jurisdictions, share of subnational government employment, and the share of subnational government expenditures. ${ }^{407}$ The results suggest a negative-but only weakly statistically significant-association between decentralization and corruption. ${ }^{408}$ The author concludes: "The empirical results are not

401. Id. at 319 .

402. See Alok K. Bohara, Neil J. Mitchell \& Carl F. Mittendorff, Compound Democracy and the Control of Corruption: A Cross-Country Investigation, 32 POL'y STUD. J. 481 (2004).

403. See id. at 493 ("[T]he relationship between federalism and corruption is significant in only one of the 16 models").

404. See Raymond Fisman \& Roberta Gatti, Decentralization and Corruption: Evidence Across Countries, 83 J. PuB. ECON. 325 (2002).

405. Id. at 329-31.

406. See id. at 326 .

407. See G. Gulsun Arikan, Fiscal Decentralization: A Remedy for Corruption?, 11 InT'L TAX \& PUB. Fin. 175 (2004).

408. See $i d$. at 188 ("[A]ll of the estimated decentralization coefficients are positive, indicating (as expected) that greater decentralization reduces corruption.... Despite this favorable sign pattern, however, only four out of the first eight decentralization coefficients are significantly 
particularly strong, but they offer tantalizing evidence that corruption may indeed be lower in countries where the extent of fiscal decentralization is high." ${ }^{\prime 409}$

Professors Fan, Lin, and Treisman investigate the same issues, except they use firm-level data. ${ }^{410}$ The World Business Environment Survey interviewed business managers from over 9000 firms across eighty countries between 1999 and 2000. Managers were asked about the frequency and amount of bribes paid. The primary measure of decentralization used captures the number of tiers of government within a country. ${ }^{411}$ The results indicate a meaningful association between this measure of decentralization and the frequency and amount of bribes. ${ }^{412}$ For example, adding an additional tier of government is associated with a $2.6 \%$ increase in the probability that a manager reports "always needing to make informal payments to get things done." "113 In addition, the subnational share of government employment is positively associated with the frequency and amount of bribes. ${ }^{414}$ Interestingly, the association between government tiers and the frequency of bribes is only statistically meaningful for less developed countries once the sample is split by level of development. However, subnational share of government employment remains positively associated with corruption in both subsamples. ${ }^{415}$ Thus, the lack of association between government tiers and corruption among developed countries may reflect a lack of variation in this subsample.

Lastly, a series of studies investigate two complementary questions. Analyses by Fisman and Gatti and Professors Brollo, Nannicini, Perotti, and Tabellini explore a different type of relationship between fiscal decentralization and corruption. Specifically, each assesses the impact of federal transfers on the behavior of subnational governments. Fisman and Gatti utilize statelevel data from the United States to investigate whether greater federal transfers-yielding a divergence between state-level revenue generation and expenditures - result in greater corruption by state

different from zero, with three of these instances showing significance at just the 10 percent level.").

409. Id. at 192 .

410. See C. Simon Fan, Chen Lin \& Daniel Treisman, Political Decentralization and Corruption: Evidence from Around the World, 93 J. Pub. ECOn. 14 (2009).

411. Id. at $20-23$.

412. See id. at 24 .

413. Id.

414. See id. at 29 ("[A] larger share of public employment at subnational levels was significantly associated with more frequent bribery ...").

415. See id. at 30. 
officials. ${ }^{416}$ Federal transfers are interpreted as inducing a "soft budget constraint" at the state level. ${ }^{417}$ Data on state-level corruption comes from the Report to Congress on the Activities and Operations of the Public Integrity Section for 1987 and measures the annual number of public officials (from any level of government) convicted in a state for abuse of public office between 1976 and 1987. This is then scaled by population or public sector employment in the state. The fiscal variable of interest is the share of state and local expenditures financed by federal transfers. ${ }^{418}$ The results indicate a meaningful, positive association between the softness of the state budget constraint and corruption. ${ }^{419}$

Brollo, Nannicini, Perotti, and Tabellini exploit discontinuities in the size of transfers from the federal government to municipalities in Brazil arising from deterministic allocation rules related to municipality population. ${ }^{420}$ Using data from between 2001 and 2008, the authors assess the impact of transfers in non-election years on local corruption and the quality of individuals seeking local office, such as the office of a municipal mayor. Corruption is measured using municipal audit reports prepared by an independent body, the Corregedoria Geral da União, under Brazil's anti-corruption program. Candidate quality is measured by education. ${ }^{421}$ The results indicate that a ten percent increase in transfers results in at least a six percent increase in corruption, a seven percent increase in the probability of an incumbent being reelected, and a six percent reduction in the college graduation rates of an incumbent's opponents. ${ }^{422}$

416. See Raymond Fisman \& Roberta Gatti, Decentralization and Corruption: Evidence from U.S. Federal Transfer Programs, 113 PuB. CHoice 25 (2002).

417. Id. at $26-27$.

418. Id. at $27-29$.

419. See id. at 33 ("Consistent with theories emphasizing the importance of hardness of budget constraints, we find that the rate of prosecutions for abuse of public office is greater in states with higher rates of federal transfers.").

420. See Fernanda Brollo, Tommaso Nannicini, Roberto Perotti \& Guido Tabellini, The Political Resource Curse, 103 Am. Econ. REv. 1759 (2013)

421. Id. at $1769-77$.

422. See $i d$. at 1794 ("In particular, a 10 percent increase in the federal transfers to municipal governments raises local corruption by 6 percent (broad definition, possibly including bad administration) or by 16 percent (narrow definition, with only severe violation episodes). Moreover, this fiscal windfall increases the incumbent mayor's probability of reelection by 7 percent, and shrinks the fraction of his opponents with a college degree by 6 percent."). 
Professors Fredriksson and Vollebergh assemble data from eleven industrial sectors across twelve OECD countries over the period from 1982 to $1996 .{ }^{423}$ Instead of assessing the impact of decentralization on the level of corruption, the authors explore whether a given level of corruption has a larger impact on environmental policy in decentralized countries. Environmental policy is measured at the sector level within each country and is proxied by the aggregate physical energy units used per unit of value added. Corruption is measured using data from TI. The findings indicate a positive association between corruption and energy intensity (environmental laxity) in unitary countries. ${ }^{424}$ There is no meaningful association between corruption and energy intensity with federal structures. ${ }^{425}$ The authors attribute this finding to the fact that corrupt political officials have less power to influence policy outcomes in decentralized systems. ${ }^{426}$

In sum, the empirical literature on lobbying and corruption in federal systems is inconclusive for a few reasons. First, the difficulty of dealing with the potential endogeneity of the presence of a federal structure or the level of fiscal decentralization makes it unlikely that the results discussed here have a causal interpretation. Second, from the perspective of environment federalism, the debate is not over the choice between a federal and a unitary system. Unfortunately, studies using binary measures indicating a federal structure or a continuous measure of the number of government tiers offer little guidance on whether the federal or local level is responsible (or both) for the positive association between corruption and non-unitary systems. Finally, while studies assessing continuous measures of fiscal decentralization - such as the share of subnational government expenditures - are more helpful, the results are mixed and seem to depend on characteristics of the budget at the local level.

423. See Per G. Fredriksson \& Herman R.J. Vollebergh, Corruption, Federalism, and Policy Formation in the OECD: The Case of Energy Policy, 140 Pub. Choice 205 (2009).

424. See id. at 217 (" $[\mathrm{G}]$ reater government corruption leads to weaker energy policy standards, but the effect is conditional on whether the country is a federal system or not. The effect of corruption is reduced in federal systems.").

425. See id. at 213.

426. See id. at 217 ("The intuition is that the greater the number of political units (veto players) involved in determining policy (in a federal system), ceteris paribus, the larger the number of bribes paid by lobby groups, and the more expensive it becomes for these groups to influence policy through influence-seeking. The bribe offer to each political unit declines, and the environmental/energy policy becomes more stringent."). 


\section{Political Participation}

Besides the potential for decentralization to affect the level of lobbying or corrupt activity, it also has the potential to affect individual participation in the political process. Decentralized policy making is often advocated on the grounds that individual participation is greater at the local level. Oates summarizes this view: "The basic presumption here is that more decentralized political systems are conducive to increase citizen impact on political outcomes and political participation." ${ }^{27}$ Bednar similarly states: "Democratic outcomes improve with higher participation, and participation is boosted when one's vote is likely to be pivotal, which is more likely in smaller-scale elections ...." 428 However, a trade-off may exist if participation leads to policies that are not socially efficient when the electorate is relatively uninformed. ${ }^{429}$

In the interest of relative brevity, this Article does not conduct a thorough review of the empirical literature - located predominantly within the political science field - on political participation. Rather, this Author refers the interested reader to Professor Horiuchi, who provides an excellent review. ${ }^{430}$ Specifically, Horiuchi begins by stating that American and European political scientists claim, contrary to the statements above, that subnational elections have lower voter turnout than national elections in most democracies. ${ }^{431}$ However, the author goes on to state that the opposite is true in select countries such as Australia, Canada, Finland, France, India, Italy, Northern Ireland, Spain, and Switzerland. ${ }^{432}$ Horiuchi posits that political participation depends on the likelihood that one's vote affects the electoral outcome and the ability of the electoral outcome to influence policy decisions. ${ }^{433}$ Thus, even if it is the case that subnational political participation is lower in many democracies, this might change with greater decentralization as local policy makers become more influential. That

427. See Oates, supra note 16 , at 1138.

428. See Bednar, supra note 1 , at 274-75.

429. See Esty, supra note 158, at 649 ("In fact, the technical complexity of the regulatory process and the need to put competing values on a commensurate basis makes environmental decisionmaking especially obscure to the average citizen.").

430. Yusaku Horiuchi, Turnout Twist: Higher Voter Turnout in Lower-Level Elections (June 2001) (unpublished Ph.D. dissertation, Massachusetts Institute of Technology), available at http://hdl.handle.net/1721.1/8240.

431. Id. at 12 .

432. Id. at 15 .

433. See id. at 16 ("I hypothesize that the relative level of voter turnout in subnational vs. national elections is a function of not only how much is at stake but also how much citizens' votes count in elections."). 
said, devolution of environmental policy making alone may be insufficient to affect political participation decisions at the local level.

\section{Knowledge}

The final political economy issue that may impact a government's implementation of social welfare-maximizing policies concerns knowledge. In the absence of any other distortions, the ability of any government to maximize social welfare rests first and foremost with the government's knowledge of the true social welfare function. There are at least two reasons why, in the context of environmental federalism, governments may inadvertently maximize the wrong social welfare function. First, the scientific basis of the social welfare function (for example, the so-called damage functions for different environmental hazards) may be incorrect. Second, governments may overvalue the acquisition of capital due to the so-called winner's curse.

There is little empirical research related to environmental federalism and scientific knowledge. However, due to potential economies of scale and the incentive for jurisdictions to free ride, many advocate that scientific research be centralized regardless of the extent of decentralization of actual policy making. For example, Esty states: "Sound environmental policies depend on good science, which, in turn, requires a level of investment in sophisticated technical analysis that many smaller jurisdictions are in no position to make." ${ }^{34}$ On the other hand, Adler espouses concern that the "overcentralization of scientific research may increase the risks of political manipulation of science." ${ }^{435}$ Future work into the objectivity of scientific research conducted at various levels of government appears warranted. Moreover, it may be fruitful to consider a decentralized system of scientific research that overcomes the incentive to free ride through the creation of something akin to a patent system. For example, in the context of policy innovation (discussed in Part II.E), Rose-Ackerman states:

However, there is a more innovative way to encourage low-level governments to search for new ways of doing things. The central government might institute a system of prizes awarded to governments after they have come up with new ideas. Prizes could be a function of a jurisdiction's own activities or could be awarded only if the jurisdiction happened to generate the best project. ${ }^{436}$

434. Esty, supra note 158, at 573.

435. Adler, supra note 9, at 147.

436. Susan Rose-Ackerman, Risk Taking and Reelection: Does Federalism Promote Innovation?, 9 J. Legal Stud. 593, 615-16 (1980). 
There is also little empirical research related to environmental federalism and the so-called winner's curse. ${ }^{437}$ The winner's curse refers to the fact that when multiple agents bid for a single good with an uncertain value based on unbiased, agent-specific forecasts of the good's true value, the agent with the highest bid frequently ends up disappointed either because the bid exceeds the value of the good (resulting in a net loss) or because the value is less than presumed (resulting in a smaller net gain than envisioned).

The winner's curse is relevant to the environmental federalism debate because it suggests that in the presence of multiple jurisdictions bidding for mobile capital (through environmental standard setting) in order to maximize social welfare, the winning jurisdiction may set the environmental standard too low and suffer from the winner's curse. ${ }^{438}$ As such, decentralized policy making, resulting in multiple jurisdictions competing for mobile, lumpy capital investments, may induce inefficiently low environmental standards even if all jurisdictions seek to maximize social welfare and have unbiased forecasts concerning the social value of attracting capital.

Much of the empirical evidence in support of the winner's curse is obtained by laboratory experiments conducted by economists. Some behaviors in the field have also been shown to be consistent with the winner's curse. ${ }^{439}$ In sum, there is ample evidence that the winner's curse is a frequent outcome not only in the laboratory, but also in practice. While fully rational agents should be able to eliminate the winner's curse, the evidence suggests that agents possess only "bounded rationality" and do not recognize the difference between the unconditional expected value of the good and the expected value of the good conditional on submitting the highest bid. ${ }^{440}$

The potential for the winner's curse to apply to jurisdictional bidding for capital is very real. Engel states: "To entice new plants within their borders, or to prevent their existing plants from leaving, states offer firms lucrative packages consisting of a dizzying array of economic incentives." ${ }^{441}$ That said, the only study to this Author's knowledge that relates directly to interjurisdictional competition for

437. But see Richard H. Thaler, Anomalies: The Winner's Curse, 2 J. Econ. PERSP. 191 (1988) (providing an early overview of the topic).

438. See Esty, supra note 158, at 632 (citing Peter P. Swire, The Race to Laxity and the Race to Undesirability: Explaining Failures in Competition Among Jurisdictions in Environmental Law, 14 YALE L. \& POL'Y REV. 67, 98 (1996)).

439. See Thaler, supra note 437; Gary Charness \& Dan Levin, The Origin of the Winner's Curse: A Laboratory Study, 1 Am. Econ. J.: Microeconomics 207 (2009).

440. Charness \& Levin, supra note 439, at 228.

441. Engel, supra note 64 , at 319. 
capital is by Professors Greenstone and Moretti. ${ }^{42}$ The authors utilize data collected from various issues of Site Selection over the period from 1982 to 1993. Each issue details the siting decision of so-called million dollar plants. In particular, the winning county is listed along with one or two runner-up counties. ${ }^{443}$ This enables Greenstone and Moretti to compare the county that won the new plant to counties that merited final consideration but ultimately lost out on the plant. While the size of any inducements offered by the winning and losing counties is not known, the authors examine relative changes in property values across winners and losers to estimate the welfare gains experienced by winning counties. The findings are that property values increased by roughly $1.1 \%$ to $1.7 \%$, indicating that winning counties experienced a net gain due to the attraction of the plants. ${ }^{444}$ Thus, at least this study concludes that the stronger version of the winner's curse - the winner suffering a net reduction in welfare - does not seem to characterize jurisdictional competition for large capital investments.

In sum, there are numerous political economy issues that play a role in the debate over environmental federalism. Unfortunately, the empirical evidence is less clear than on other issues discussed in this Article. Empirical studies of the Leviathan model suffer from the empirical equivalence of Leviathan and interjurisdictional competition models: both predict lower tax rates in decentralized settings. Distinguishing between the two requires knowledge of the socially efficient tax rate, which is not an easy task. Empirical studies of the Leviathan model, as well as of the effects of decentralization on lobbying and corruption, suffer from the proper measurement of decentralization and difficulty in dealing with the potential endogeneity of institutional arrangements. As such, the results of existing studies should not be interpreted in a causal manner. Finally, there is limited evidence on whether decentralization of environmental policy making induces greater political participation and leads to inefficient decisions due to the winner's curse. Nor is there much empirical evidence concerning the optimal structure regarding scientific research.

442. See Michael Greenstone \& Enrico Moretti, Bidding for Industrial Plants: Does Winning a "Million Dollar Plant" Increase Welfare? (Nat'l Bureau of Econ. Research, Working Paper No. 9844, 2003), available at http://www.nber.org/papers/w9844.

443. Id. at 14, 33 tbl.1.

444. See $i d$. at 27 ("The most reliable data suggest that there is a relative trend break of $1.1-1.7 \%$ in property values."). 


\section{E. Policy Instruments}

The Tiebout and interjurisdictional competition frameworks invoke assumptions concerning the ability of jurisdictions to implement a "full range of needed tax and regulatory instruments" to obtain efficient outcomes. ${ }^{445}$ Similarly, Dalmazzone states that "governments must be... in conditions to avail themselves of the best suited among expenditure, tax, and environmental policy instruments." "446 Part II.E will briefly discuss two final issueslaboratory and bottom-up federalism-factoring into the debate over environmental federalism under this umbrella. Laboratory, or horizontal, federalism refers to policy replication by other subnational governments once one subnational government discovers a successful policy. Bottom-up, or vertical, federalism refers to policy adoption by the federal government after successful demonstration of the policy at the subnational level.

\section{Laboratory Federalism}

One of the virtues of decentralized policy making is the ability of jurisdictions to experiment with new policies, thereby developing potentially new and welfare-improving policy instruments. ${ }^{447}$ This notion is commonly referred to as laboratory federalism. Oates states that "a federal system may offer some real opportunities for encouraging such experimentation and thereby promoting 'technical progress' in public policy." ${ }^{448}$ Adler refers to the ability of states to act as "environmental "laboratories." ${ }_{449}$ Bednar writes that "subnational governments" have the opportunity to become "laboratories of democracy." ${ }^{450}$ Of course, this notion dates back at least to Justice Brandeis's well-known statement: "It is one of the happy incidents of the federal system that a single courageous State may, if its citizens choose, serve as a laboratory; and try novel social and economic experiments without risk to the rest of the country." ${ }^{451}$

Direct empirical evidence on the value of experimentation in decentralized settings is limited given the difficulty of question

445. See Oates, supra note 4 , at 6.

446. Dalmazzone, supra note 249 , at 467.

447. See generally William M. Shobe \& Dallas Burtraw, Rethinking Environmental Federalism in a Warming World, 3 Climate Change ECON. 1 (2012) (providing an excellent introduction to many of the issues).

448. Oates, supra note 16 , at 1132.

449. Adler, supra note 9, at 137.

450. Bednar, supra note 1, at 273.

451. New State Ice Co. v. Liebmann, 285 U.S. 262, 311 (1932) (Brandeis, J., dissenting). 
involved. There is much literature on the diffusion of policies across jurisdictions, exemplified, in part, by the literature discussed in Part II.C on horizontal and vertical externalities in policy making. However, this does not shed much light on the development or evaluation of experimental policies in decentralized versus centralized settings. Thus, early explorations into this issue were entirely theoretical.

The seminal study in this area is by Rose-Ackerman. ${ }^{452}$ She explored the incentives that local politicians have to undertake risky experimentation. Three conclusions are of interest. First, secure incumbents have little incentive to experiment and risk undermining their re-election prospects. ${ }^{453}$ Instead, they can choose to free ride off experiments conducted elsewhere. Second, local politicians may have an incentive to experiment even if their local position is secure if they aspire to federal office and are credited by the electorate for developing innovative local policies. ${ }^{454}$ Kostogiannis and Schwager provide additional theoretical support for this point. ${ }^{455}$ Finally, wasteful duplication of experiments at subnational levels may arise due to a failure to coordinate among jurisdictions and the desire for all politicians to implement the policy with the greatest chance for success. ${ }^{456}$

Professor Strumpf focuses on the incentives for jurisdictions to free ride. ${ }^{457}$ If innovative policies can be easily replicated, then there is no advantage to being the first-mover unless there are political gains of the type discussed by Rose-Ackerman. Strumpf states:

Because successful policy experiments are eventually emulated, they have a public good component. Experiments benefit not just the innovating government but also potential imitators, and so local governments have an incentive to free-ride off their neighbors. Alternatively, a central government should take this

452. See Rose-Ackerman, supra note 436.

453. See id. at 614 (finding that "secure politicians chose low-risk projects" due to "the relatively low level of electoral benefit associated with a major success").

454. See id. ("[F]ederalism may encourage innovation at lower levels . . . by increasing the attractiveness of low-level elected office.").

455. See Christos Kostogiannis \& Robert Schwager, On the Incentives to Experiment in Federations, 60 J. URB. ECON. 484 (2006).

456. See Rose-Ackerman, supra note 436, at 594 ("[P] oliticians' choices will depend upon their knowledge of other jurisdictions' actions. If they ignore other governments, wasteful duplication can occur. If they hope to benefit from other governments' activities, few risky projects may be undertaken.").

457. See Koleman S. Strumpf, Does Government Decentralization Increase Policy Innovation?, 4 J. Pub. ECon. Theory 207 (2002). 
learning externality into account when it is deciding whether to consider a policy experiment. ${ }^{458}$

Similarly, Professors Galle and Leahy write: "Innovations in government produce positive externalities for other jurisdictions. Theory therefore predicts that local government will tend to produce a lower than optimal amount of innovation, as officials will prefer to free ride on innovation by others." 459 That said, Strumpf assesses conditions under which free riding is more likely to occur. He predicts that the level of policy experimentation will be relatively greater under centralization as the number of subnational jurisdictions increases and as the similarity of these jurisdictions increases (specifically, as the welfare effects of different policies become more highly correlated across locations). ${ }^{460}$ Professors Callander and Harstad expand on this point, documenting that jurisdictions may opt for a less-than-ideal policy if this policy is less useful to other jurisdictions, and that incentives to do so are greater when the jurisdictions are similar. ${ }^{461}$

Interestingly, the potential for subnational free riding is often used to justify centralization of scientific research, but is often omitted in the environmental federalism literature when discussing local policy innovation. On the one hand, Galle and Leahy state that "any number of scholars of federalism routinely argue that experimentation is a reason to favor decentralized government, generally acknowledging [Rose-Ackerman] with a 'but see' footnote and at most a few sentences of explanation." ${ }^{462}$ On the other hand, Dalmazzone writes that "the generation and diffusion" of scientific research related to environmental problems is a "task that is generally assigned, in theory as in the real world, to the central level of government" as these are "activities that benefit everyone and that tend to be subject to important economies of scale." ${ }^{463}$ However, while these positions may seem a bit contradictory at first glance, they may

458. Id. at 208 .

459. Brian Galle \& Joseph Leahy, Laboratories of Democracy? Policy Innovation in Decentralized Governments, 58 EMORY L.J. 1333, 1333 (2009).

460. See Strumpf, supra note 457, at 208-09; see also Hongbin Cai \& Daniel Treisman, Political Decentralization and Policy Experimentation, 4 Q.J. PoL. SCI. 35 (2009) (examining similar issues theoretically while allowing for centralized experimentation to entail non-uniform policies).

461. See Steven Callander \& Bård Harstad, Experimentation in Federal Systems 35 (Natl. Bureau of Econ. Research Working Paper No. 19601, 2013), available at http://www.nber.org/papers/w19601.

462. Galle \& Leahy, supra note 459, at 1337.

463. Dalmazzone, supra note 249 , at $464-65$. 
not be inconsistent. Galle and Leahy argue that policies that are transparent and cheap to copy are the most susceptible to free riding. ${ }^{464}$ This may be a more apt description of scientific research than subtle policy components of environmental regulation. Moreover, local policy makers may be more likely to receive credit for policy innovations than the advancement of scientific knowledge. Rabe notes that state-led initiatives regarding climate change may be due to the fact that "some states have consciously chosen to be 'first movers,' often taking bold steps with the explicit intent of trying to take national leadership roles on climate policy." 465

In terms of empirical research, the questions that can be addressed are a bit more limited as direct assessments of whether centralization leads to more or less policy experimentation are difficult to conceptualize. Professor Volden examines whether states emulate successful policies implemented in other states. ${ }^{466}$ Emulation of successful policies by other jurisdictions is a necessary but not sufficient condition for policy experimentation to be a benefit to decentralization. The author examines the specific case of the Children's Health Insurance Program (CHIP) over the period from 1998 to 2001. ${ }^{467}$ Specifically, Volden looks at amendments to particular aspects of each state's CHIP program to see if these changes are driven in part by the design of other states' CHIP programs that were successful in reducing the proportion of uninsured children in poor households. The results indicate that states are more likely to emulate design choices from states that achieved past

464. See Galle \& Leahy, supra note 459, at 1346 ("If it is very costly to implement domestically someone else's experiment, if it is hard to acquire information about that experiment, or if it is dubious whether the experiment is relevant to anyone else, then the incentives for freeriding are obviously much lessened.").

465. Barry G. Rabe, States on Steroids: The Intergovernmental Odyssey of American Climate Policy, 25 Rev. Pol'y Res. 105, 107 (2008).

466. See Craig Volden, States as Policy Laboratories: Emulating Success in the Children's Health Insurance Program, 50 Am. J. Pol. ScI. 294 (2006).

467. See id. at 299-301. 
success. ${ }^{468}$ However, this is only the case if these design choices do not necessarily result in higher costs. ${ }^{469}$

Further studies provide anecdotal evidence in support of greater policy experimentation at the subnational level in the United States in the case of GHG reductions targets. Specifically, Professors Cale and Reams note that seventeen states adopted GHG reduction targets between 1998 and 2008 despite the federal government never ratifying the Kyoto Protocol. ${ }^{470}$ Rabe documents that twenty-two statesrepresenting roughly half of the U.S. population - adopted at least two of eight climate change policies over roughly this same time period..$^{471}$

In sum, the theoretical literature indicates that the relationship between decentralization and policy experimentation is not straightforward. ${ }^{472}$ Whether policy innovation is greater at the

468. See $i d$. at 302 ("The Success variable captures whether State B was especially effective in lowering its uninsured rate among poor children. Its coefficient is positive and statistically different from zero. Its effect is sizable. Dyads in which State B was successful have nearly a $20 \%$ greater odds of State A abandoning its policy in favor of that in State B, when compared to dyads in which State B was unsuccessful. This provides strong initial support for the Emulation of Successes Hypothesis.").

469. See $i d$. at 307 ("[T] he role of best practices is somewhat evident in all three types of policy changes, although the coefficient on Success is statistically distinct from zero only for less costly policy changes and for those with mixed components.").

470. See Tabitha M. Cale \& Margaret A. Reams, Influences on Adoption of Greenhouse Gas Reduction Targets Among US States, 1998-2008, 3 Open J. Pol. ScI. 39, 41 (2013) ("The 17 states with GHG reduction targets [by 2008] are listed in alphabetical order: Arizona, California, Connecticut, Florida, Hawaii, Illinois, Maine, Massachusetts, Minnesota, New Hampshire, New Jersey, New Mexico, New York, Oregon, Rhode Island, Vermont and Washington.").

471. The eight policies include renewable electricity mandates or portfolio standards, carbon taxes, renewable fuel mandates or equivalent programs that mandate expanded use of biofuels, carbon cap-and-trade programs, statewide emissions reduction targets, mandatory reporting of carbon emissions, formal participation as a co-plaintiff in the 2007 Supreme Court case on carbon dioxide regulation, and adoption of the carbon emission standards for vehicles enacted by California. Rabe, supra note 465, at 109-10 ("Twenty-two states representing about onehalf of the American population have enacted two or more of these eight climate policies, indicating a considerable degree of political support for policy and formal engagement in climate policy adoption. A few of these states, such as California, Massachusetts, Connecticut, and New York, have adopted as many as six or seven of them.").

472. See Callander \& Harstad, supra note 461, at 34 ("[T] he prominence of policy experimentation in policy and popular discourse has not been matched by development of a formal understanding of the underlying phenomenon."). 
subnational level depends on the level of fragmentation at the subnational level, the degree of heterogeneity across jurisdictions, the level of transparency and replicability of local policies, the incentives of policy makers, and the extent to which politicians can claim credit for successful policies. Goulder and Stavins state:

The case for state-level experimentation needs to be considered carefully: why the laboratories should be at the state, rather than national, level is not clear, and - in any event - there is some question regarding whether state authorities will allow their 'laboratory' to be closed after the experiment has been completed and the information delivered. ${ }^{473}$

In light of this, it is not surprising that Galle and Leahy conclude that "the question whether innovation adds to the allure of decentralized government is a highly nuanced one, not to be resolved in a footnote or an aside." ${ }^{\prime 74}$ Unfortunately, empirical evidence on this issue is limited and likely to remain so given the difficulty in designing appropriate statistical tests of the underlying hypothesis.

\section{Bottom-Up Federalism}

Another potential virtue of decentralization is the notion of bottom-up federalism. Professors Shipan and Volden use this term to denote vertical policy diffusion from lower to upper levels of government. ${ }^{475}$ This question is distinct from the prior discussion of vertical externalities in policy making as that literature focuses exclusively, to the Author's knowledge, on the effects of federal policies on state choices.

Empirical evidence on the importance of bottom-up federalism is extremely limited. Oates provides anecdotal evidence in the context of the creation of a $\mathrm{SO}_{2}$ permit trading scheme in the United States. He writes:

More recently, in the area of environmental policy, the experience in a number of states with their own forms of Emissions Trading was an important prelude to the adoption, in the 1990 Clean Air Act Amendments, of a national trading program in sulfur allowances to address the problem of acid rain. Without this experience in a number of states, I seriously doubt that policy-makers would have been willing to introduce

473. Goulder \& Stavins, supra note 337, at 256.

474. Galle \& Leahy, supra note 459, at 1339.

475. See Charles R. Shipan \& Craig Volden, Bottom-Up Federalism: The Diffusion of Antismoking Policies from U.S. Cities to States, 50 Aм. J. POL. SCI. 825, 825 (2006) (defining bottom-up federalism as "bottom-up diffusion of policies from local governments to states"). 
such a new and unfamiliar policy measure as tradeable emissions rights on a national scale. More generally, since the dawn of the nation, programs successfully developed at the state level have often provided models for subsequent federal programs. ${ }^{476}$

More generally, Bednar suggests that " $[\mathrm{s}]$ ubnational involvement in national policy making may also help to overcome bureaucratic inertia." ${ }^{477}$ Rabe states:

In many instances, early state policy engagement has provided models that were ultimately embraced as national policy by the federal government. This has been evident in a range of social policy domains, including health care and education, and can either result in federal preemption that obliterates earlier state roles or a more collaborative system of shared governance. ${ }^{478}$

Shipan and Volden address this issue more formally by examining state and local adoptions of antismoking laws in the United States over the period from 1975 to $2000 .{ }^{479}$ Conceptually, the authors argue that greater adoptions by cities within a state may spur state action due to a snowball effect or it may reduce the likelihood of state action due to a "pressure valve" effect. 480 Data on state antismoking laws comes from the State Cancer Legislative Database maintained by the National Cancer Institute. Data on city-level laws comes from the Local Tobacco Control Ordinance Database compiled by the American Nonsmokers' Rights Foundation. The results indicate no meaningful effect of local laws on state propensity to adopt antismoking laws on average. However, further analysis reveals that local laws reduce the probability of state adoption in states with low values of legislative professionalism and raise the probability in states with high values. ${ }^{481}$

476. Oates, supra note 16 , at 1132-33.

477. Bednar, supra note 1, at 273.

478. Rabe, supra note 465, at 106.

479. See Shipan \& Volden, supra note 475, at 829-32.

480. See id. at $827-28$.

481. See id. at 840 ("[L]ocal-to-state diffusion does exist, but . . . it depends crucially on the political environment. Ignoring the role of legislative professionalism and of interest groups produces evidence of neither a snowball nor a pressure valve effect; instead, these effects counterbalance each other and produce null results for the influence of local laws."). 


\section{Conclusion}

Theoretical models used to frame the environmental federalism debate - based on the Tiebout and interjursidctional competition models-highlight several issues that play a salient role in the efficiency of decentralized environmental policy making: resource mobility, preference heterogeneity, interjursidctional externalities, political economy concerns, and policy instrument choice. The objective of this Article has been to provide a reasonably thorough, yet concise, survey of what we do and do not know, empirically speaking, concerning these various issues. While a complete accounting of the magnitudes of the "imperfections," as suggested by Oates in the Introduction, ${ }^{482}$ is beyond the scope of the current Article (and perhaps any article), several preliminary conclusions can be drawn.

First, environmental concerns play, at best, a small role in explaining patterns of resource mobility. Population mobility seems relatively low in most developed countries and is declining in the United States. Moreover, mobility seems to be driven predominantly by economic, as opposed to environmental, factors. That said, there is some evidence that environmental amenities may affect residential location choices along the "spatial" margin (across very spatially disaggregate neighborhoods). However, whether the lack of overall population mobility reflects immobility or convergence to some spatial equilibrium is unclear. Moreover, whether the threat of mobility is sufficient to yield an efficient, market-like outcome -akin to contestable markets - is also unclear. The impact of differential mobility rates, particularly by education, on the efficiency of decentralization is also unclear. Capital, while perhaps relatively more mobile, appears to be influenced by environmental regulation only in a few, highly pollution-intensive sectors. Other factors such as taxes and endowments of physical and human capital seem to play more important roles.

Second, the empirical evidence suggests that preferences over environmental issues are heterogeneous, particularly across political ideologies, income levels, and sectors of employment. However, variation in preferences is much greater across countries than within countries. Moreover, it is not clear that individuals sort themselves across jurisdictions according to environmental preferences. Lastly, there is no empirical evidence to support the (intuitive) notion that subnational jurisdictions are better able to act on community preferences than the central government.

Third, the empirical evidence concerning the importance of interjursidictional externalities is compelling, particularly as it relates

482. See Oates, supra note 16 , at 1136. 
to transboundary pollution and strategic policy making. The limited but persuasive evidence on environment importing is also noteworthy. One issue in this literature that gives this Author some pause is the fact that externalities are less informative in understanding the spatial distribution of enforcement than emissions and effluent discharge. Moreover, it is also noteworthy that there exists limited evidence on whether strategic policy making is due to a race to the top or a race to the bottom.

Fourth, the empirical evidence regarding political economy issues is less convincing and informative owing to limited data availability and the difficulty of dealing with the endogeneity of decentralization. Further empirical analysis is needed along several lines, such as the efficacy of environmental and industry lobbying, the propensity for policy makers to engage in corrupt activity, and political engagement by the populous at different levels of government. Furthermore, evidence regarding the empirical relevance of the winner's curse in the competition for capital and the optimal institutional structure for promoting scientific research is required. Finally, significantly more empirical investigation is needed to assess the arguments concerning laboratory and bottom-up federalism in order to move these arguments beyond mere speculation. 